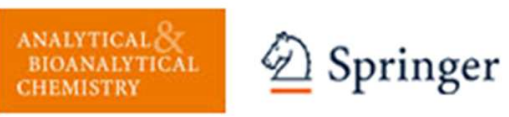

\title{
Py-GC/MS applied to the analysis of synthetic organic pigments: characterization and identification in paint samples
}

\begin{tabular}{|r|l|}
\hline Journal: & Analytical and Bioanalytical Chemistry \\
\hline Manuscript ID: & ABC-01879-2014.R1 \\
\hline Type of Paper: & Research Paper \\
\hline Complete List of Authors: & $\begin{array}{l}\text { Ghelardi, Elisa; Università di Pisa, Chimica e Chimica Industriale } \\
\text { Degano, Ilaria; Università di Pisa, Chimica e Chimica Industriale } \\
\text { Colombini, Maria Perla; Università di Pisa, Chimica e Chimica Industriale; } \\
\text { ICVBC-CNR, } \\
\text { Mazurek, Joy ; Getty Conservation Institute, ; Getty Conservation Institute, } \\
\text { Schilling, Michael; Getty Conservation Institute, } \\
\text { Learner, Thomas; Getty Conservation Institute, }\end{array}$ \\
\hline Keywords: & $\begin{array}{l}\text { Py-GC/MS, Synthetic organic pigments, Clyfford Still, Jackson Pollock, } \\
\text { Contemporary Art, Mass Spectrometry }\end{array}$ \\
\hline \multicolumn{2}{|c}{} \\
\hline
\end{tabular}


Dear Editor,

we improved the manuscript accordingly to the suggestions and issues raised by the reviewers, and we are confident that the new version of the manuscript will be suitable for publication on Analytical and Bioanalytical chemistry.

Detailed answers to the referees' comments follow.

Referee A:

- The list of figures is included in the supplementary material.

In fact, the supplementary materials were included twice in the manuscript! We amended the mistake in the new version of the manuscript.

- Please see comments on unknowns in attached file. Ideally more of the spectra would be given as a part of the supplementary material. The suggestions in the attached relate to the unknowns, but spectra of the knowns and possibly the match factors with the NIST database should be given.

The suggestions provided in the attached file were extremely useful for the identification of some compounds and also for a more correct peak assignment. The new identifications were included in the manuscript (Tables 1 and 2 ) and comments on the possible presence of isomers were added as footnotes in Tables 1, 2, 10 and 16.

The match factor with the NIST database was always higher than $90 \%$; notwithstanding, and a thoughtful comparison of each spectrum with its NIST counterpart was undertaken in each case. We included the spectra of the unknown peaks in the Electronic Supplementary Material, while the relevant $\mathrm{m} / \mathrm{z}$ values of the knowns were given in the tables, being their spectra already published and included in NIST library.

- In addition, sample pyrograms with identification of both identified and unknown components would be a valuable addition to the paper - again in supplementary material.

All the pyrograms obtained by the analysis of the paint materials and paint samples and not reported in the manuscript were included in the ESM, with the identification of the components.

- The last pyrogram given in the paper (Fig 13) has a large number of manor peaks that are not identified. In addition, the mass spectrum shown is hard to understand, the successive neutral losses of $\mathrm{m} / \mathrm{z} 14$ do not seem reasonable.

The pyrogram in Fig. 13 was re-interpreted and an higher number of peaks was assigned. Moreover, the mass spectrum was commented in detail and a new figure was also included in order to clarify the spectrum interpretation. The referee was absolutely right - there were no successive neutral losses, because the spectrum was due to the co-elution of two different species (differing in the presence or absence of a methyl group).

Referee B:

Novelty and Impact:

The paper is novel in that it has extended the data that is available for the analysis of modern organic pigments and has also added, to a small extent, to the knowledge of the materials used by two modern artists and thus contributes to the fields of analytical chemistry and technical art History. It will have an impact on the analysis of modern organic pigments in modern art and possibly in Forensic contexts.

Paper type:

The results are a significant step forward in that some new classes of pigments are analysed and data is supplied here on additional pigments in other classes. The paper will attract the interest of a majority of experts in the fields of pigment analysis, conservation science and possibly forensic science and will be cited. 
1

2

3

4

5

6

7

8

9

10

11

12

13

14

15

16

17

18

19

20

21

22

23

24

25

26

27

28

29

30

31

32

33

34

35

36

37

38

39

40

41

42

43

44

45

46

47

48

49

50

51

52

53

54

55

56

57

58

59

60

- $\quad$ There are some errors, for example page 13 line 20 the reference to Sonada is reference 13 not 18 which is Stenger

We corrected the reference number

- page 24 line 11 'other' should be 'another'

We corrected the text accordingly to the suggestion

- careful proofreading is advised

We subjected the text to a professional proofreader 







\title{
Py-GC/MS applied to the analysis of synthetic organic pigments: characterization and identification in paint samples
}

\author{
Elisa Ghelardi ${ }^{1}$, Ilaria Degano ${ }^{1 *}$, Maria Perla Colombini ${ }^{1,2}$, Joy Mazurek ${ }^{3}$, Michael Schilling ${ }^{3}$, Tom \\ Learner $^{3}$ \\ ${ }^{1}$ Dipartimento di Chimica e Chimica Industriale, Università di Pisa, via Moruzzi 3, 56124 Pisa (Italy) \\ * ilaria.degano@unipi.it \\ ${ }^{2}$ ICVBC-CNR, Via Madonna del Piano, 50019 Sesto Fiorentino (Florence, Italy) \\ ${ }^{3}$ Getty Conservation Institute, 1200 Getty Center Drive, Suite 700, Los Angeles, CA (US)
}

\begin{abstract}
A collection of 76 synthetic organic pigments was analysed using pyrolysis-gas chromatographymass spectrometry (Py-GC/MS). The purpose of this work was to expand the knowledge on synthetic pigments and to assess characteristic pyrolysis products that could help in the identification of these pigments in paint samples.

We analysed several classes of synthetic pigments not previously reported as being analysed by this technique: some metal complexes, $\beta$-naphthol pigment lakes, BONA pigment lakes, disazopyrazolone, triarylcarbonium, dioxazine, anthraquinone, indanthrone, isoindoline and thioindigo classes. We also report for the first time the Py-GC/MS analysis of a number of naphthol AS, benzimidazolone, phthalocyanine and perylene pigments and other miscellaneous pigments including pigments with unpublished chemical structure.

We successfully used the Py-GC/MS technique to the analysis of paints by artists Clyfford Still and Jackson Pollock to identify the synthetic organic pigments and the binding media.
\end{abstract}

\section{Keywords}

Py-GC/MS, Synthetic organic pigments, Clyfford Still, Jackson Pollock, Contemporary Art, Mass Spectrometry

\section{Introduction}

The rapid development of synthetic chemistry during the $19^{\text {th }}$ century, partly driven by the textile dying industry, led to the development of synthetic organic pigments.

Synthetic organic pigments now dominate the colorant market and have partially replaced traditional natural organic colorants. 
The term "synthetic organic pigment" refers specifically to those pigments that are synthesised in a laboratory and must be distinguished from natural organic pigments obtained from plants or animal sources.

Synthetic pigments are classified in the Colour Index, a reference record for all the dyes and pigments, created by the Society of Dyers and Colourists. The pigments are recorded by a generic name and a number. In this work we use the Colour Index names [1] to indicate the pigments analysed. Several classification systems have been proposed for synthetic organic pigments, in this work we have adopted the one of Herbst and Hunger [2], based on the chemical constitution.

The identification of the pigments in a work of art is of paramount importance to improve the knowledge on the work of art itself, on the historical context, on the artist and on the painting technique. Moreover, in selected cases, it may allow to solve authenticity, attribution and conservation problems.

The main issue in synthetic organic pigments analysis is their difficult detection and identification, particularly in complex matrixes such as paint samples. The main reasons are: the great range of possible analytes (hundreds of such pigments, compared to a handful of traditional ones), their small particle size, usually less than $1 \mu \mathrm{m}$, and the low concentration of the pigment in paint formulations, sometimes less than $1 \%$ or lower.

Moreover, organic pigments, both natural and synthetic, are subjected to photo-induced degradation, which may further reduce their concentration in the paint sample. Thus, their detection is more challenging, compared to that of inorganic pigments.

Several techniques are used in the analysis of synthetic pigments, mainly FTIR and Raman spectroscopies [3] [4] [5] [6] [7] [8] [9], Direct Temperature Mass Spectrometry (DTMS) [9] [10] [11], Laser Desorption Mass Spectrometry (LDMS) [11] [12] and Pyrolysis-Gas Chromatography/Mass Spectrometry (Py-GC/MS) [13] [14] [15]. A review by Lomax and Learner focuses on the chemistry, properties, and uses of synthetic organic pigments and examines in depth the analytical techniques currently used for the analysis of these materials [16].

The creation of a library of the chemical-physical properties of synthetic organic pigments is fundamental for their identification in unknown samples. Raman libraries already exist, while an equivalent library prepared with chromatographic techniques is lacking, mainly because authors have analysed only some classes of synthetic pigments. Moreover, the pyrolysis profiles highly depend on the instrumental parameters. The purpose of this work was to expand the knowledge on selected compounds by Py-GC/MS analysis and to integrate the work of other authors by assessing the characteristic pyrolysis products that can be useful in the identification.

In our study we analysed with Py-GC/MS 76 synthetic pigments, 45 of them never previously reported as being analysed by this technique.

We report for the first time the Py-GC/MS analysis of the following classes of pigments: metal complex, $\beta$-naphthol pigment lakes, BONA pigment lakes, disazopyrazolone, triarylcarbonium, dioxazine, anthraquinone, indanthrone, isoindoline and thioindigo. We also analysed three pigments with unpublished chemical structure (PV51, PV52, PV53) and we expanded the data on the naphthol AS, benzimidazolone, phthalocyanine and perylene classes, with respect to the literature. 
Our Py-GC/MS procedure for the analysis of synthetic pigments was successful in discriminating between the listed classes of synthetic pigments and in several cases we were able to identify the pyrolysis products characteristic of individual pigments, that can be used as markers.

To further test our method, we applied our procedure to the analysis of selected pigments and paint samples from two $20^{\text {th }}$ century American artists, Clyfford Still (1904-1980) and Jackson Pollock (1912-1956). Py-GC/MS was successful in identifying the synthetic organic pigments present in the analysed paint samples.

\section{Experimental}

\section{Reference pigment samples}

Samples of synthetic organic pigments were collected from the Getty Conservation Institute's reference material collection. The pigments analysed are listed in Supplementary Information, Table SI1. In this work we present only the results of the pigments never previously reported as being analysed by Py-GC/MS. For the other pigments, the results were consistent with the ones of other authors [15] [13].

\section{Paint samples}

Clyfford Still. Ten samples from six different paintings and seven samples from the pigments found in the artist's studio were analysed with Py-GC/MS. The samples from Still's paintings included: three samples from "Untitled", dating 1948 (private collection); one sample from "Untitled" (1948); two samples from "Untitled", dating 1951-1952, one sample from "Untitled" (1954), and two samples from "Untitled" (1974), all owned by the San Francisco Museum of Modern Art; one sample from "Untitled" (1960), owned by the Hirshhorn Museum of Washington.

Jackson Pollock. two samples from Mural (1943) were analysed. The painting belongs to the University of lowa Museum of Art and was from 2012 till 2014 at the Getty Center in Los Angeles, CA, undergoing a technical study and a conservation treatment [17].

\section{Apparatus}

Pyrolysis - gas chromatography/mass spectrometry was carried out on a 7890A gas chromatograph, coupled with a 5975C triple axis detector mass spectrometer (Agilent Technologies, USA), coupled with a EGA/PY 3030D multi-shot pyrolyzer (Frontier Laboratories, Japan). The pyrolysis was carried out at $550^{\circ} \mathrm{C}$ for $12 \mathrm{~s}$. The chromatographic separation was carried out on a DB-5ms Ultra Inert column, $40 \mathrm{~m} \times 250 \mu \mathrm{m} \times 0.25 \mu \mathrm{m}$ (Agilent J\&W, USA). The helium (purity 99.9995\%) flow rate was $1 \mathrm{ml} / \mathrm{min}$. The inlet temperature of the $\mathrm{GC}$ was $320^{\circ} \mathrm{C}$, the MS transfer line was kept at $320^{\circ} \mathrm{C}$ and the ion source at $230^{\circ} \mathrm{C}$. The $\mathrm{GC}$ injection program was: pulsed split mode, with an injection pulse pressure of $30 \mathrm{psi}$ until $45 \mathrm{sec}$. The split ratio was 20:1, with a split flow of $20 \mathrm{ml} / \mathrm{min}$. The GC temperature program was: initial temperature $40^{\circ} \mathrm{C}$, held for $2 \mathrm{~min}$, then ramped at $20^{\circ} \mathrm{C} / \mathrm{min}$ to $320^{\circ} \mathrm{C}$ for $14 \mathrm{~min}$.

For the Py-GC/MS analysis we analysed the neat pigments, without any binder, and without any derivatisation step.

Fragments were recognized using the NIST library of standards (the match factor was $\geq 90 \%$ ) and the AMDIS software (US National Institute of Standards and Technology, NIST). The most 
important unknown products for each pigment are reported and the mass spectra are shown in the Electronic Supplementary Material.

\section{Results}

\section{Azo pigments}

ß-naphthol pigment lakes. Historically, "lakes" referred to the first type of synthetic organic pigments made from water soluble dyes by formation of insoluble $\mathrm{Al}^{3+}$ complexes with alum. Today these compounds are used as pigments after being rendered insoluble by conversion into insoluble alkali earth or manganese salts [2]. $\beta$-naphthol pigment lakes originated with the discovery of lithol red by Julius at BASF in 1899 . Lithol red is one of the earliest colorants specifically developed as a pigment rather than a dyestuff. $\beta$-naphthol lakes, with sulfonic and/or carboxylic functional groups, are used in their insoluble form as alkali earth metals or manganese salts [2]. We analysed four pigments belonging to this class: lithol red PR49 (the barium PR49:1 and the calcium PR49:2 salts), PR53:1 and PO46 (both barium salts). PR49 and PO46 are currently used as inexpensive industrial paints, especially in the USA. PR53:1 is found in inexpensive colour pencils and water colours. Their structure is given in Fig. 1 . The results obtained by interpreting the pyrograms achieved by the analysis of these four pigments are reported in Table 1 . The pyrogram obtained for PR49:2 is presented in Fig. 2 as an example. The main products of pyrolysis for these pigments in our experimental conditions are those originated from the 2-naphthol structure. Thus, the analysed pigments have many products in common. As a consequence, their identification is very difficult. As an example, 2,2'-dinaphthyl ether is the only characteristic product of PR49, but it is not one of the most abundant. This result is not in agreement with the data reported on PR49 by Stenger et al. [18]. In their work, many techniques were used for the analysis of PR49, one being Py-GC/MS. They report two pyrolysis products specific for the unambiguous identification of PR49, 2-naphthol and an unknown compound with $\mathrm{m} / \mathrm{z} 268,239$, 134. We found, however, that 2-naphthol is a common pyrolysis product not only of the $\beta$ naphthol pigment lakes class, but of several other classes of synthetic pigments, and thus cannot be used as a marker for PR49. We identified the second compound indicated by Stenger as a characteristic product of PR49 as dinaphtho[2,1b:1',2'-d]furan or dinaphtho[2,1b:1,2-d]furan, which we found also in PR52, PR53 and PR63 pyrograms. Two isobaric peaks are present in the chromatogram at $17.7 \mathrm{~min}$ and $18 \mathrm{~min}$, which most probably correspond to the two positional isomers. 
Fig. 1 Structure of $\beta$-naphthol pigment lakes with breaking points highlighted.

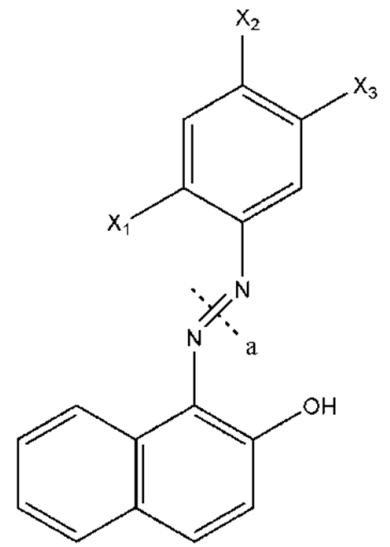
Table 1 Pyrolysis products of $\beta$-naphthol pigment lakes.

\begin{tabular}{|c|c|c|c|c|c|}
\hline \multirow[t]{2}{*}{ Cl name } & \multicolumn{3}{|c|}{ Substituents (Fig.1) } & \multicolumn{2}{|l|}{ Products of pyrolysis (main $\mathrm{m} / \mathrm{z}$ ) } \\
\hline & $\mathbf{x 1}$ & $\mathbf{X 2}$ & X3 & $\mathbf{a}$ & others \\
\hline PR49:1 & \multicolumn{3}{|c|}{$\begin{array}{l}\text { 2-aminonaphthalene-1-sulfonic } \\
\text { acid as diazo component }\end{array}$} & & $\begin{array}{l}\text { 2-naphthol } \\
(144,115) \\
\text { 1-naphthalenamine } \\
(143,115) \\
\text { dinaphtho[2,1b:1',2'-d]furan* } \\
(268,239,119) \text { - small peak }\end{array}$ \\
\hline PR49:2 & \multicolumn{3}{|c|}{$\begin{array}{l}\text { 2-aminonaphthalene-1-sulfonic } \\
\text { acid as diazo component }\end{array}$} & & $\begin{array}{l}\text { 2-naphthol } \\
(144,115) \\
\text { 1-naphthalenamine } \\
(143,115) \\
\text { dinaphtho[2,1b:1',2'-d]furan* } \\
(268,239,119) \text { - most } \\
\text { abundant peak }\end{array}$ \\
\hline PR53:1 & $\mathrm{SO}_{3}^{-}$ & $\mathrm{Cl}$ & $\mathrm{CH}_{3}$ & $\begin{array}{l}\text { a- } X_{1}-X_{2}: \text { m-toluidine } \\
(106,107,77) \\
\text { a- } X_{1}: 4 \text {-chloro-3-methylaniline } \\
(141,106,77)\end{array}$ & $\begin{array}{l}\text { 9-chloro-5,6- } \\
\text { dihydronaphtho[1,2-c]cinnoline } \\
(266,231,202)\end{array}$ \\
\hline P046 & $\mathrm{SO}_{3}{ }^{-}$ & $\mathrm{Cl}$ & $\mathrm{C}_{2} \mathrm{H}_{5}$ & $\begin{array}{l}\text { a- } X_{1}-X_{2}: \text { m-toluidine } \\
(106,107,77)\end{array}$ & $\begin{array}{l}\text { 9-chloro-5,6- } \\
\text { dihydronaphtho[1,2-c]cinnoline } \\
(266,231,202)\end{array}$ \\
\hline
\end{tabular}




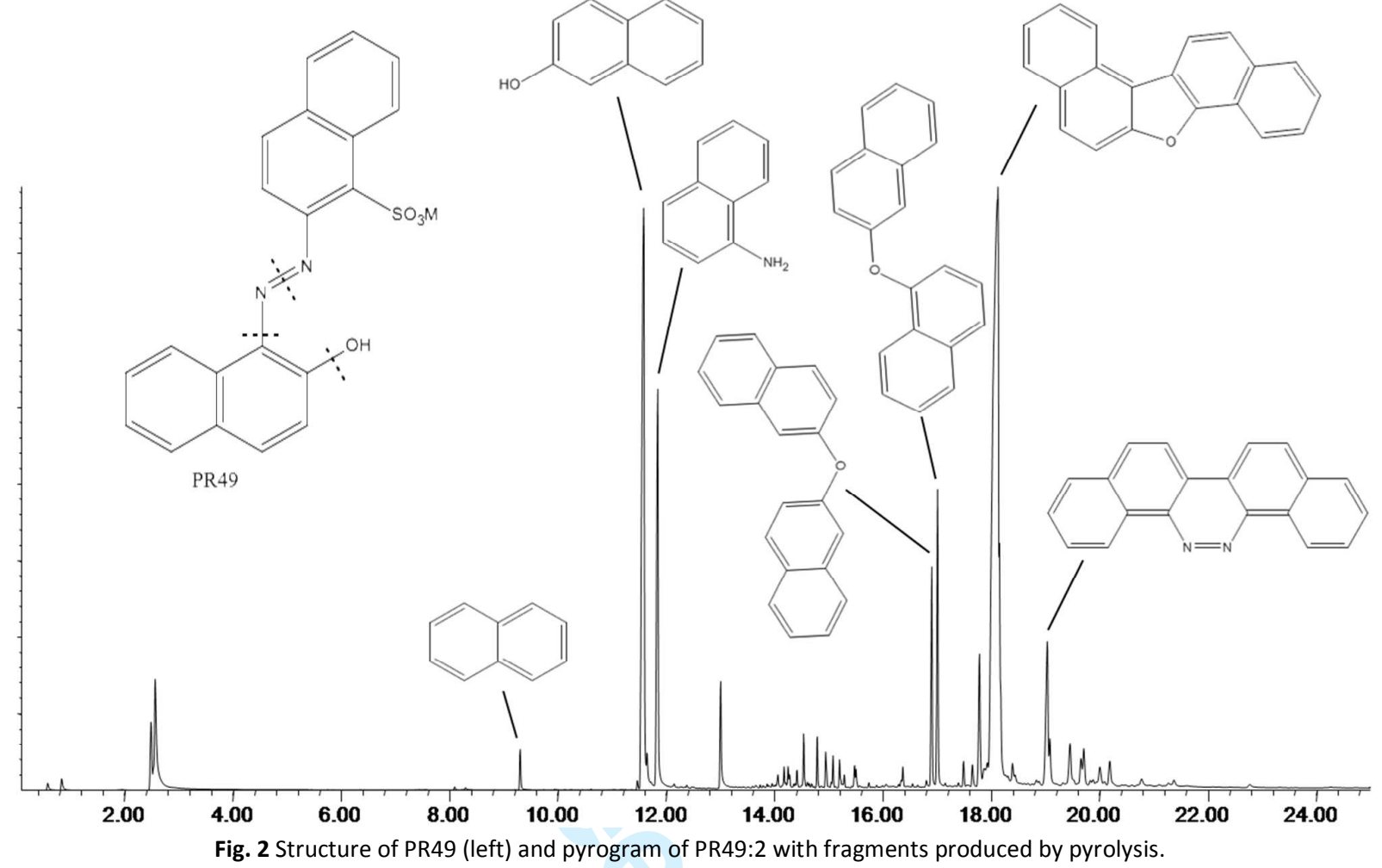

BONA Pigment Lakes. These pigments derive their name from Beta-OxyNaphthoic Acid (BONA) which is used as a coupling component in their synthesis. We analysed six pigments belonging to this class: PR48 (the barium PR48:1 and the calcium PR48:2 salts), PR52 (the calcium PR52:1 and the manganese PR52:2 salts), PR57:1 and PR63:1 (both calcium salts). The structure of the BONA pigment lakes sub-class and the fragmentation pattern undergone by these compounds during pyrolysis is shown in Fig. 3, and the products originated from the pyrolysis are summarized in Table 2. Pyrolysis causes decarboxylation on the naphthol ring and loss of $X_{1}$ substituent. Moreover, the azo bond is broken, leading to the formation of 2-naphthol and $X_{2}$ and $X_{3}$ substituted benzene and benzenamine. As expected, no significant differences were observed in the pyrograms of pigments that differ only for the metal ion. 

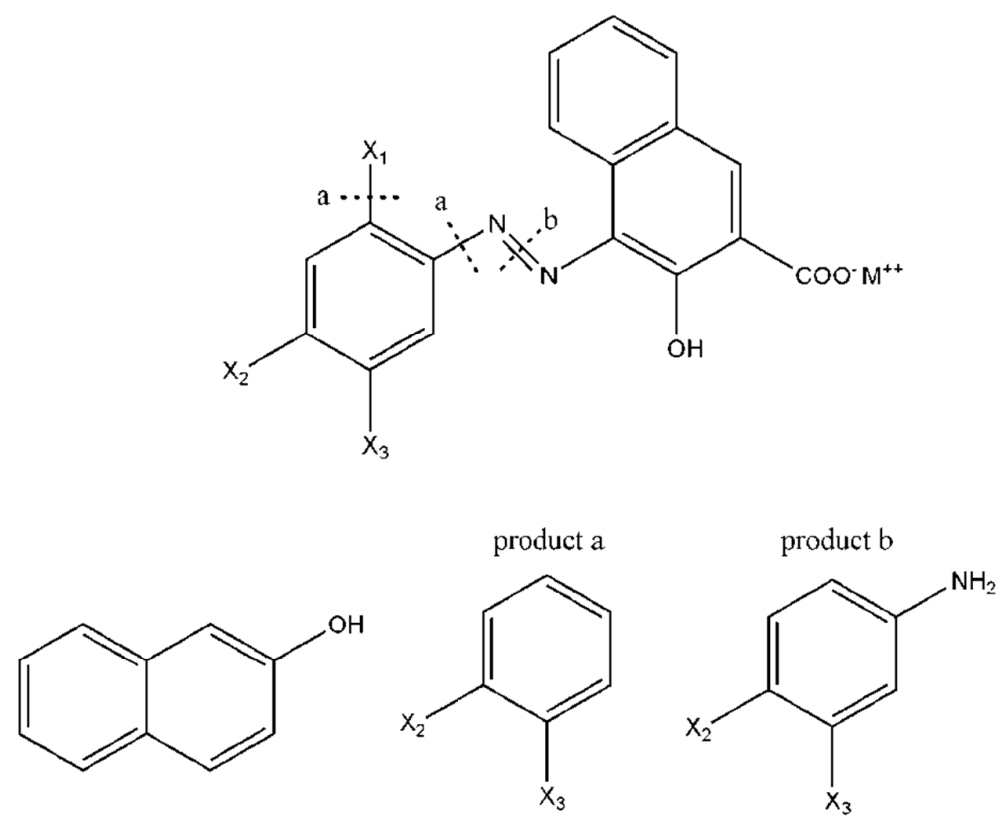

Fig. 3 Structure of BONA pigment lakes (top), with fragments produced by pyrolysis (bottom). 
Table 2 Pyrolysis products of BONA pigment lakes.

\begin{tabular}{|c|c|c|c|c|c|c|c|}
\hline \multirow[t]{2}{*}{$\mathrm{Cl}$ name } & \multicolumn{3}{|c|}{ Substituents (Fig.3) } & \multicolumn{4}{|c|}{ Products (main $\mathrm{m} / \mathrm{z}$ ) } \\
\hline & $\mathrm{X1}$ & $\mathrm{X} 2$ & X3 & $a$ & $\mathbf{b}$ & 2-naphthol & others \\
\hline $\begin{array}{l}\text { PR48:1 } \\
\text { and } \\
\text { PR48:2 }\end{array}$ & $\mathrm{SO}_{3}^{-}$ & $\mathrm{CH}_{3}$ & $\mathrm{Cl}$ & & $\begin{array}{l}\text { benzenamine, } 3- \\
\text { chloro-4-methyl } \\
(140,141,106)\end{array}$ & $(144,115)$ & $\begin{array}{l}\text { 2-naphthol, 1-amino } \\
(159,130,103) \\
\text { 8-chloro-5,6-dihydronaphtho[1,2-c]cinnoline } \\
(266,231,202)\end{array}$ \\
\hline $\begin{array}{l}\text { PR52:1 } \\
\text { and } \\
\text { PR52:2 }\end{array}$ & $\mathrm{SO}_{3}^{-}$ & $\mathrm{Cl}$ & $\mathrm{CH}_{3}$ & $\begin{array}{l}\text { benzene, } 1 \text { - } \\
\text { chloro-2-methyl } \\
(91,126,63)\end{array}$ & $\begin{array}{l}\text { m-toluidine, 4- } \\
\text { chloro- } \\
(141,106,77)\end{array}$ & $(144,115)$ & $\begin{array}{l}\text { 9-chloro-5,6-dihydronaphtho[1,2-c]cinnoline } \\
(266,231,202)\end{array}$ \\
\hline PR57:1 & $\mathrm{SO}_{3}^{-}$ & $\mathrm{CH}_{3}$ & $\mathrm{H}$ & & $\begin{array}{l}\text { p-toluidine } \\
(106,107,77)\end{array}$ & $(144,115)$ & $\begin{array}{l}\text { 5,6-dihydronaphtho[1,2-c]cinnoline } \\
(232,231,202)\end{array}$ \\
\hline PR63:1 & \multicolumn{3}{|c|}{$\begin{array}{l}\text { 2-aminonaphthalene-1- } \\
\text { sulfonic acid as diazo } \\
\text { component }\end{array}$} & & & $(144,115)$ & $\begin{array}{l}\text { 1-naphthalenamine }(143,115) \\
\text { dinaphtho[2,1b:1',2'-d]furan* } \\
(268,239,119) \\
\text { benzo[h]naphtho[1,2-c]cinnoline** } \\
(280,140,126)\end{array}$ \\
\hline
\end{tabular}


Naphthol AS pigments. Naphthol AS is one of the most important group of azo pigments in the paint industry; these pigments were first synthesized in 1911.

We have integrated the work of Russell et al. [15] on naphthol AS pigments by analysing PR7 and PV44. The structure and the fragmentation pattern for this class of pigments is reported in Fig. 4. The results for PR7 are consistent with the ones described by Russell: the pigment shows two characteristic pyrolysis products (products $a$ and $b$ of Russell's scheme) and also o-toluidine. The pyrolysis of PV44, instead, yields aniline and 2-naphthol, which are products common to several classes of pigments, but also other characteristic products not attributable to the fragmentation pattern indicated by Russell (see Table 3 ), for example the product "a" with the loss of $X_{2}$ substituent, or with the loss of both $X_{1}$ and $X_{3}$ substituents.

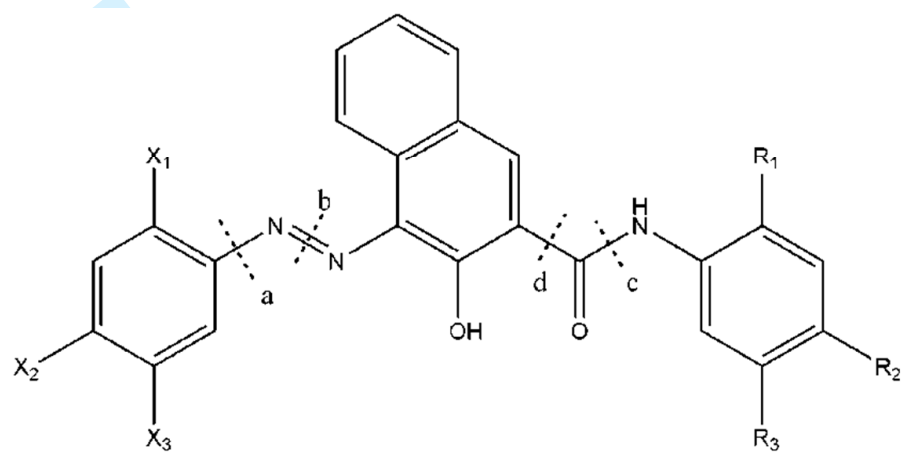

Fig. 4 Structure of Naphthol AS pigments with breaking points highlighted. 
Table 3 Pyrolysis products of Naphthol AS pigments.

\begin{tabular}{|c|c|c|c|c|c|c|c|c|c|c|c|}
\hline \multirow[t]{2}{*}{ Cl name } & \multicolumn{6}{|c|}{ Substituents (Fig. 4) } & \multicolumn{5}{|c|}{ Products (main $\mathrm{m} / \mathrm{z}$ ) } \\
\hline & $X_{1}$ & $x_{2}$ & $x_{3}$ & $R_{1}$ & $\mathbf{R}_{\mathbf{2}}$ & $\mathbf{R}_{\mathbf{3}}$ & $\mathbf{a}$ & b & c & d & others \\
\hline PR7* & $\mathrm{CH}_{3}$ & $\mathrm{Cl}$ & $\mathrm{H}$ & $\mathrm{CH}_{3}$ & $\mathrm{Cl}$ & $\mathrm{H}$ & $\begin{array}{l}\text { benzene, 1-chloro, } \\
\text { 3-methyl } \\
(91,126,63)\end{array}$ & $\begin{array}{l}\text { benzenamine, 4- } \\
\text { chloro, } 2 \text {-methyl } \\
(106,141,140) \\
\text { b- } x_{2}: \text { o-toluidine } \\
(106,107,77)\end{array}$ & & $\begin{array}{l}\text { 4-chloro-o-tolyl } \\
\text { isocyanate } \\
(167,138,132)\end{array}$ & \\
\hline PV44 & $\mathrm{OCH}_{3}$ & $\begin{array}{c}\text { benza } \\
\text { mide }\end{array}$ & $\mathrm{OCH}_{3}$ & $\mathrm{H}$ & $\mathrm{H}$ & $\mathrm{H}$ & $\begin{array}{l}\text { benzamide, N-(4- } \\
\text { amino-5-methoxy- } \\
\text { 2-methylphenyl)- } \\
(256,151,105) \\
\text { a - } \mathrm{X}_{2} \text { : benzamide } \\
(121,105,77) \\
\text { a }-\mathrm{X}_{1}-\mathrm{X}_{3} \text { : } \\
\text { benzenamide, N- } \\
\text { phenyl } \\
(105,77,197)\end{array}$ & & $\begin{array}{l}\text { aniline } \\
(93,66)\end{array}$ & & $\begin{array}{l}\text { benzoic acid, } \\
\text { methyl ester } \\
(105,77,136) \\
\text { naphthol AS } \\
(170,273,115 \text {, } \\
152)\end{array}$ \\
\hline
\end{tabular}

*A Py-GC/MS analysis of PR7 has already been published by Sonoda [13] 
Benzimidazolone pigments. Developed and patented by Hoechst in 1960 , the benzimidazolones are monoazo pigments with the 5-aminocarbonyl benzimidazolone group. The main pyrolysis product of PV32, in Fig. 5, is 2-naphthol. Other characteristic products not attributable to the fragmentation pattern indicated in the literature by Russell [15] for this class of pigments are also present in the pyrogram. Their main $\mathrm{m} / \mathrm{z}$ are listed in Table 4.

Table 4 Pyrolysis products of PV32, benzimidazolone violet.

\begin{tabular}{l|l|l|l|l|l|l}
\hline C.I. name & \multicolumn{5}{|l|}{ Substituents (Fig. 5) } & \multicolumn{2}{l}{ Products (main $\mathbf{~} / \mathbf{z}$ ) } \\
\hline & $\mathbf{X 1}$ & $\mathbf{X 2}$ & $\mathbf{X 3}$ & $\mathbf{a}$ & $\mathbf{b}$ & others \\
\hline $\mathrm{PV} 32$ & $\mathrm{OCH}_{3}$ & $\mathrm{SO}_{2} \mathrm{NHCH}_{3}$ & $\mathrm{OCH}_{3}$ & $/$ & $\begin{array}{l}\text { b- } \mathrm{X}_{2} \text { : benzenamine, } \\
2,5-\text { dimethoxy } \\
(138,153,110)\end{array}$ & $\begin{array}{l}\text { unknown product } \\
(231,170,107)\end{array}$ \\
& & & & & & $\begin{array}{l}\text { unknown product } \\
(246,231,168,202)\end{array}$ \\
\hline
\end{tabular}

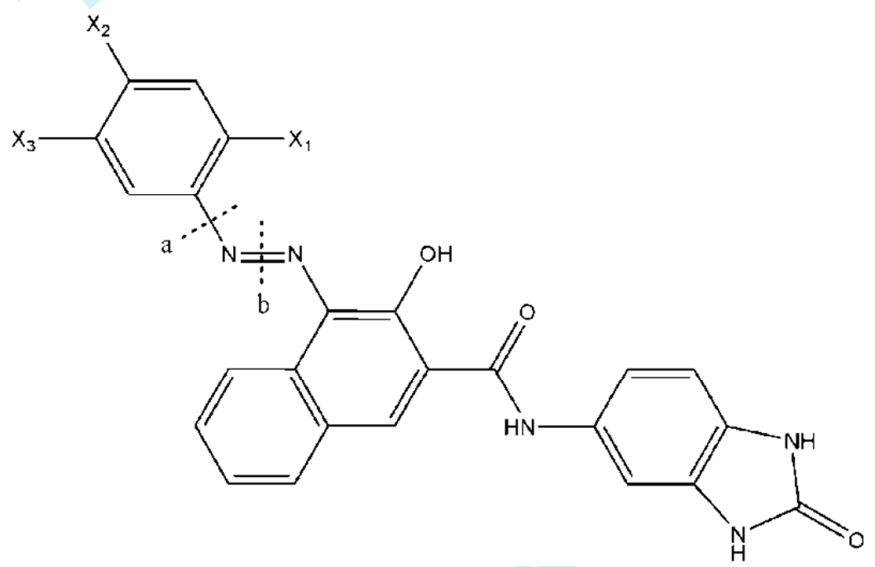

Fig. 5 PV32 structure with breaking points highlighted.

Metal complex pigments. First developed around 1920, many metal complex pigments did not appear on the market until the late 1940's. Only a few azo metal complexes are available as pigments. The chelating metal is usually nickel, and less commonly, cobalt or iron(II). We analysed two green pigments, PGr8 and PGr10. PGr8 is used in emulsion paints. PGr10, a nickel azo complex that has been known since 1947, is used primarily in high grade industrial paints [2].

The Py-GC/MS results are listed in Table 5. Interestingly, the pyrogram of PGr8 highlights the presence of the methyl ester of 11-octadecenoic acid, which could have been used in the synthesis of the pigment as in the case of PR83, whose pyrolysis profile will be discussed later on.

The structure of PGr10 is shown in Fig. 6, with the main fragments produced by pyrolysis.

Table 5 Pyrolysis products of metal complex pigments.

\begin{tabular}{|c|c|c|}
\hline C.I. name & Products (main $\mathrm{m} / \mathrm{z}$ & \\
\hline & $a$ & others \\
\hline PGr8 & & $\begin{array}{l}\text { quinoline } \\
(129,102) \\
\text { 2-naphthol } \\
(144,115)\end{array}$ \\
\hline
\end{tabular}


<smiles>Clc1ccccc1</smiles>

product a<smiles>Nc1ccc(Cl)cc1</smiles>

product b

Fig. 6 PGr10 with fragments produced by pyrolysis.

Isoindoline pigments. This high-quality products class was introduced in the mid-1960s and is characterized by the isoindoline ring. We analysed $\mathrm{PBr} 38$, a methine-type isoindoline pigment. The commercial type was used as a colorant for plastics, especially for PVC and LDPE, but it was withdrawn from the market [2]. The fragmentation pattern and the pyrolysis products are shown in Fig. 7 and listed in Table 6. The $2(1 \mathrm{H})$-quinolinone is a characteristic pyrolysis product of this pigment.

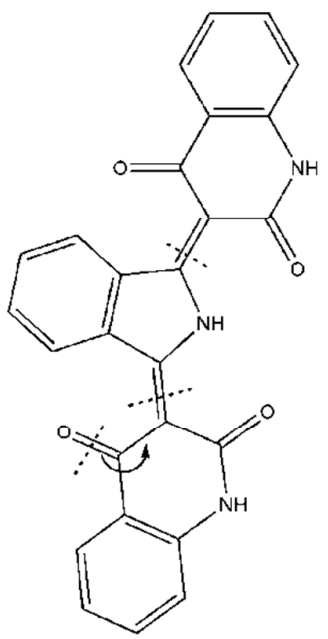<smiles>c1ccc2c(c1)CNC2</smiles><smiles>O=c1ccc2ccccc2[nH]1</smiles>

Fig. $7 \mathrm{PBr} 38$ structure (left), with fragments produced by pyrolysis: indole (top right) and 2(1H)-quinolinone (bottom right). 
Table 6 Pyrolysis products of $\mathrm{PBr} 38$.

\begin{tabular}{l|l}
\hline C.I.name & Products (main $\mathbf{m} / \mathbf{z})$ \\
\hline PBr38 & $\begin{array}{l}\text { 2(1H)-quinolinone } \\
(145,117,90) \\
\text { indole } \\
(117,90,63) \\
\text { aniline } \\
(93,66) \\
1 H \\
14 \text {-isoindole-1,3(2H)-dione } \\
(147,76,104)\end{array}$ \\
\hline
\end{tabular}

Disazopyrazolone pigments. In the early 1950s, Ciba researches succeeded in synthesizing red disazo compounds of relatively high molecular weight. These products were known as disazo condensation pigments [2]. PR41 is also known as pyrazolone red. The structure is shown in Fig. 8 , and the products of pyrolysis are listed in Table 7.

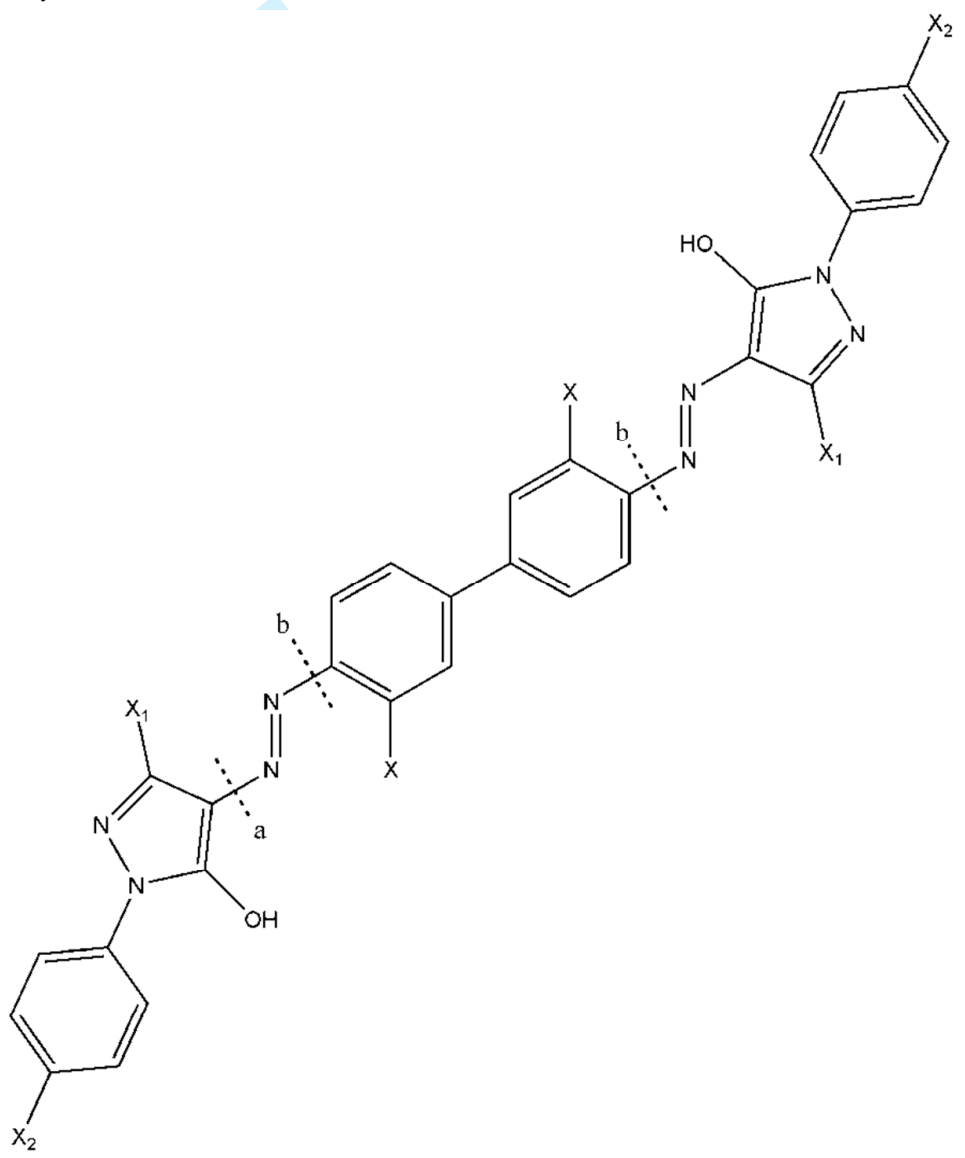

Fig. 8 PR41 structure with breaking points highlighted. 


\section{Polycyclic pigments}

Phthalocyanine pigments. Phthalocyanines are among the most important modern synthetic organic pigments used in artists' paint formulations. Phthalo blues were first introduced in 1935, while phthalo greens in 1938 (chlorinated) and 1959 (chlorinated and brominated) [16]. We extended the work of Russell [15] and Sonoda [13] on phthalocyanine pigments by analysing PB16, PB17, PB76, PGr13 and all the PB15 crystal modifications: PB15:0, PB15:1, PB15:2, PB15:3, PB15:4, PB15:6. The main products are shown in Fig. 9 and listed in Table 8. We confirmed that 1,2-dicyanobenzene is a characteristic pyrolysis products of the phthalocyanine pigments class. We found also that the pyrograms of the PB15 series contain the characteristic o-cyanobenzoic acid that can be considered as a marker and thus can help in the identification of this pigment. PB15 has been already analysed by Sonoda [13]; he observed only a small peak corresponding to 1,2-dicyanobenzene, while we were able to identify other specific products, listed in Table 8. As for the other phthalocyanine pigments analysed, PGr13 shows o-cyanobenzoic acid as the PB15 series, but it can be distinguished on the basis of its different colour. The pyrogram of PB76 is characterized by products originated from the chlorinated substituents.

Table 8 Pyrolysis products of the phthalocyanine pigments.

\begin{tabular}{|c|c|c|c|c|c|c|c|c|c|}
\hline Product (main $\mathrm{m} / \mathrm{z}$ ) & PB15:0* & PB15:1 & PB15:2 & PB15:3 & PB15:4 & PB15:6 & PB17 & PB76 & PGr13 \\
\hline $\begin{array}{l}\text { methenamine } \\
(42,140)\end{array}$ & & & & & & 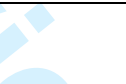 & $x$ & & \\
\hline $\begin{array}{l}\text { tetrahydrofuran } \\
(42,72)\end{array}$ & & & & & & $x$ & & & \\
\hline $\begin{array}{l}\text { benzene, 1,3 dimethyl } \\
(91,106)\end{array}$ & $x$ & $x$ & & & & & & & \\
\hline $\begin{array}{l}\text { benzonitrile } \\
(103,76)\end{array}$ & $x$ & & & $x$ & & & & & $x$ \\
\hline $\begin{array}{l}\text { 2-oxepanone } \\
(55,42,84)\end{array}$ & & & & & $x$ & & & & \\
\hline $\begin{array}{l}\text { benzene, } 1,2,4 \\
\text { trichloro } \\
(180,182,144)\end{array}$ & $x$ & & & & & & & & \\
\hline $\begin{array}{l}\text { benzene, } 1-(1- \\
\text { methylethenyl)-3-(1- } \\
\text { methylethyl) } \\
(145,160,117)\end{array}$ & & & & $x$ & & & & & \\
\hline $\begin{array}{l}\text { 1,2-dicyanobenzene } \\
(128,101)\end{array}$ & $x$ & $x$ & $x$ & $x$ & $x$ & $x$ & $x$ & $x$ & $x$ \\
\hline $\begin{array}{l}\text { o-cyanobenzoic acid } \\
(147,76,104)\end{array}$ & $x$ & $x$ & $x$ & $x$ & $x$ & $x$ & & & $x$ \\
\hline benzene, $1,1^{\prime}$ - & & & & $x$ & & & & & \\
\hline
\end{tabular}




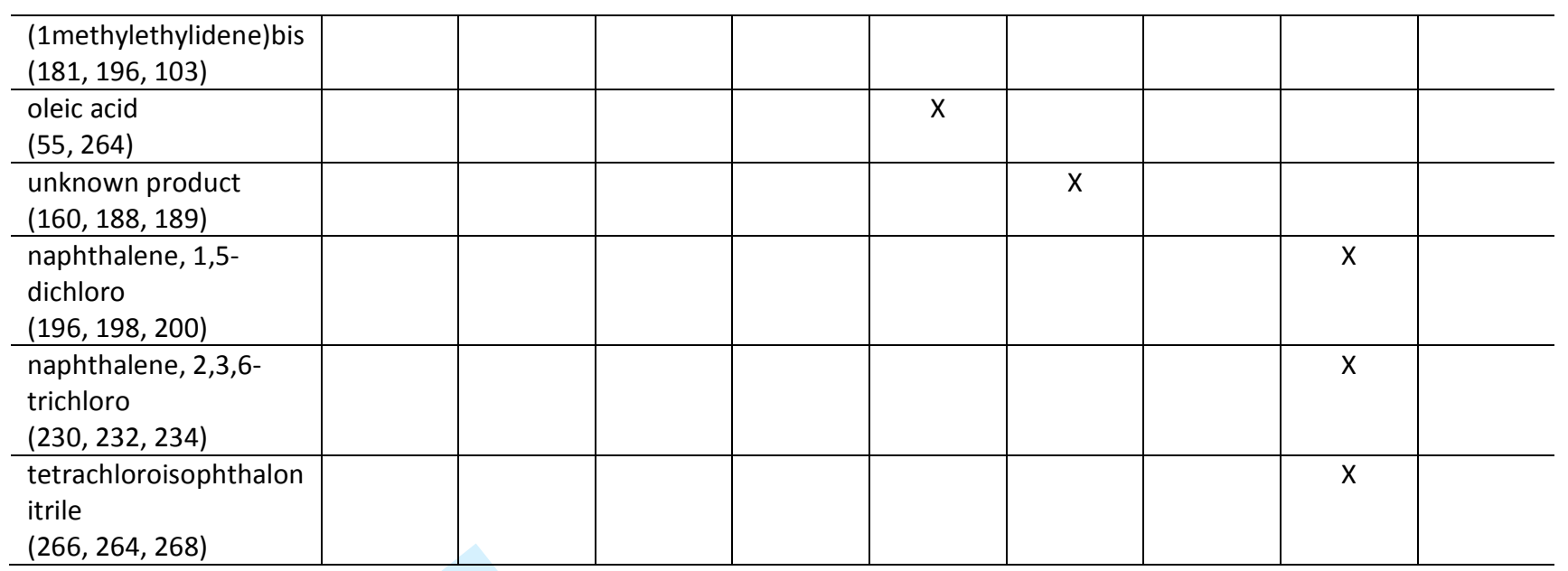

*A Py-GC/MS analysis of PB15 has already been published by Sonoda [13].

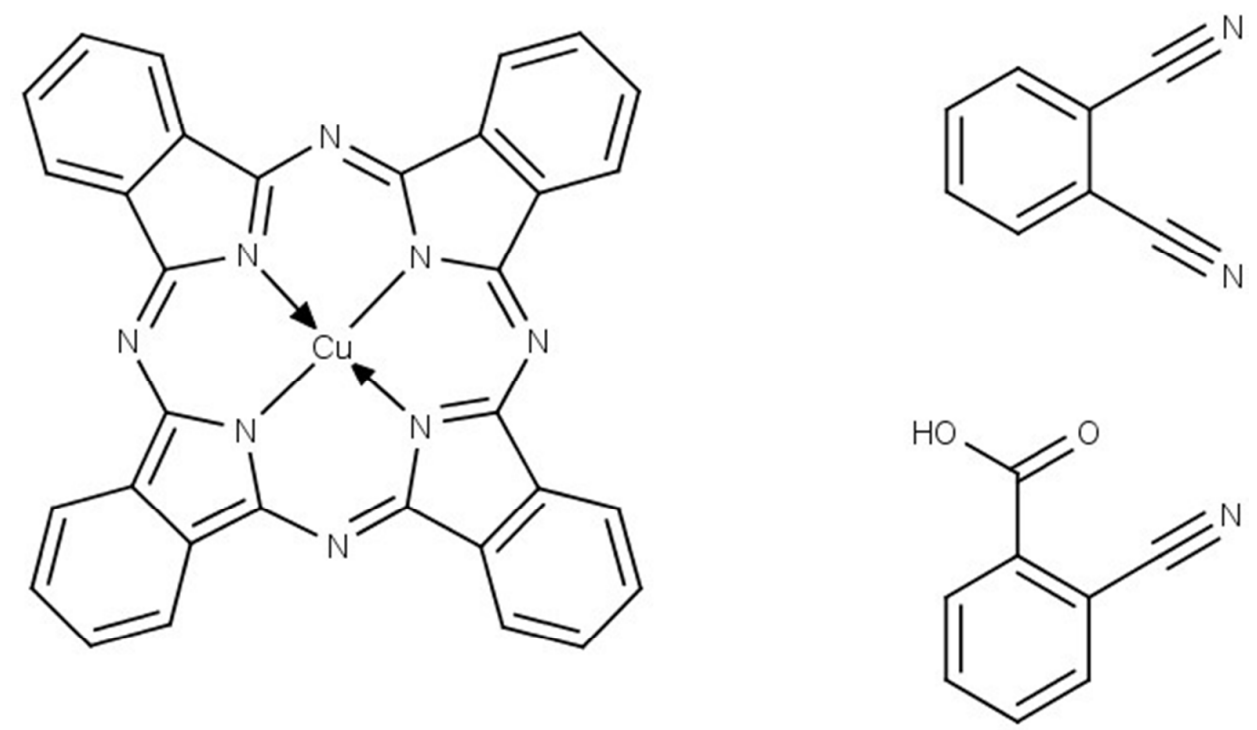

Fig. 9 Structure of phthalocyanine pigments (left) with fragments of the PB15 series produced by pyrolysis: 1,2-dicyanobenzene (top right) and o-cyanobenzoic acid (bottom right).

Quinacridone pigments. Quinacridone pigments have excellent fastness and resistance properties and have been used since their appearance on the market in high-quality artists' materials [2]. We analysed PV19 and PV42. The formulation of PV42, a mixed phase pigment, has never been published yet. The results are shown in Table 9. The pyrogram of PV19 shows an unknown product, while that of PV42 contains several products, one being the characteristic 2methylacridone (Fig. 10).

Although the pyrolysis profile does not allow us to hypothesise the formulation of PV42 pigment, it might be used for its identification in unknown paint samples. 
Anthraquinone and Indanthrone pigments. This class groups those pigments sharing the 9,10anthraquinone skeleton. PR83, alizarin crimson, is an hydroxyanthraquinone pigment and the synthetic counterpart of the natural madder lake. The identification of PR83 by Py-GC/MS is possible on the basis of its characteristic fragments (phenanthrene; anthrone; 9,10anthracenedione; 9,10-anthracenedione-2-hydroxy). The only other pigment with a similar fragmentation pattern is an indanthrone blue pigment, PB60, which can be easily distinguished from PR83 because of its blue colour. The products of pyrolysis are listed in Table 10 for both pigments.

The Py-GC/MS analysis of PR83 has an interesting feature: the pyrogram (Fig. 11) shows linoleic acid as the most intense peak, with the presence of other fatty acids. According to Pratt [19], the preparation of PR83 involves the precipitation of a complex made up of the dyestuff, a metal and a fatty acid such as Turkey Red oil on an alumina hydrate base. The fatty acids peaks in the pyrogram of PR83 could be ascribed to the Turkey Red oil used for the synthesis of the pigment. Turkey red oil, also called sulphonated castor oil, is prepared by adding sulphuric acid to vegetable oils, most notably castor oil. To verify our hypothesis, we analysed PR83 also with GC/MS using TMTFTH (m-trifluoromethylphenyl trimethylammonium hydroxide), also called Meth Prep $\|^{\circledR}$, as derivatising agent [20] [21], and a marker of castor oil, methyl ricinoleate, was detected. This result is important and must be considered for the identification of the binding media in the presence of PR83. If a modified vegetable oil is added to the pigment itself, the quantitative analysis of the fatty acids cannot be reliably applied to determine the type of siccative oil used. 
Table 10 Pyrolysis products of anthraquinone and indantrone pigments.

\begin{tabular}{l|c|c}
\hline Pyrolysis product (main m/z) & PR83 & PB60 \\
\hline $\begin{array}{l}\text { aniline } \\
(93,66)\end{array}$ & & $\mathrm{X}$ \\
\hline $\begin{array}{l}\text { benzene, nitro } \\
(77,123,51)\end{array}$ & $\mathrm{X}$ & \\
\hline $\begin{array}{l}\text { 2-naphthol } \\
(144,115)\end{array}$ & $\mathrm{X}$ & \\
\hline $\begin{array}{l}\text { phenanthrene } \\
(178)\end{array}$ & $\mathrm{X}$ & $\mathrm{X}$ \\
\hline $\begin{array}{l}\text { anthrone } \\
(194,165)\end{array}$ & $\mathrm{X}$ & $\mathrm{X}$ \\
\hline $\begin{array}{l}\text { 9,10-anthracenedione } \\
(208,180,152)\end{array}$ & $\mathrm{X}$ & \\
\hline $\begin{array}{l}\text { linoleic acid } \\
(280)\end{array}$ & & $\mathrm{X}$ \\
\hline $\begin{array}{l}\text { 9,10-anthracenedione, 1-amino } \\
(223,139,167)\end{array}$ & & \\
\hline $\begin{array}{l}\text { 9,10-anthracenedione, 2-hydroxy } \\
(224,139,196)\end{array}$ & $\mathrm{X}$ & \\
\hline $\begin{array}{l}\text { dinaphtho[2,1b:1',2'-d]furan* } \\
(268,239,119)\end{array}$ & $\mathrm{X}$ & \\
\hline
\end{tabular}

*or dinaphtho[2,1b:1,2-d]furan.

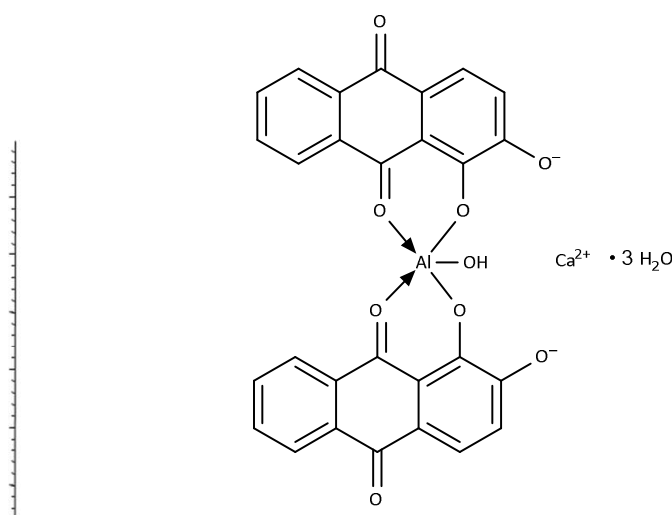

응 
which is the form in which they can be applied as pigments [2]. We have analysed PV1, PV3, PV27, PV39, PB1 and PB62. The results are shown in Table 11.

In some cases the molecule did not fragment in the pyrolyzer in the adopted conditions: the pyrograms of PV3, PV27, PV39 and PB62 all show the intact molecule peak, as shown in Fig. 13 for PV27 (peak \#17). Unfortunately, for PV3 and PV27 the intact molecule of both pigments co-elutes with the de-methylated molecule. This makes the identification of the pigments of this class difficult but not impossible: the different relative abundances of ions in the mass spectra can be exploited to differentiate the pigments, as demonstrated in Fig. 14. On the one hand, the presence of the intact molecule makes the identification of this class of pigments rather easy, on the other hand it is not simple to differentiate between the pigments because they are structurally very similar and have similar mass spectra.

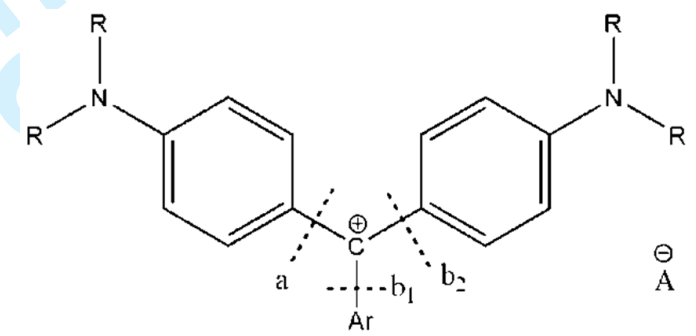

Fig. 12 Structure of triarylcarbonium pigments with breaking points highlighted. 
Table 11 Pyrolysis products of triarylcarbonium pigments.

\begin{tabular}{|c|c|c|c|c|c|c|}
\hline \multirow[t]{2}{*}{ C.I. name } & \multicolumn{3}{|c|}{ Substituents (Fig. 12) } & \multicolumn{3}{|l|}{ Products (main $\mathrm{m} / \mathrm{z}$ ) } \\
\hline & $A^{-*}$ & $\mathrm{Ar}$ & $\mathbf{R}$ & $\mathbf{a}$ & b & others \\
\hline PV1 & / & / & / & & & $\begin{array}{l}\text { 1H-indole, 1,2,3-trimethyl } \\
(158,159,144) \\
\text { 1H-Indole, } 2,3 \text {-dihydro 1,3,3- } \\
\text { trimethyl-2-methylene } \\
(158,173,143)\end{array}$ \\
\hline PV3 & $\begin{array}{l}\text { PTM } \\
\text { PM }\end{array}$ & & $\mathrm{CH}_{3}$ & $\begin{array}{l}\text { Benzenamine, N,N-dimethyl } \\
(120,121,77)\end{array}$ & $\begin{array}{l}\text { b1+b2: Benzenamine, N,N,4- } \\
\text { trimethyl } \\
(134,135) \\
\text { b1: Benzenamine, 4,4'- } \\
\text { methylenebis N,N-dimethyl } \\
(254,253,210)\end{array}$ & $\begin{array}{l}\begin{array}{l}\text { Aniline } \\
(93,66)\end{array} \\
\text { Aniline, N-methyl } \\
(106,107,77) \\
\text { PV3 intact molecule } \\
(253,373,359,237)\end{array}$ \\
\hline PV27 & CF & & $\mathrm{CH}_{3}$ & $\begin{array}{l}\text { Benzenamine, N,N-dimethyl } \\
(120,121,77)\end{array}$ & $\begin{array}{l}\text { b1+b2: Benzenamine, N,N,4- } \\
\text { trimethyl } \\
(134,135)\end{array}$ & $\begin{array}{l}\begin{array}{l}\text { Aniline } \\
(93,66)\end{array} \\
\text { Aniline, N-methyl } \\
(106,107,77) \\
\text { PV27 intact molecule } \\
(239,359,345,253,373)\end{array}$ \\
\hline PV39 & $\begin{array}{l}\text { PM } \\
\text { PTM }\end{array}$ & & $\mathrm{CH}_{3}$ & $\begin{array}{l}\text { Benzenamine, N,N-dimethyl } \\
(120,121,77)\end{array}$ & $\begin{array}{l}\text { b1+b2: Benzenamine, N,N,4- } \\
\text { trimethyl } \\
(134,135) \\
\text { b1: Benzenamine, 4,4'- } \\
\text { methylenebis N,N-dimethyl } \\
(254,253,210)\end{array}$ & $\begin{array}{l}\text { Aniline } \\
(93,66) \\
\text { Aniline, N-methyl } \\
(106,107,77) \\
\text { PV39 intact molecule } \\
(253,373,359,252)\end{array}$ \\
\hline PB1 & $\begin{array}{l}\text { PTM } \\
\text { PM }\end{array}$ & & $\mathrm{C}_{2} \mathrm{H}_{5}$ & $\begin{array}{l}\text { N,N-Diethyl aniline } \\
(134,106,149)\end{array}$ & $\begin{array}{l}\text { b1+b2: Benzenamine, N,N- } \\
\text { diethyl-4-methyl } \\
(148,120,163)\end{array}$ & $\begin{array}{l}\text { Aniline } \\
(93,66) \\
\text { Benzenamine, N-ethyl }\end{array}$ \\
\hline
\end{tabular}




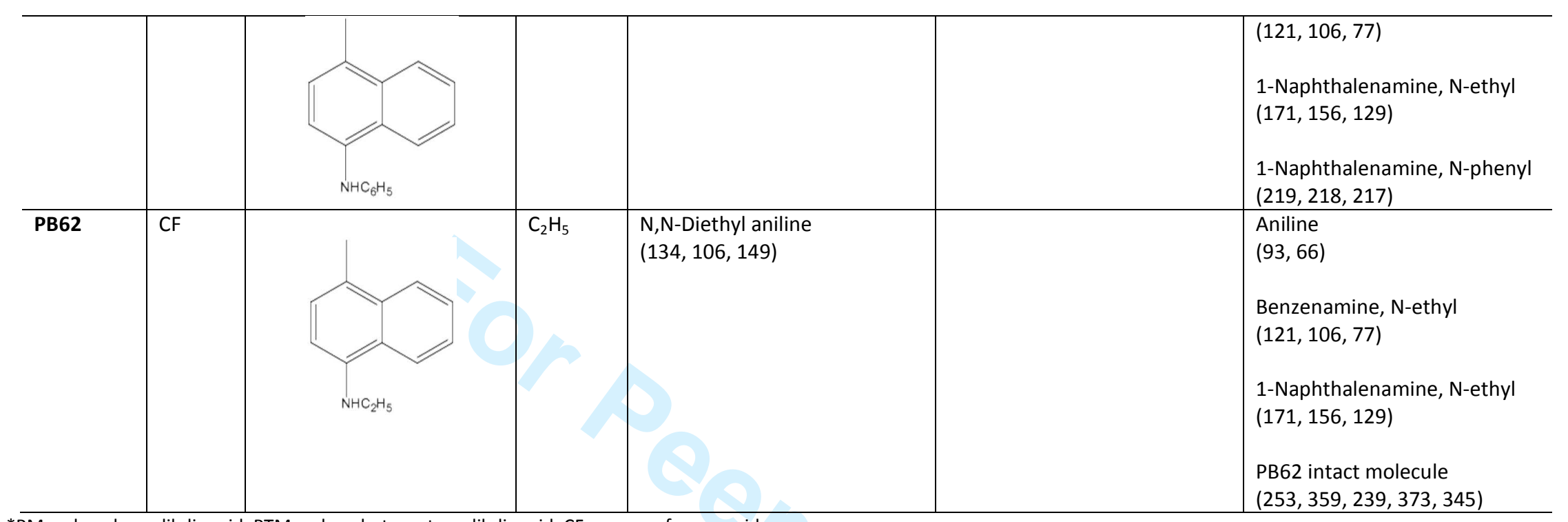

*PM = phosphomolibdic acid; PTM = phosphotungstomolibdic acid; $\mathrm{CF}$ = copper ferrocyanide. 


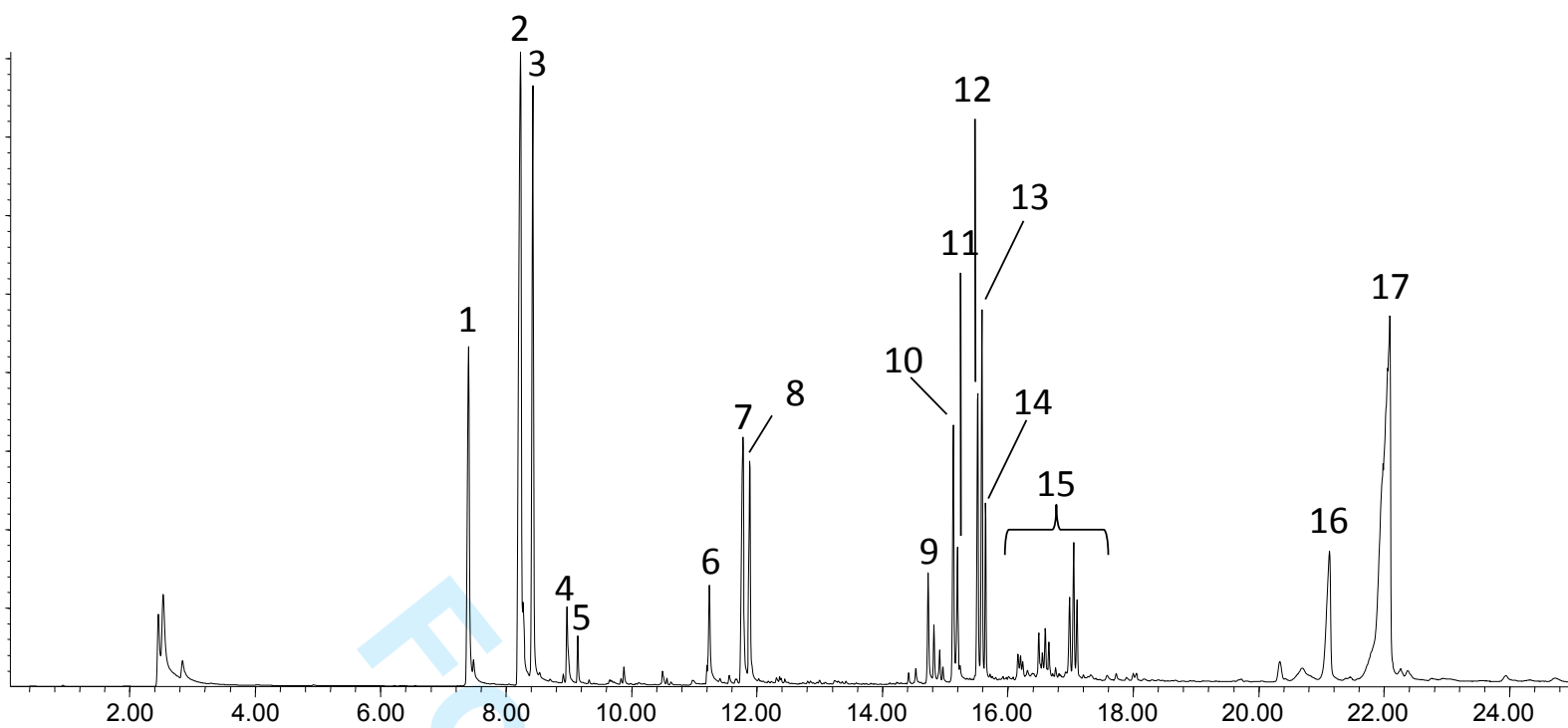

Fig. 13 Pyrogram of PV27. 1. Aniline; 2. aniline, N-methyl-; 3. benzenamine, N,N-dimethyl-; 4. benzenamine, N,4-dimethyl-; 5. benzenamine, N,N,4-trimethyl-; 6. 4-aminobenzonitrile; 7. 4-aminobenzonitrile, N-methyl; 8. 4-aminobenzonitrile, N,N-dimethyl; 9. 4,4'-methylenedianiline; 10. 4,4'-methylenedianiline, N-methyl; 11. 4,4'-methylenedianiline, N,N-dimethyl; 12. 4,4'methylenedianiline, N,N-dimethyl (positional isomer of \#11); 13. 4,4'-methylenedianiline, N,N,N-trimethyl; 14. 4,4'methylenedianiline, N,N,N,N-tetramethyl; 15. unknown products typical of PV27 (RT $16.99 \mathrm{~min}$ : m/z 251, 145, 221, 236; RT 17.05 min: $\mathrm{m} / \mathrm{z}$ 265, 221, 159, 144; RT $17.11 \mathrm{~min}: \mathrm{m} / \mathrm{z} 279,235,158,143)$ (spectra reported in Fig. S12, S13 and S14); 16. 4,4'-((4aminophenyl)methylene)bis( $\mathrm{N}, \mathrm{N}$-dimethylaniline); 17 . intact molecules $(4,4$ ' 4 "'-methanetriyltris( $\mathrm{N}, \mathrm{N}$-dimethylaniline) coeluting with 4,4'-((4-(methylamino)phenyl)methylene)bis( $\mathrm{N}, \mathrm{N}$-dimethylaniline).
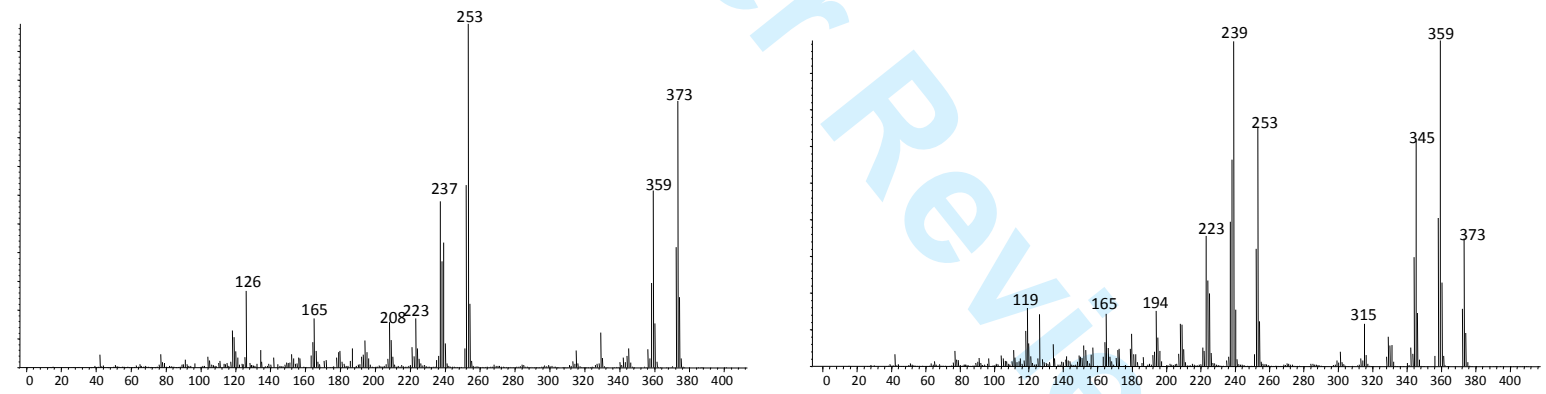

Fig. 14 Mass spectra of intact molecules of PV3 (left) and PV27 (right): (4,4',4"-methanetriyltris(N,N-dimethylaniline) coeluting with 4,4'-((4-(methylamino)phenyl)methylene)bis(N,N-dimethylaniline).

Dioxazine pigments. The dioxazine pigments were first synthesized in 1928, but patented as pigments only in 1952 [16]. The dioxazine molecule is derived from triphenodioxazine, a linear system of five anellated rings.

PV23, Carbazole Violet, is the commercially most important pigment of this class and it is used in almost all media, from coatings and paints to plastics and printing inks [2]. The structure of dioxazine pigments is shown in Fig. 15, and the results are listed in

Table 12. Pyrolysis produces chlorinated benzenes deriving from the central structure of the molecule and other smaller aromatic products. 
Table 12 Pyrolysis products of dioxazine pigments.

\begin{tabular}{|c|c|c|c|c|}
\hline \multirow[t]{2}{*}{ C.I. name } & \multicolumn{4}{|c|}{ Product (main $\mathrm{m} / \mathrm{z}$ ) } \\
\hline & $a$ & $\mathbf{b}$ & c & others \\
\hline PV23 & $\begin{array}{l}\text { Benzene, 1,4- } \\
\text { dichloro } \\
(146,148,111)\end{array}$ & $\begin{array}{l}\text { Indole } \\
(117,90,109)\end{array}$ & $\begin{array}{l}\text { Carbazole } \\
(167,166,139)\end{array}$ & $\begin{array}{l}\text { Unknown product } \\
(183,154,196,211) \\
\text { Unknown product } \\
(182,195,210,181) \\
\text { Unknown product } \\
(222,235,250,153)\end{array}$ \\
\hline PV37 & $\begin{array}{l}\text { Benzene, 1,4- } \\
\text { dichloro } \\
(146,148,111)\end{array}$ & & & $\begin{array}{l}\text { Benzonitrile } \\
(103,76) \\
\text { Benzoic acid, ethyl ester } \\
(105,77,122,150) \\
\text { Benzamide } \\
(105,77,121,51) \\
\text { Benzoxazole, 2-phenyl } \\
(195,63,167) \\
\text { Unknown product } \\
(211,104)\end{array}$ \\
\hline
\end{tabular}

Perylene pigments. The group of perylene pigments is derived from perylene-3,4,9,10tetracarboxylic acid. These compounds have been used as vat dyes since 1913 and were first introduced commercially as pigments in 1950 [2]. We analysed PV29 (Fig. 16), which gives a characteristic product, naphthalimide, a fragment originated from the central polycyclic structure of the pigment. This fragmentation was not observed by Russell [15], who studied substituted perylenes only.

Fig. 15 Structure of dioxazine pigments with breaking points highlighted. 

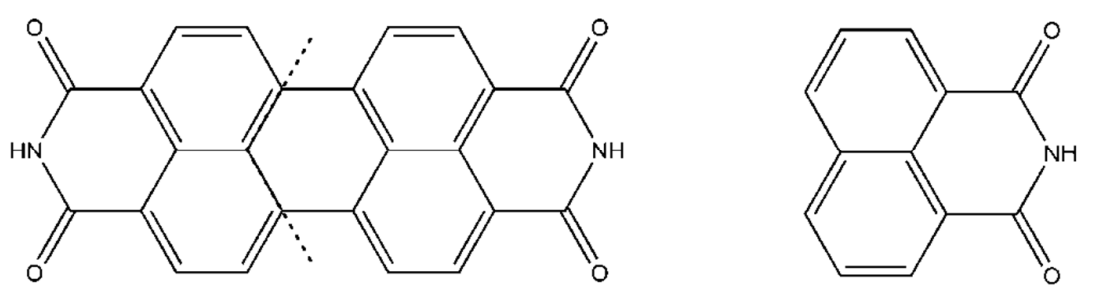

Fig. 16 Structure of PV29 (left), with naphthalimide, a fragment produced by pyrolysis (right).

Thioindigo Pigments. Thioindigo pigments were first discovered in 1907 and are structurally related to indigo, the natural dyestuff derived from the plant Indigofera tinctoria. We analysed PV36. The structure of the pigment is shown in Fig. 17, with its main pyrolysis product.<smiles>Cc1cc(Cl)cc2c1S/C(=C1/Sc3c(C)cc(Cl)cc3C1=O)C2=O</smiles><smiles>Oc1cc(Cl)c(Cl)cc1Cl</smiles>

Fig. 17 Structure of PV36 (left) with 2,4,5-trichlorophenol, a fragment produced by pyrolysis (right).

Miscellaneous pigments. Of the pigments not grouped in the azo or in the polycyclic classes, we analysed PR90. PR90, eosin lake, was used extensively to produce lake pigments (such as geranium lake), where the dyestuff was commonly precipitated with an aluminium hydroxide base or a lead (II, III) oxide [22]. The structure of the pigment is shown in Fig. 18 and the products of the pyrolysis are listed in Table 13.

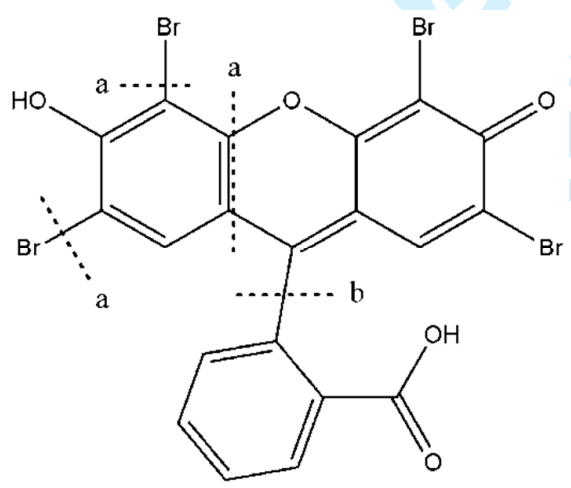

Fig. 18 Structure of PR90 with breaking points highlighted.

Table 13 Pyrolysis products of PR90.

\begin{tabular}{l|l|l|l}
\hline \multirow{2}{*}{ C.I. name } & \multicolumn{3}{|l}{ Product (main $\mathbf{~} / \mathbf{z})$} \\
\cline { 2 - 4 } & $\mathbf{a}$ & $\mathbf{b}$ & others \\
\hline PR90 & Phenol & Benzoic acid & $1,4-$-Dioxane \\
& $(94,66)$ & $(105,122,77,51)$ & $(88,28,58)$ \\
& & & Biphenyl \\
& & & $(154,153)$ \\
\hline
\end{tabular}




\section{Pigments with unpublished chemical structure}

We analysed three pigments with an unpublished chemical structure, PV51, PV52 and PV53. The results of the Py-GC/MS analysis are listed in Table 14.

On the basis of the identified fragments, which mainly are rearrangement products, it is not possible to unambiguously hypothesise the structure of PV51, PV52 or PV53. Nonetheless, they share common fragments with the $\beta$-naphthol pigment lakes, BONA pigment lakes and naphthol AS. Thus, their structures most probably contain a 2-naphthol linked by a diazo bond to other aromatic substituents.

Table 14 Pyrolysis products of pigments with unpublished chemical structure.

\begin{tabular}{l|c|c|c}
\hline $\begin{array}{l}\text { Pyrolysis product (main m/z) } \\
(55,70,41)\end{array}$ & PV51 & PV52 & PV53 \\
\hline $\begin{array}{l}\text { 2-Propyl-1-pentanol } \\
(57,41,70,83)\end{array}$ & $\mathrm{X}$ & & $\mathrm{X}$ \\
\hline $\begin{array}{l}\text { Naphthalene } \\
(128)\end{array}$ & & & $\mathrm{X}$ \\
\hline $\begin{array}{l}\text { Benzenamine, 4-methoxy } \\
(108,123,80)\end{array}$ & $\mathrm{X}$ & $\mathrm{X}$ & \\
\hline $\begin{array}{l}\text { Phenol, 4-amino } \\
(109,80)\end{array}$ & $\mathrm{X}$ & $\mathrm{X}$ & \\
\hline $\begin{array}{l}\text { 2-Naphthol } \\
(144,115)\end{array}$ & $\mathrm{X}$ & $\mathrm{X}$ & $\mathrm{X}$ \\
\hline $\begin{array}{l}\text { 2-Naphthalenamine } \\
(143,115)\end{array}$ & & & $\mathrm{X}$ \\
\hline $\begin{array}{l}\text { Benz[c,d]indol-2(1H)one } \\
(169,114,141)\end{array}$ & $\mathrm{X}$ & & \\
\hline $\begin{array}{l}\text { Bis(2ethylhexyl) maleate } \\
\text { (57, 117, 71, 100) }\end{array}$ & $\mathrm{X}$ & $\mathrm{X}$ & \\
\hline $\begin{array}{l}\text { 2-Butenedioic acid (E)- } \\
\text { bis(2ethylhexyl) ester } \\
\text { (70, 112, 57, 211) }\end{array}$ & $\mathrm{X}$ & $\mathrm{X}$ & $\mathrm{X}$ \\
\hline $\begin{array}{l}\text { Dinaphtho[2,1b:1 2-d] furan } \\
\text { (268, 239, 119) }\end{array}$ & & & \\
\hline
\end{tabular}

\section{Discussion of the analysis of reference pigments}

In this work we expanded the data available on some classes of synthetic pigments already being analysed by other authors [13] [15] and the fragmentation patterns are generally consistent with literature data. We also report the pyrolysis profiles of pigments never previously analysed by this technique. Several pyrolysis products are common to different classes of synthetic pigments, for example 2-naphthol and aniline; thus these compounds cannot be used in the identification of the pigments. In particular, the pigments belonging to the beta-naphthol and BONA pigment lakes 
classes cannot be easily distinguished because they share many products in common. Nonetheless, the interpretation of the profile generally allows the identification of the class. For PGr8, a metal complex pigment, and PR83, an anthraquinone pigment, we assessed the presence in the pyrograms of products derived from vegetable oils, even if the pigments analysed were not expected to contain binding media. Thus, we hypothesised that the fatty acids detected originated from an oil used in the synthesis of the pigments themselves.

With regard to the isoindoline and disazopyrazolone pigments analysed, we found characteristic products, respectively $2(1 \mathrm{H})$-quinolinone and norphenazone, that can help in the identification of these classes.

We confirmed the results of Russell [15] for the phthalocyanine pigments, but we expanded the database analysing another three phthalo pigments and the six crystal modifications of PB15. Py$\mathrm{GC} / \mathrm{MS}$ allows us to differentiate between the various PB15 crystal modifications, because they show different pyrolytic profiles.

The pyrogram of PV19, a quinacridone pigment extensively used in paint industry, shows only an unknown product, which can still be used for the identification of this pigment. The other quinacridone pigment analysed, PV42, has 2-methyl acridone as characteristic product.

The alizarin crimson PR83 is unambiguously identifiable by Py-GC/MS, and this result is important because this pigment has been widely used in artists' paints.

Another interesting result is the one of the triarylcarbonium class: we found that some of the pigments belonging to this class show in the pyrograms the intact molecule peak.

As for the dioxazine pigments, the products of PV23, one of the most used pigments in paint materials, are unknown, but the $\mathrm{m} / \mathrm{z}$ reported could help in the identification.

We analysed for the first time with Py-GC/MS PV36, a thioindigo pigment, obtaining a peculiar pyrogram with a single peak, the 2,4,5-trichlorophenol.

We also reported for the first time the Py-GC/MS results of three violet pigments with unpublished chemical structure, PV51, PV52 and PV53.

\section{Clyfford Still's and Jackson Pollock's paints and works}

\section{Clyfford Still}

In his studio Clyfford Still had a big collection of pigments that he used to paint his artworks. The paints were prepared by pouring dry pigments onto a palette in a mound and creating a well at the top, where Still poured boiled linseed oil as well as a small amount of turps and driers. He then mixed the ingredients with a palette knife [23].

We analysed ten paint samples and seven pigments from Still's collection. The results are shown in Table 15.

We were able to identify the class of the pigment used in five of the ten paint samples, namely the red azo pigment lakes class. For the pigments in the artist's studio, we identified four pigments as PR49, belonging to the red azo pigment lakes class.

In two paint samples we identified PR83, anthraquinone red. As an example we report the pyrogram of a paint sample from Untitled, 1948 (Fig. 19). Three paint samples and three pigments 
form the artist's studio showed products common to several classes of pigments or too few products to allow an identification.

\begin{tabular}{|c|c|c|c|}
\hline type & paint & sample $n^{\circ}$ & Py-GC/MS results \\
\hline \multirow[t]{10}{*}{ Paint sample } & Untitled, 1948 (a) & $339 \_8$ & / \\
\hline & Untitled, 1948 (a) & 339_11 & PR83 \\
\hline & Untitled, 1948 (a) & 339_12 & PR83 \\
\hline & Untitled, 1948 (b) & 322_11 & Red azo pigment lakes class \\
\hline & Untitled, 1951-1952 & 968_1 & Red azo pigment lakes class \\
\hline & Untitled, 1951-1952 & $968 \_2$ & Red azo pigment lakes class \\
\hline & Untitled, 1954 & $969 \_2$ & Red azo pigment lakes class \\
\hline & Untitled, 1960 & $693 \_4$ & Red azo pigment lakes class \\
\hline & Untitled, 1974 & 920_1 & 1 \\
\hline & Untitled, 1974 & $920 \_2$ & $/$ \\
\hline \multirow{7}{*}{$\begin{array}{l}\text { Pigment from the } \\
\text { artist' studio }\end{array}$} & & 18 & PR49 \\
\hline & & 21 & PR49 \\
\hline & & 31 & / \\
\hline & & 35 & $/$ \\
\hline & & 38 & PR49 or PR63 \\
\hline & & 39 & 1 \\
\hline & & $40 a$ & PR49 \\
\hline
\end{tabular}

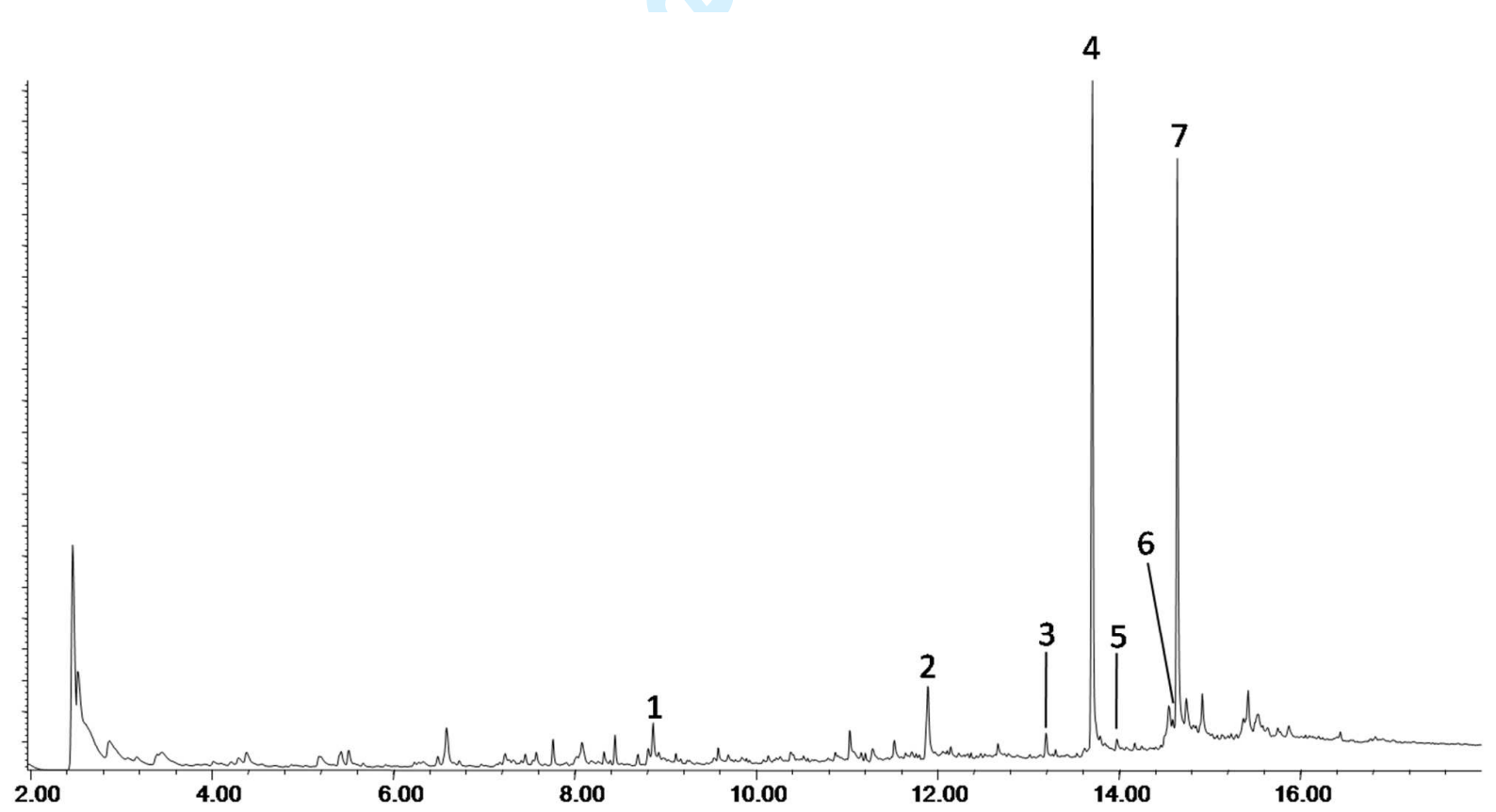

Fig. 19 Pyrogram of Clyfford Still paint sample 339_12, from Untitled (1948). 1. caprylic acid; 2. azelaic acid; 3. phenanthrene; 4. palmitic acid; 5. anthrone; 6. 9,10-anthracenedione,2-hydroxy; 7. stearic acid.

The Py-GC/MS analysis also showed that the binder used by Clyfford Still is a vegetable oil [24] [25] [26], in fact palmitic, stearic and azelaic acids are the main peaks in the pyrograms for all the paint samples. 


\section{Jackson Pollock}

Mural $(247$ x $605 \mathrm{~cm})$, realized in 1943, is an early work by Jackson Pollock. The painting was from 2012 till 2014 at the Getty Center in Los Angeles, CA, undergoing a technical study and a conservation treatment. Two red paint samples from Mural were analysed by Py-GC/MS. Sample \#8 was collected from the end of a drip of thin, very fluid red paint that descends from a diagonal brushstroke. Sample \#27 was collected from the lower right part of the painting.

Results are shown in Table 16. The program of sample \#27 is shown in Fig. 20.

Table 16 Results of the Py-GC/MS analysis on two paint samples from Jackson Pollock's Mural.

\begin{tabular}{|c|c|c|c|c|c|}
\hline Product & $\begin{array}{l}\text { Time } \\
\text { (min) }\end{array}$ & $\mathrm{m} / \mathrm{z}$ & $\begin{array}{c}\text { Marker } \\
\text { of }\end{array}$ & JP \#8 & JP \#27 \\
\hline Naphthalene & 9.2 & 128 & generic & & $x$ \\
\hline 2-Naphthol & 11.5 & 144,115 & generic & $x$ & $x$ \\
\hline Phenanthrene & 13.1 & 178 & PR83 & & $x$ \\
\hline Anthrone & 13.9 & 194,165 & PR83 & & $x$ \\
\hline 9,10-anthracenedione & 14.1 & $208,180,152$ & PR83 & & $\mathrm{X}$ \\
\hline 9,10-anthracenendione, 2-hydroxy & 15.8 & $224,139,196$ & PR83 & & $x$ \\
\hline Unknown PR3 product & 17 & $275,246,128$ & PR3 & $\mathrm{x}$ & \\
\hline Dinaphtho[2,1b:1',2'-d]furan* & 17.9 & $268,239,119$ & PR83 & & $x$ \\
\hline
\end{tabular}

*or dinaphtho[2,1b:1,2-d]furan.

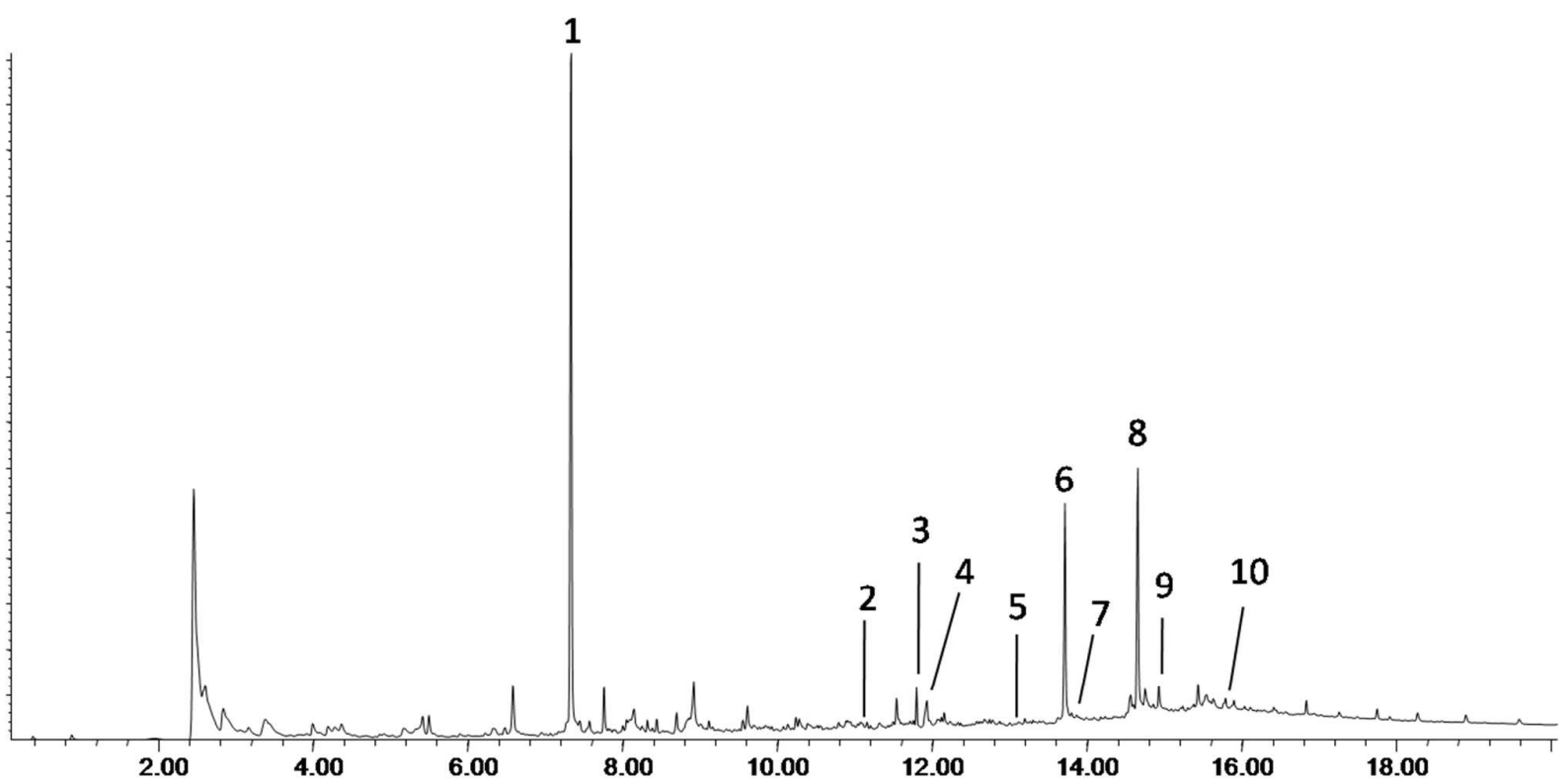

Fig. 20 Pyrogram of Jackson Pollock paint sample 27, from Mural (1943). 1. n-buthyl methacrylate; 2. 2-naphthol; 3. diethyl phthalate; 4 . azelaic acid; 5 . phenanthrene; 6. palmitic acid; 7. anthrone; 8. stearic acid; 9. linoleic acid; 10. 9,10anthracenedione,2-hydroxy.

Sample \#27 shows all the characteristic pyrolysis products of alizarin crimson PR83, confirming that Pollock has used this synthetic pigment. The typical PR83 products are all present in the painting sample: phenanthrene; anthrone; 9,10-anthracenedione; 9,10-anthracenedione-2hydroxy, while naphthalene and 2-naphthol are common products of many synthetic pigments. The pyrogram of this sample also shows several peaks due to fatty acids (azelaic, palmitic, stearic and linoleic), thus indicating that Pollock used an oil paint. The pyrogram of sample \#8 shows a 
product (unknown) at 17 min characteristic of toluidine red PR3, but other expected products of PR3, such as the peak corresponding to the intact molecule, are absent. Thus, the identification of the pigments as PR3 is only tentative.

The two paint samples analysed show also n-buthyl methacrylate as the most abundant peak at $7.3 \mathrm{~min}$. The painting has undergone a restoration during which a varnish named Soluvar (Liquitex) has been applied. Soluvar varnishes are composed of a mixture of $n$-butyl and isobutyl methacrylate (Paraloid B-67 and F-10) resins. The presence of the restoration varnish may thus account for the detection of n-buthyl methacrylate in the pyrogram [27] [28] [29] [30].

\section{Conclusions}

The application of Py-GC/MS technique has proven to be a useful tool for the identification of synthetic pigments and for their detection in paint samples. In this work we expanded the database of pyrolysis products by analysing classes of synthetic pigments never previously analysed by this technique. The publication of a complete database of pyrolysis products derived from the analysis of synthetic pigments is fundamental to unambiguously identify the pigments in paint formulations and in paint samples.

As for the reference pigments analysed, Py-GC/MS in some cases produces the same fragments for more than one pigment, but the overall pyrolysis profile generally allows the identification of the individual pigment.

In the analysed paint samples, only the most abundant products were detected, in most cases due to the low concentration of the pigment compared to the binding medium. Moreover, in many cases these products are not the specific markers of individual pigments. Nonetheless, in most cases we were able to identify at least the class of the synthetic pigment used, as in the case of five of the Clyfford Still's paint samples.

The identification of PR83 alizarin crimson, instead, is rather easy, because this pigment is the only synthetic anthraquinone used in paints formulations. We identified the characteristic pyrolysis products that can be considered as markers of PR83 and we used them to identify the pigment both in the Jackson Pollock's paint sample and in two Still's paint samples. 


\section{References}

1 SOCIETY OF DYERS AND COLOURISTS. Colour Index 1971. third ed., Bradford, 1971.

2 Herbst W., Hunger K. Industrial Organic Pigments: Production, Properties, Applications, (3rd edn). Wiley-VCH, Weinheim, 2004.

3 Bell I.M., Clark R.J.H., Gibbs P.J. Raman spectroscopic library of natural and synthetic pigments. Spectrochimica Acta Part A, 53 (1997), 2159-2179.

4 Burgio L., Clark R.J.H. Library of FT-Raman spectra of pigments, minerals, pigment media and varnishes, and supplement to existing library of Raman spectra of pigments with visible excitation. Spectrochimica Acta Part A, 57 (2001), 1491-1521.

5 Ropret P., Centeno S.A., Bukovec P. Raman identification of yellow synthetic organic pigments in modern and contemporary paintings: Reference spectra and case studies. Spectrochimica Acta Part A, 69 (2008), $486-497$.

6 Scherrer N.C., Stefan Z., Francoise D., Annette F., Renate K. Synthetic organic pigments of the 20th and 21st century relevant to artist's paints: Raman spectra reference collection. Spectrochimica Acta Part A, 73 (2009), 505524.

7 Vandenabeele P., Moens L., Edwards H.G.M., Dams R.. Raman spectroscopic database of azo pigments and application to modern art studies. Journal of Raman Spectroscopy, 31 (2000), 509-517.

8 Fremout W., Saverwyns S. Identification of synthetic organic pigments: the role of a comprehensive digital Raman spectral library. Journal of Raman Spectroscopy, 43 (2012), 1536-1544.

9 Lomax S.Q., Schilling M., Learner T. The identification of synthetic organic pigments by FTIR and DTMS. In Modern Paints Uncovered. Getty Conservation Institute, Tate Modern, London, 2007.

10 Menke C.A., Rivenc R., Learner T. The use of direct temperature-resolved mass spectrometry (DTMS) in the detection of organic pigments found in acrylic paints used by Sam Francis. International Journal of Mass Spectrometry, 284 (2009), 2-11.

11 Boon J.J., Learner T. Analytical mass spectrometry of artists' acrylic emulsion paints by direct temperature resolved mass spectrometry and laser desorption ionisation mass spectrometry. Journal of Analytical and Applied Pyrolysis, 64, 2 (2002), 327-344.

12 Kirby D.P., Khandekar N., Sutherland K., Price B.A. Applications of laser desorption mass spectrometry for the study of synthetic organic pigments in works of art. International Journal of Mass Spectrometry, 284 (2009), 115-122.

13 Sonoda N. Characterization of Organic Azo-Pigments by Pyrolysis-Gas Chromatography. Studies in Conservation, 44, 3 (1999), 195-208.

14 Learner T. Analysis of modern paints. Getty Conservation Institute, 2004.

15 Russell J., Singer B.W., Perry J.J., Bacon A. The identification of synthetic organic pigments in modern paints and modern paintings using pyrolysis-gas chromatography-mass spectrometry. Analytical and Bioanalytical Chemistry, 400 (2011), 1473-1491. 
16 Lomax S.Q., Learner T. A Review of the Classes, Structures, and Methods of Analysis of Synthetic Organic Pigments. Journal of the American Institute for Conservation, 45, 2 (2006), 107-125.

17 Szafran Y., Rivers L., Phenix A., Learner T., Landau E.G., Martin S. Jackson Pollock's Mural: The Transitional Moment. Getty Publications, 2014.

18 Stenger J., Kwan E.E., Eremin K., Speakman S., Kirby D., Stewart H., Huang S.G., Kennedy A.R., Newman R., Khandekar N. Lithol Red Salts: Characterization and Deterioration. e-PS web edition, 7 (2010), 147-157.

19 Pratt L.S. The chemistry and physics of organic pigments. John Wiley, New York, 1947.

20 Piccirillo A., Scalarone D., Chiantore O. Comparison between off-line and on-line derivatisation methods in the characterisation of siccative oils in paint media. Journal of Analytical and Applied Pyrolysis, 74, 1-2 (2005), 33-38.

21 Dredge P., Schilling M.R., Gautier G., Mazurek J., Learner T., Wuhrer R. Lifting the lids off Ripolin: A collection of paint from Sidney Nolan's studio. Journal of the American Institute for Conservation, 52, 4 (2013), 213-226.

22 Eastaugh N., Walsh V.,Chaplin T., Siddall R. Pigment Compendium. Elsevier, 2008.

23 Sobel D., Anfam D. Clyfford Still - The Artist's Museum. Skira Rizzoli, New York, 2012.

24 Bonaduce I., Andreotti A. Py-GC/MS of organic paint binders. In Organic Mass Spectrometry in Art and Archaeology. John Wiley \& Sons, 2009.

25 Shedrinsky A., Baer N.S. The application of analytical pyrolysis to the study of cultural materials. In Applied Pyrolysis Handbook (II ed). CRC Press, 2006.

26 Chiavari G., Prati S. Analytical Pyrolysis as Diagnostic Tool in the Investigation of Works of Art. Chromatographia, 58, 9-10 (2003), 543-554.

27 Learner T. The analysis of synthetic paints by pyrolysis-gas chromatography-mass spectrometry (PyGCMS). Studies in Conservation, 46, 4, 225-241.

28 Scalarone D., Chiantore O. Separation techniques for the analysis of artists' acrylic emulsion paints. Journal of Separation Science, 27 (2004), 263-274.

29 Sonoda N., Rioux J.P. Identification des matériaux synthétiques dans les peintures modernes. I. Vernis et liants polymères. Studies in Conservation, 35, 4 (1990), 189-204.

30 Peris-Vicente J., Baumer U., Stege H., Lutzenberger K., Gimeno-Adelantado J.V. Characterization of Commercial Synthetic Resins by Pyrolysis-Gas Chromatography/Mass Spectrometry: Application to Modern Art and Conservation. Analytical Chemistry, 81, 8 (2009), 3180-3187. 


\section{Captions for figures}

Fig. 1 Structure of $\beta$-naphthol pigment lakes with breaking points highlighted.

Fig. 2 Structure of PR49 (left) and pyrogram of PR49:2 with fragments produced by pyrolysis.

Fig. 3 Structure of BONA pigment lakes (top), with fragments produced by pyrolysis (bottom).

Fig. 4 Structure of Naphthol AS pigments with breaking points highlighted.

Fig. 5 PV32 structure with breaking points highlighted.

Fig. 6 PGr10 with fragments produced by pyrolysis.

Fig. $7 \mathrm{PBr} 38$ structure (left), with fragments produced by pyrolysis: indole (top right) and 2(1H)-quinolinone (bottom right).

Fig. 8 PR41 structure with breaking points highlighted.

Fig. 9 Structure of phthalocyanine pigments (left) with fragments of the PB15 series produced by pyrolysis: 1,2-dicyanobenzene (top right) and o-cyanobenzoic acid (bottom right).

Fig. 10 2-methyl acridone, a characteristic pyrolysis product of PV42.

Fig. 11 Structure of PR83 (left) and its pyrogram with fragments produced by pyrolysis.

Fig. 12 Structure of triarylcarbonium pigments with breaking points highlighted.

Fig. 13 Pyrogram of PV27. 1. Aniline; 2. aniline, N-methyl-; 3. benzenamine, N,N-dimethyl-; 4. benzenamine, $\mathrm{N}$,4-dimethyl-; 5. benzenamine, N,N,4-trimethyl-; 6. 4-aminobenzonitrile; 7. 4-aminobenzonitrile, N-methyl; 8. 4-aminobenzonitrile, N,N-dimethyl; 9. 4,4'-methylenedianiline; 10. 4,4'-methylenedianiline, N-methyl; 11. 4,4'-methylenedianiline, N,N-dimethyl; 12. 4,4'-methylenedianiline, N,N-dimethyl (positional isomer of \#11); 13. 4,4'-methylenedianiline, N,N,N-trimethyl; 14. 4,4'-methylenedianiline, N,N,N,N-tetramethyl; 15. unknown products typical of PV27 (RT $16.99 \mathrm{~min}: \mathrm{m} / \mathrm{z}$ 251, 145, 221, 236; RT $17.05 \mathrm{~min}: \mathrm{m} / \mathrm{z}$ 265, 221, 159, 144; RT $17.11 \mathrm{~min}: \mathrm{m} / \mathrm{z}$ 279, 235, 158, 143) (spectra reported in Fig. S12, S13 and S14); 16. 4,4'-((4aminophenyl)methylene)bis(N,N-dimethylaniline); 17 . intact molecules $\left(4,4^{\prime}, 4^{\prime \prime}\right.$-methanetriyltris $(\mathrm{N}, \mathrm{N}$ dimethylaniline) coeluting with 4,4'-((4-(methylamino)phenyl)methylene)bis( $\mathrm{N}, \mathrm{N}$-dimethylaniline).

Fig. 14 Mass spectra of intact molecules of PV3 (left) and PV27 (right): $\left(4,44^{\prime}, 44^{\prime \prime}-\right.$ methanetriyltris(N,Ndimethylaniline) coeluting with 4,4'-((4-(methylamino)phenyl)methylene)bis(N,N-dimethylaniline).

Fig. 15 Structure of dioxazine pigments with breaking points highlighted.

Fig. 16 Structure of PV29 (left), with naphthalimide, a fragment produced by pyrolysis (right).

Fig. 17 Structure of PV36 (left) with 2,4,5-trichlorophenol, a fragment produced by pyrolysis (right).

Fig. 18 Structure of PR90 with breaking points highlighted.

Fig. 19 Pyrogram of Clyfford Still paint sample 339_12, from Untitled (1948). 1. caprylic acid; 2. azelaic acid; 3. phenanthrene; 4. palmitic acid; 5. anthrone; 6. 9,10-anthracenedione,2-hydroxy; 7. stearic acid.

Fig. 20 Pyrogram of Jackson Pollock paint sample 27, from Mural (1943). 1. n-buthyl methacrylate; 2. 2naphthol; 3. diethyl phthalate; 4. azelaic acid; 5. phenanthrene; 6. palmitic acid; 7. anthrone; 8. stearic acid; 9. linoleic acid; 10. 9,10-anthracenedione,2-hydroxy. 
Fig. 13 Pyrogram of PV27. 1. Aniline; 2. aniline, N-methyl-; 3. benzenamine, N,N-dimethyl-; 4. benzenamine, N,4-dimethyl-; 5. benzenamine, N,N,4-trimethyl-; 6. 4-aminobenzonitrile; 7. 4aminobenzonitrile, N-methyl; 8. 4-aminobenzonitrile, N,N-dimethyl; 9. 4,4'-methylenedianiline; 10. 4,4'methylenedianiline, N-methyl; 11. 4,4'-methylenedianiline, N,N-dimethyl; 12. 4,4'-methylenedianiline, N,Ndimethyl (positional isomer of \#11); 13. 4,4'-methylenedianiline, N,N,N-trimethyl; 14. 4,4'methylenedianiline, N,N,N,N-tetramethyl; 15. unknown products typical of PV27 (RT $16.99 \mathrm{~min}: \mathrm{m} / \mathrm{z} 251$, 145, 221, 236; RT $17.05 \mathrm{~min}: \mathrm{m} / \mathrm{z} 265,221,159,144 ;$ RT $17.11 \mathrm{~min}: \mathrm{m} / \mathrm{z} 279,235,158,143)$ (spectra reported in Fig. S12, S13 and S14); 16. 4,4'-((4-aminophenyl)methylene)bis(N,N-dimethylaniline); 17. intact molecules (4,4',4'--methanetriyltris( $\mathrm{N}, \mathrm{N}$-dimethylaniline) coeluting with 4,4'-((4(methylamino)phenyl)methylene)bis(N,N-dimethylaniline). 
1

2

3

4

5

6

7

8

9

10

11

12

13

14

15

16

17

18

19

20

21

22

23

24

25

26

27

28

29

30

31

32

33

34

35

36

37

38

39

40

41

42

43

44

45

46

47

48

49

50

51

52

53

54

55

56

57

58

59

60

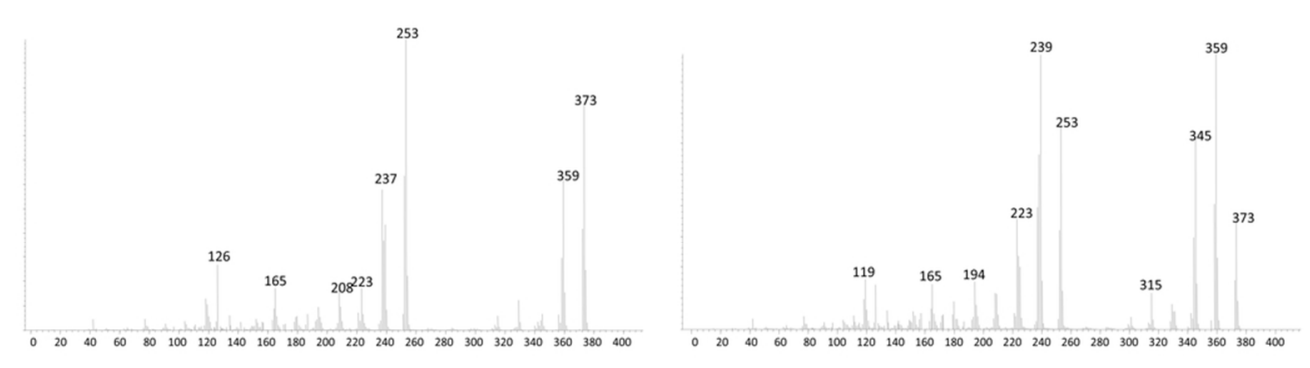

Fig. 14 Mass spectra of intact molecules of PV3 (left) and PV27 (right): $\left(4,4^{\prime}, 4^{\prime \prime}-\right.$ methanetriyltris(N,Ndimethylaniline) coeluting with 4,4'-((4-(methylamino)phenyl)methylene)bis( $\mathrm{N}, \mathrm{N}$-dimethylaniline). $88 \times 25 \mathrm{~mm}(300 \times 300 \mathrm{DPI})$ 


\section{Electronic Supplementary Material}

\section{Py-GC/MS applied to the analysis of synthetic organic pigments: characterization and identification in paint samples}

\begin{tabular}{|c|c|c|c|c|c|}
\hline \multicolumn{6}{|c|}{$\begin{array}{l}\text { Elisa Ghelardi }{ }^{1} \text {, Ilaria Degano }{ }^{1}{ }^{*} \text {, Maria Perla Colombini }{ }^{1,2} \text {, Joy Mazurek }{ }^{3} \text {, Michael Schilling }{ }^{3} \text {, Tom } \\
\text { Learner }^{3}\end{array}$} \\
\hline \multirow{4}{*}{\multicolumn{6}{|c|}{ 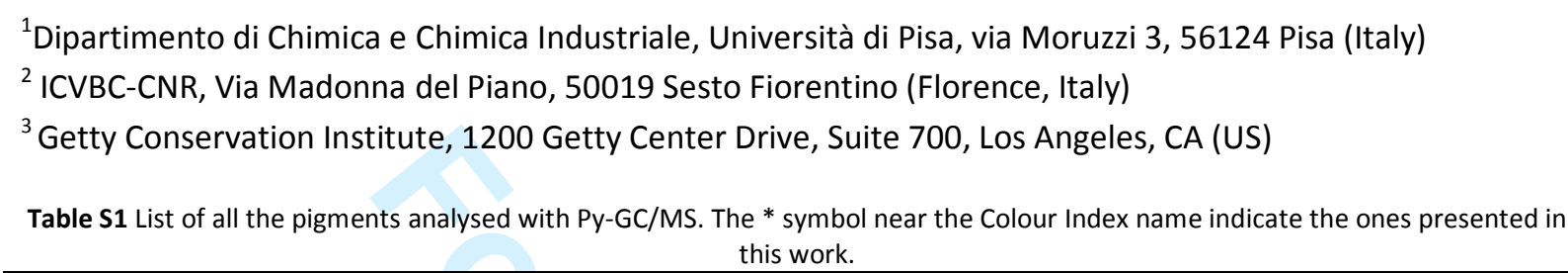 }} \\
\hline & & & & & \\
\hline & & & & & \\
\hline & & & & & \\
\hline $\begin{array}{l}\text { C.I. } \\
\text { name }\end{array}$ & $\begin{array}{l}\mathrm{Cl} \\
\text { number }\end{array}$ & Common name & Class & $\begin{array}{l}\text { Manufacturer or } \\
\text { Supplier }\end{array}$ & Year \\
\hline PR1 & 12070 & $\beta$-naphthol & $\beta$-naphthol & Clariant & nd \\
\hline PR3 & 12120 & Hansa Scarlet RNC & $\beta$-naphthol & Clariant & 2002 \\
\hline PR4 & 12085 & Hansa Red R & $\beta$-naphthol & Clariant & 2002 \\
\hline PR5 & 12490 & Monolite Red CB & Naphthol AS & ICI (Avecia) & 2002 \\
\hline PR6 & 12090 & Pigment Red 6 & $\beta$-naphthol & Kremer & nd \\
\hline PR7* & 12420 & Monolite Red 4RH & Naphthol AS & $\mathrm{ICl}$ & 1996 \\
\hline PR8 & 12335 & 3149 Fast Red F4R-Y & Naphthol AS & HY pigments & 2002 \\
\hline \multirow[t]{2}{*}{ PR12 } & 12385 & Monolite Rubine 2R & Naphthol AS & Avecia & 2002 \\
\hline & 12380 & Permanent Bordeaux & Naphthol AS & & \\
\hline PR14 & & FGR & & Clariant & 2002 \\
\hline PR17 & 12390 & Sunbrite Red 17 & Naphthol AS & Clariant & nd \\
\hline PR23 & 12355 & 1523 Naphthol Red 23 & Naphthol AS & Lansco & 2002 \\
\hline \multirow[t]{2}{*}{ PR31 } & 12360 & Symuler Fast Red 4085 & Naphthol AS & Dainippon & 2002 \\
\hline & 21200 & Suimei Dianisidine Red & Disazopyrazolone & & \\
\hline PR41* & & $\mathrm{R}$ & & Sansui & 2003 \\
\hline PR48:1* & $15865: 1$ & Cortone Scarlet 2BBT & BONA, Ba & EC pigments & nd \\
\hline PR48:2* & $15865: 2$ & Rubine Toner 2BO & BONA, $\mathrm{Ca}$ & Avecia & 2002 \\
\hline PR48:2* & $15865: 2$ & Eljon Rubine 2BRC & BONA, Ca & EC pigments & 2002 \\
\hline PR49:1* & 15630:1 & Sunbrite Red 49:1 & $\beta$-naphthol, Ba & Sun & 2002 \\
\hline PR49:2* & 15630:2 & Sunbrite Red 49:2 & $\beta$-naphthol, Ca & Sun & 2002 \\
\hline PR52:1* & 15860:1 & Sunbrite Red 52:1 & BONA, Ca & Sun & 2002 \\
\hline PR52:2* & 15860:2 & BR-522 Bon Maroon & BONA, Mn & Lansco & 2002 \\
\hline PR53:1* & $15585: 1$ & 1320 Red Lake C & $\beta$-naphthol, Ba & Lansco & 2002 \\
\hline PR57* & 15850 & Irgalite Rubine $4 \mathrm{BP}$ & BONA & Ciba & 2002 \\
\hline PR57:1* & $15850: 1$ & Cortone Rubine $4 \mathrm{BCT}$ & BONA, Ca & EC pigments & 2002 \\
\hline PR63:1* & 15880:1 & Sunbrite Red 63:1 & BONA, Ca & Sun & 2002 \\
\hline \multirow[t]{2}{*}{ PR83* } & 58000:1 & Alizarin Crimson & Anthraquinone, $\mathrm{Ca}$ & $W \& N$ & nd \\
\hline & 45380 & Cogilor Almandine & Eosine & & \\
\hline PR90:1* & & 90110 & & Anstead & nd \\
\hline PR112 & 12370 & Naphthol Red Light & Naphthol AS & Golden & 1996 \\
\hline PR144 & 20735 & Cromopthal Red BRN & Disazo condensation & Ciba & 2002 \\
\hline PR166 & 20730 & Cromophtal Red RN & Disazo condensation & Ciba & 2002 \\
\hline PR170 & 12475 & Napathol Red Medium & Naphthol AS & $W \& N$ & 1996 \\
\hline
\end{tabular}




\begin{tabular}{|c|c|c|c|c|c|}
\hline PR175 & 12513 & Novoperm Red HFT & Benzimidazolone & Clariant & 2002 \\
\hline \multirow[t]{2}{*}{ PR176 } & 12515 & Pigment Red 176 & Benzimidazolone & Royal Talens & 2002 \\
\hline & 12516 & Novoperm Carmine & Benzimidazolone & & \\
\hline PR185 & & $\mathrm{HF} 4 \mathrm{C}$ & & Sun & nd \\
\hline \multirow[t]{2}{*}{ PO5 } & 12075 & Pigment Orange 5 & $\beta$-naphthol & $W \& N$ & 1996 \\
\hline & 21160 & Spectra Pac E Orange & Diarylide yellow & & \\
\hline P016 & & 16 & & Sun & 2002 \\
\hline PO46 & 15602 & Sunbrite Orange 46 & $\beta$-naphthol, Ba & Sun & 2002 \\
\hline PY3 & 11710 & Hansa Yellow Light & Monoazo yellow & Golden & 1996 \\
\hline PY12 & 21090 & Sunbrite Yellow 12 & Diarylide yellow & Sun & 2002 \\
\hline PY100 & 19140:1 & Tartrazine yellow & $\begin{array}{l}\text { Monoazopyrazolone, } \\
\text { Al }\end{array}$ & $\begin{array}{l}\text { H. Kohnstamm \& Co., } \\
\text { Inc. 83-93 Park Place, } \\
\text { NY, NY Tartrazine } 640 \\
\text { F.D\&C Yellow Certified }\end{array}$ & nd \\
\hline PGr7 & 74260 & Pigment Green 7 & Cu-Phthalogreen & $W \& N$ & 1996 \\
\hline PGr8* & 10006 & Bricofor Green L5837 & Metal complex & Albion / Hays & 2002 \\
\hline PGr10* & 12775 & Nickel Azo Yellow & Metal complex & & nd \\
\hline PGr13* & 74200 & Phthalochrome Green & Cu-Phthalogreen & Avecia & nd \\
\hline PGr36 & 74265 & Monastral Green 6Y-C & Cu-Phthalogreen & Avecia & 2002 \\
\hline PB15:0* & 74160 & $\begin{array}{l}5561 \mathrm{Cu} \\
\text { Phthalocyanine Blue }\end{array}$ & Cu Phthaloblue & Lansco & 2002 \\
\hline PB15:1* & 74160 & Monastral Blue LBX & Cu Phthaloblue & Avecia / Zeneca & 2002 \\
\hline PB15:2* & 74160 & Monastral Blue FBN & Cu Phthaloblue & Avecia / Zeneca & 2002 \\
\hline PB15:3* & 74160 & Monastral Blue BG & Cu Phthaloblue & Avecia & nd \\
\hline PB15:4* & 74160 & Monastral Blue FGX & Cu Phthaloblue & Avecia & 2002 \\
\hline PB15:6* & 74160 & Heliogen Blue & Cu Phthaloblue & Kremer & 2002 \\
\hline \multirow[t]{2}{*}{ PB16* } & 74100 & Heliogen Blau D7490 & $\begin{array}{l}\text { Phthaloblue metal } \\
\text { free }\end{array}$ & BASF & 2002 \\
\hline & 74180 & 4230 Fast Sky Blue & Cu Phthaloblue & & \\
\hline PB17* & & Lake & & HY pigs & 2002 \\
\hline PB60* & 69800 & Monolite Blue 3R & Indanthrone & Avecia / Zeneca & 2002 \\
\hline PB62* & 44084 & Eljon Blue FR & Triarylcarbonium & EC pigments & 2002 \\
\hline PB63 & 73015:x & $\begin{array}{l}\text { Indigo Carmine } \\
\text { Aluminium Lake }\end{array}$ & $\begin{array}{l}\text { Indigo, sulphonic } \\
\text { acid, Al }\end{array}$ & KKK & 2003 \\
\hline PB76* & - & Fastogen Blue 10GN & Cu Phthaloblue & Dianippon & 2002 \\
\hline PV1* & 45170:2 & Rhodamine B PTMA & Triarylcarbonium & Magruder & 2002 \\
\hline PV3* & $42535: 2$ & 1903 PTM Violet & Triarylcarbonium & Lansco & 2002 \\
\hline PV5 & 58055 & Alizarine Violet & Anthraquinone & Kremer & 2002 \\
\hline PV19* & 73900 & Monolite Violet 4R & Quinacridone & Avecia & 2002 \\
\hline PV23* & 51319 & Monolite Violet RN & Dioxazin & Avecia & 2002 \\
\hline PV27* & $42535: 3$ & Eljon Violet CMW & Triarylcarbonium & EC pigments & 2002 \\
\hline \multirow[t]{2}{*}{ PV29* } & 71129 & Cl Pigment Violet 29 & Perylene & Bayer & 2002 \\
\hline & 12517 & Novoperm Bordeaux & Benzimidazolone & & 2002 \\
\hline PV32* & & HF3R & & Clariant & \\
\hline PV36* & 73385 & Thio Violet & Thioindigo & & nd \\
\hline PV37* & 51345 & Cromophtal Violet B & Dioxazine & Ciba & 2002 \\
\hline PV39* & $42555: 2$ & Crystal Violet & Triarylcarbonium & Sigma Aldrich & nd \\
\hline \multirow[t]{2}{*}{ PV42* } & - & Quinacridone Violet & Quinacridone & & nd \\
\hline & - & Symuler Fast Violet & Naphthol AS & & \\
\hline PV44* & & 4142 & & Dianippon & 2002 \\
\hline PV51* & - & 1120 Rightfit Violet & Monoazo & Engelhard & 2003 \\
\hline PV52* & - & 1118 Rightfit Pink & Monoazo & Engelhard & 2003 \\
\hline PV53* & - & 1117 Engeltone Red 4B & & Engelhard & 2003 \\
\hline
\end{tabular}


1

2

5

6

7

8

9

10

11

12

13

14

15

16

17

18

19

20

21

22

23

24

25

26

27

28

29

30

31

32

33

34

35

36

37

38

39

40

41

42

43

44

45

46

47

48

49

50

51

52

53

54

55

56

57

58

59

60

\begin{tabular}{|c|c|c|c|c|c|}
\hline \multirow[t]{2}{*}{ PBr23 } & 20060 & Cromophtal Brown 5R & Disazo condensation & Ciba & nd \\
\hline & 12510 & Hostaperm Brown HFR & Benzimidazolone & & \\
\hline PBr25 & & 01 & & Clariant & 2002 \\
\hline PBr38* & 561660 & Pigment Brown 38 & Isoindoline & & nd \\
\hline PBr41 & - & Translucent Brown & Disazo condensation & & nd \\
\hline PBr42 & - & Azo Golden Brown & Disazo condensation & & nd \\
\hline
\end{tabular}


1

2

3

4

5

6

7

8

9

10

11

12

13

14

15

16

17

18

19

20

21

22

23

24

25

26

27

28

29

30

31

32

33

34

35

36

37

38

39

40

41

42

43

44

45

46

47

48

49

50

51

52

53

54

55

56

57

58

59

60

\section{Mass spectra of unknown pyrolysis products}

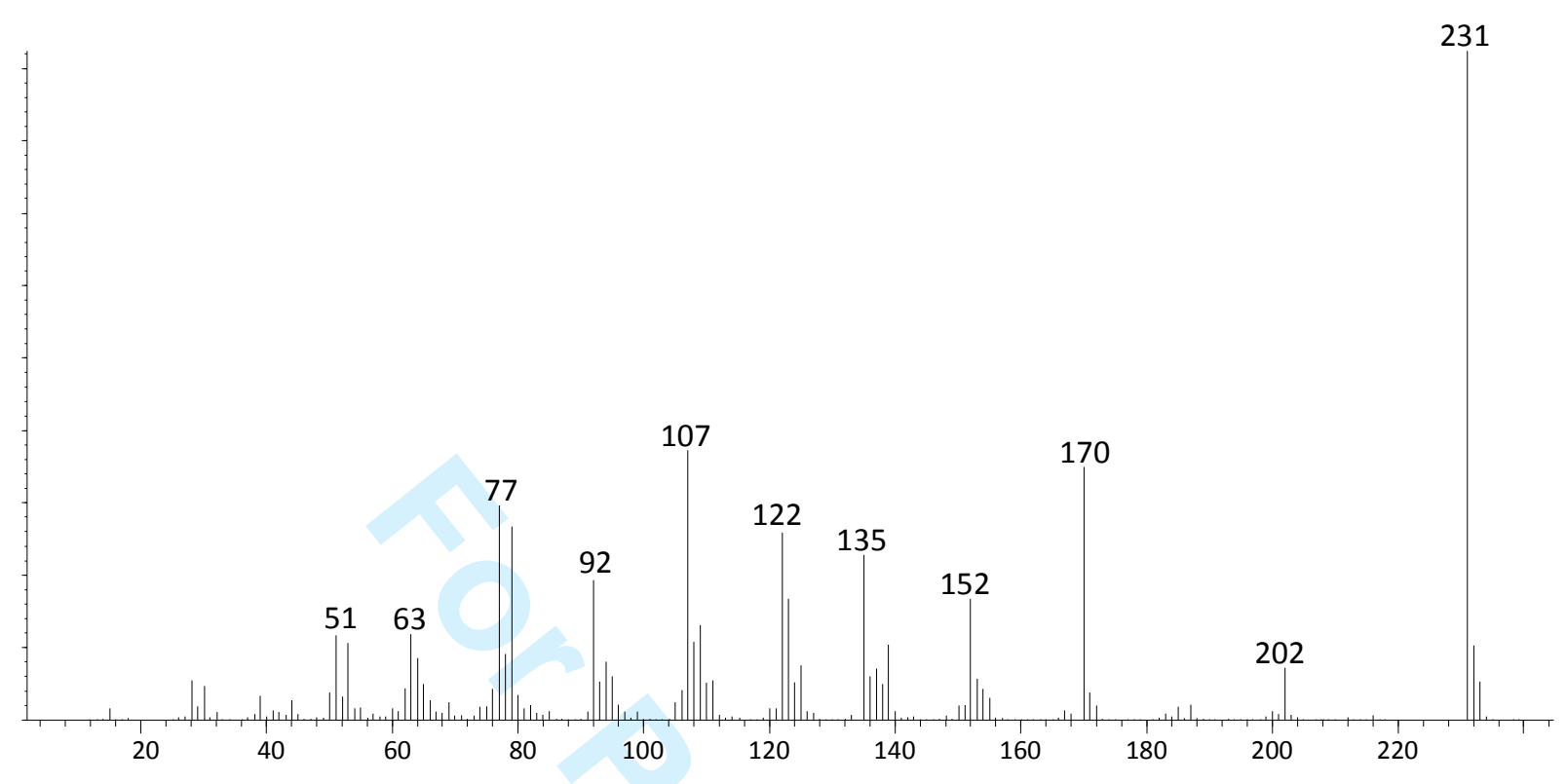

Figure S1 Unknown product $(231,170,107)$ at $13.7 \mathrm{~min}$ found in PV32.

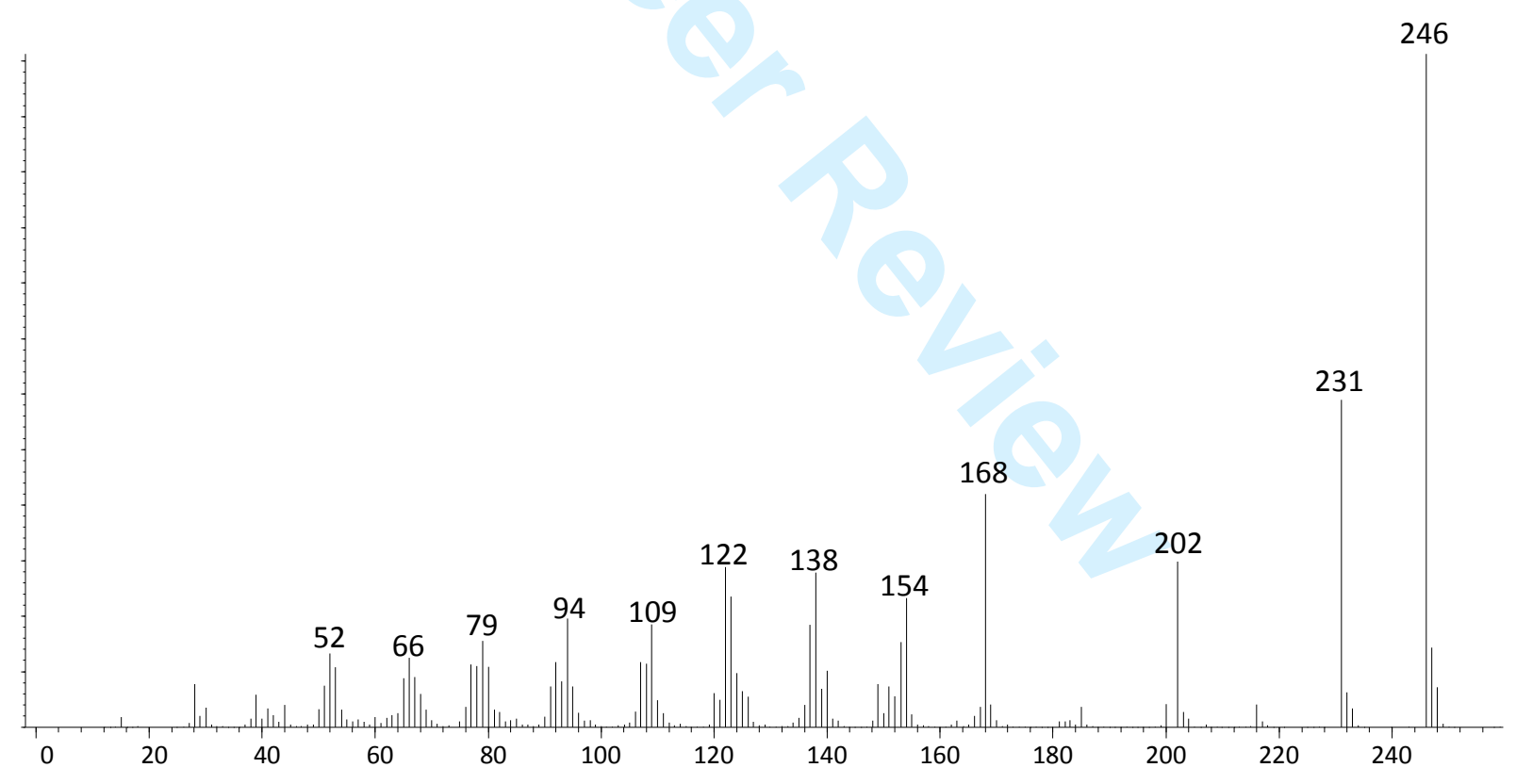

Figure S2 Unknown product $(246,231,168,202)$ at 15.5 min found in PV32. 


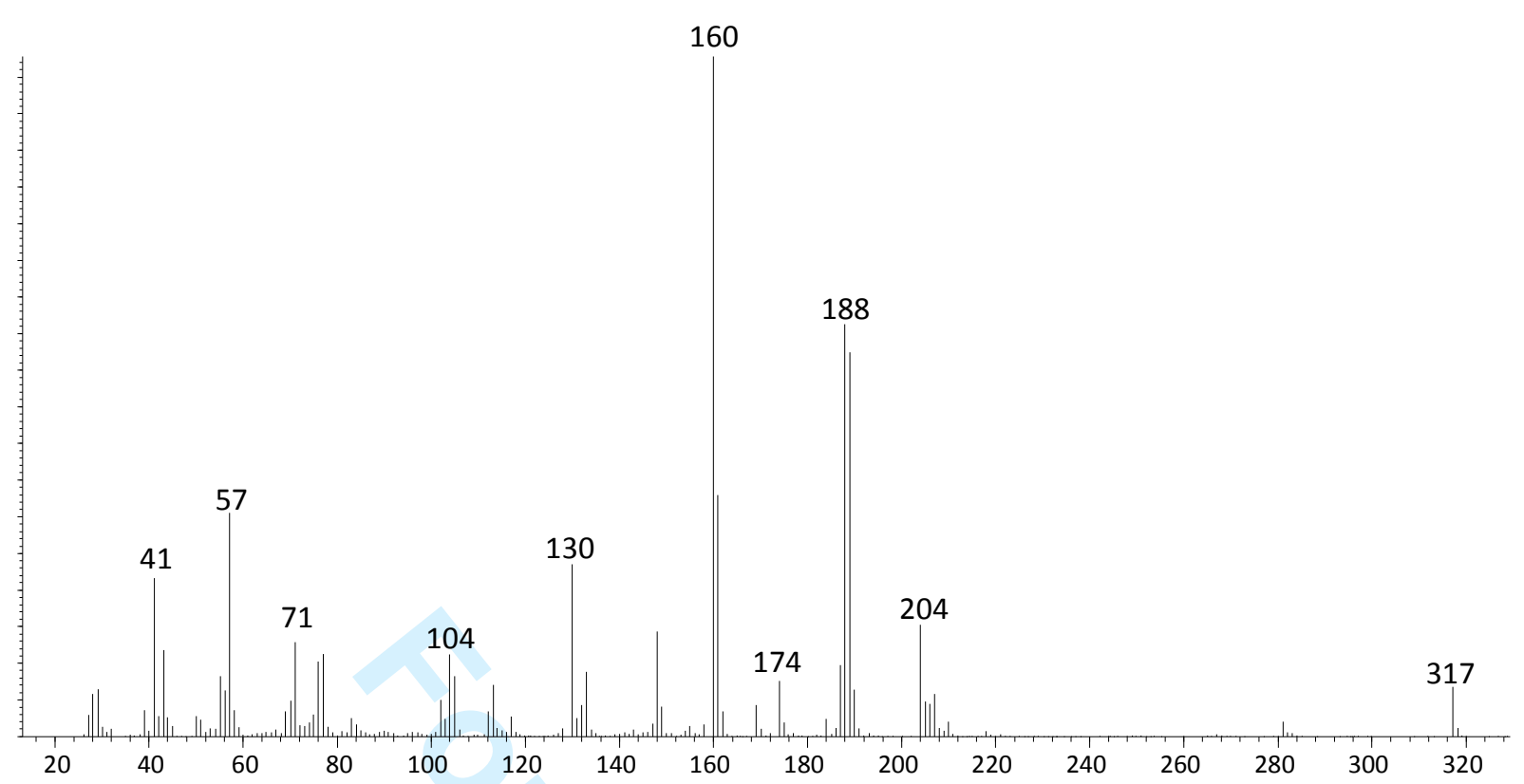

Figure S3 Unknown product $(160,188,189)$ at $15.6 \mathrm{~min}$ found in PB15:6.

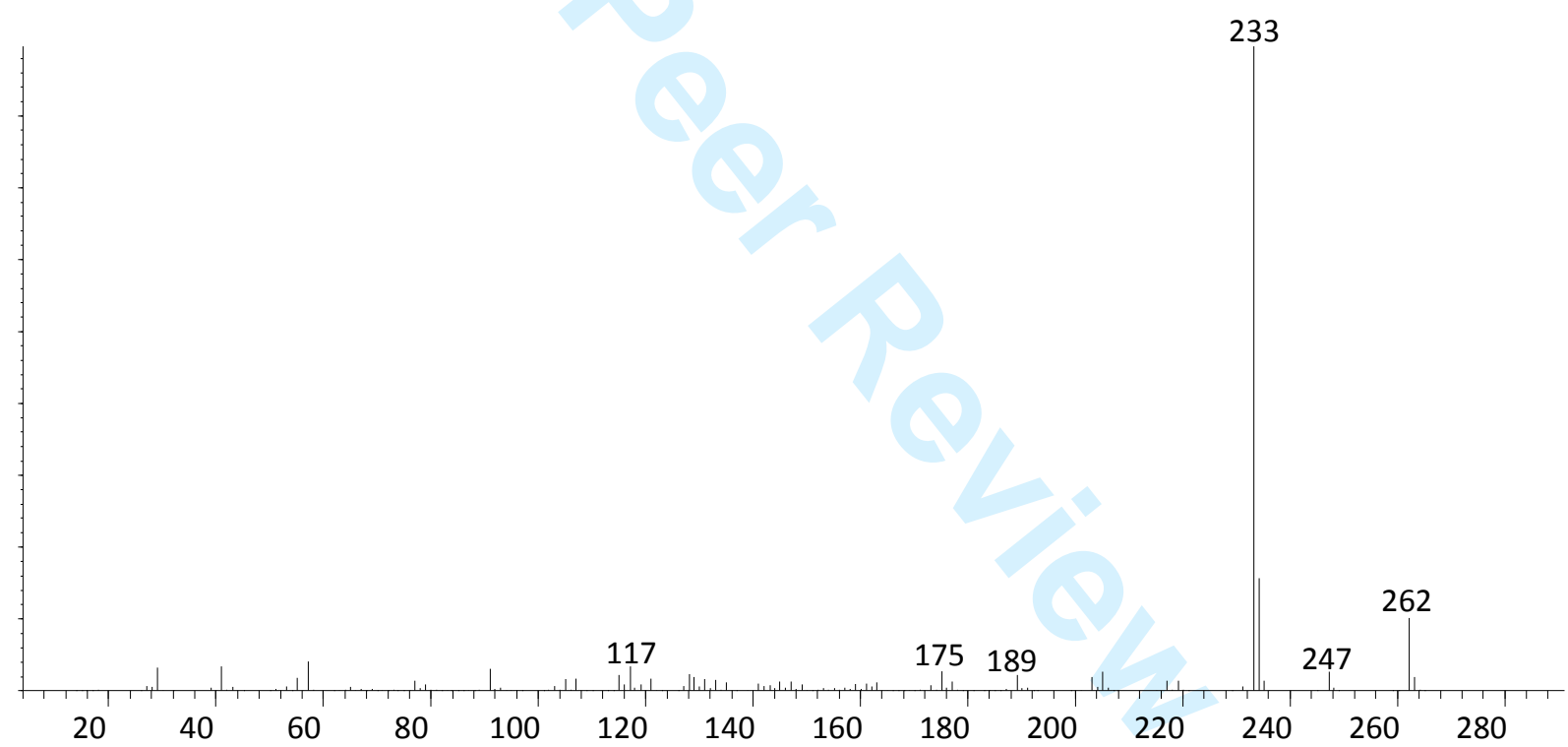

Figure S4 Unknown product $(233,262)$ at $12.3 \mathrm{~min}$ found in PV19. 


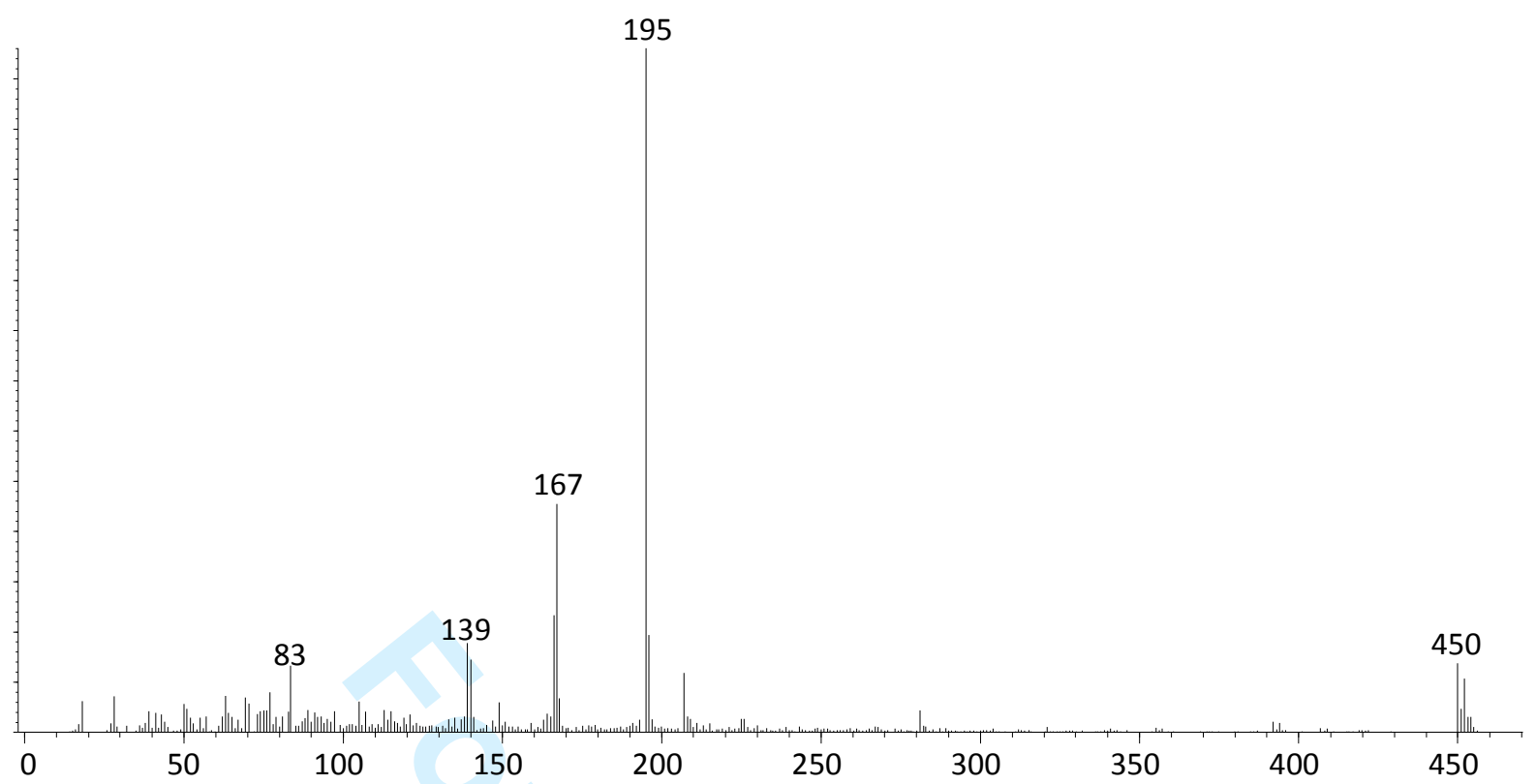

Figure S5 Unknown product $(195,167,139)$ at $15.7 \mathrm{~min}$ found in PV42.

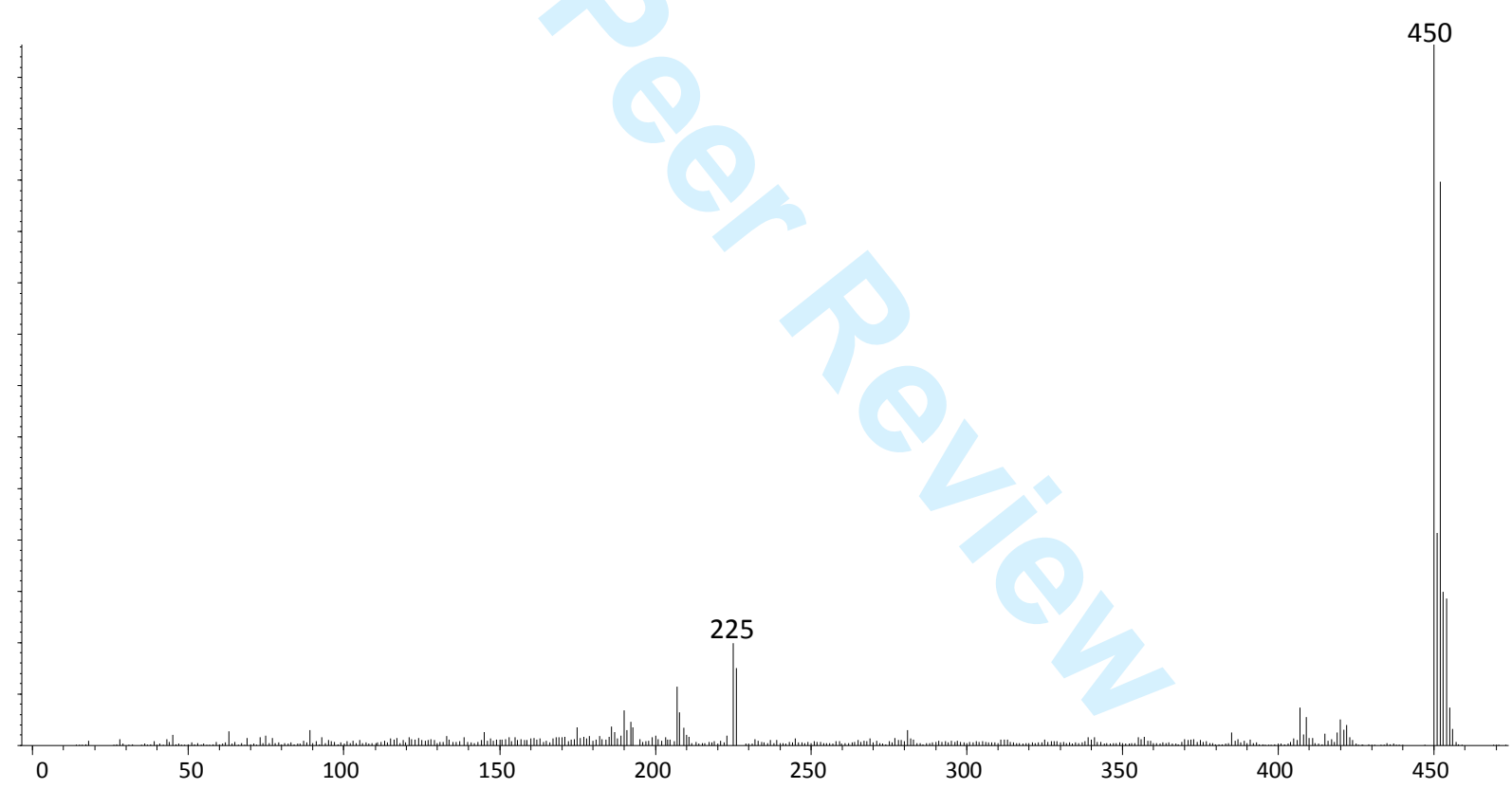

Figure S6 Unknown product $(450,452,225)$ at $23 \mathrm{~min}$ found in PV42. 


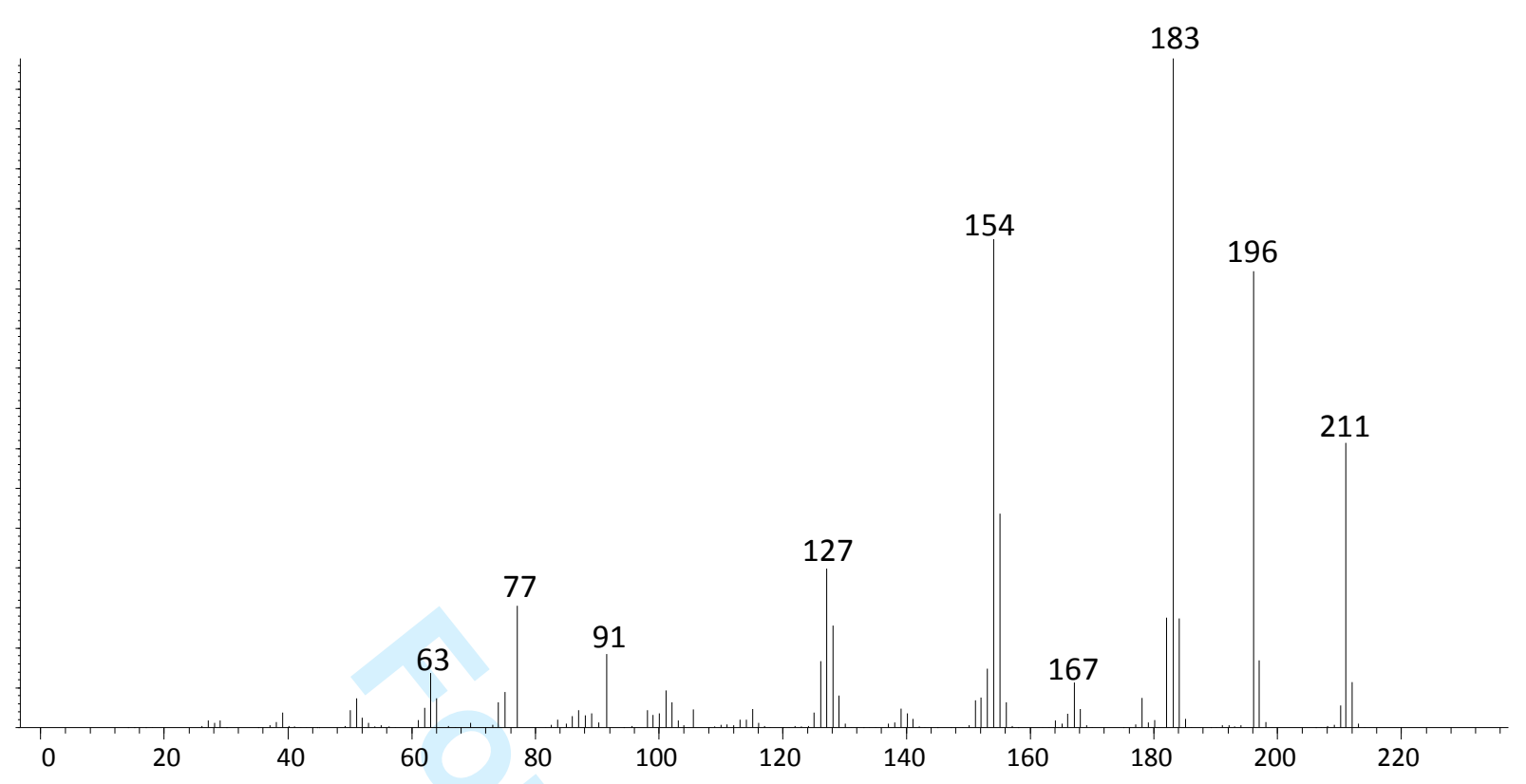

Figure S7 Unknown product $(183,154,196)$ at $14.9 \mathrm{~min}$ found in PV23.

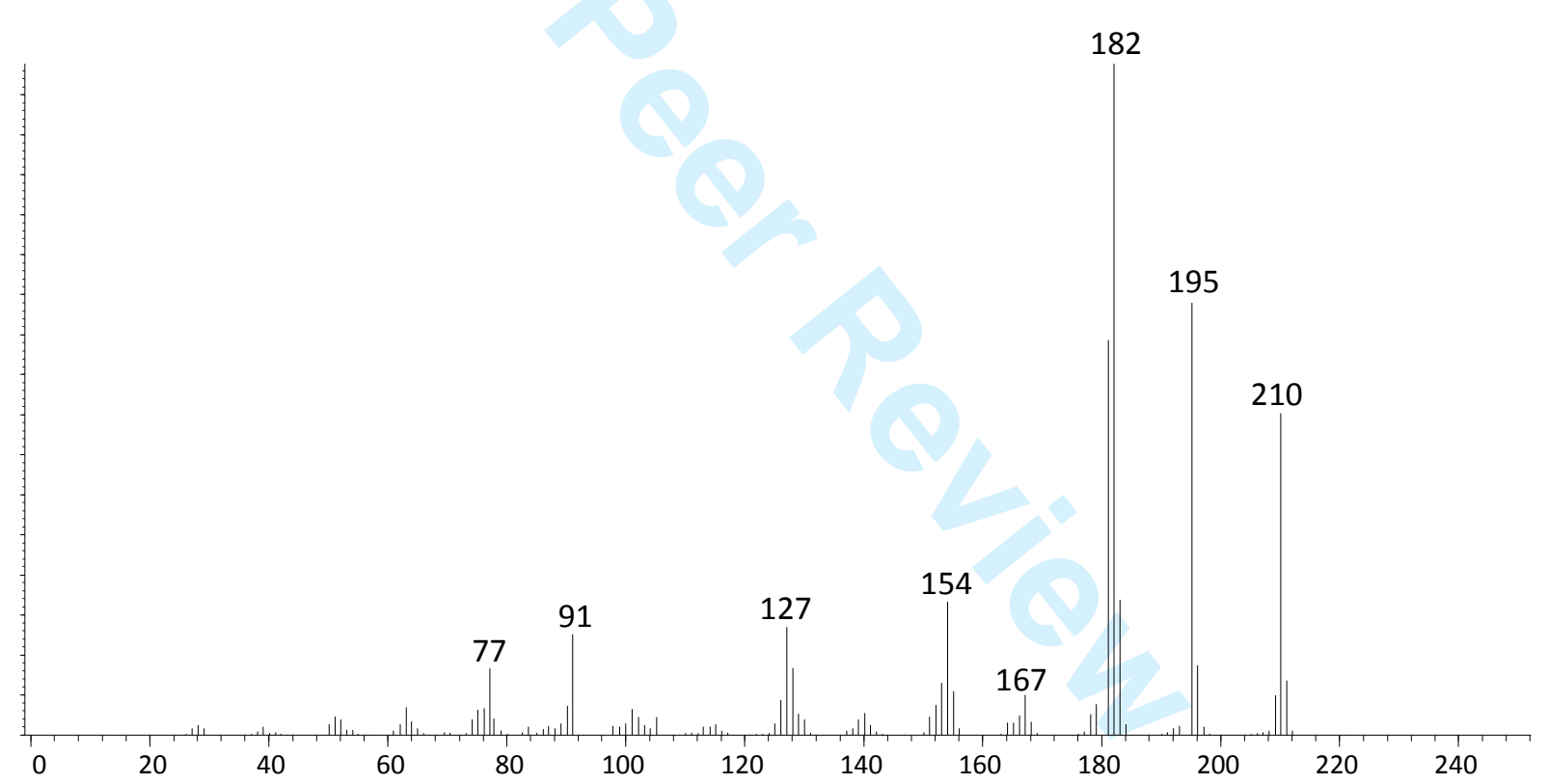

Figure S8 Unknown product $(182,195,210)$ at 15.2 min found in PV23. 


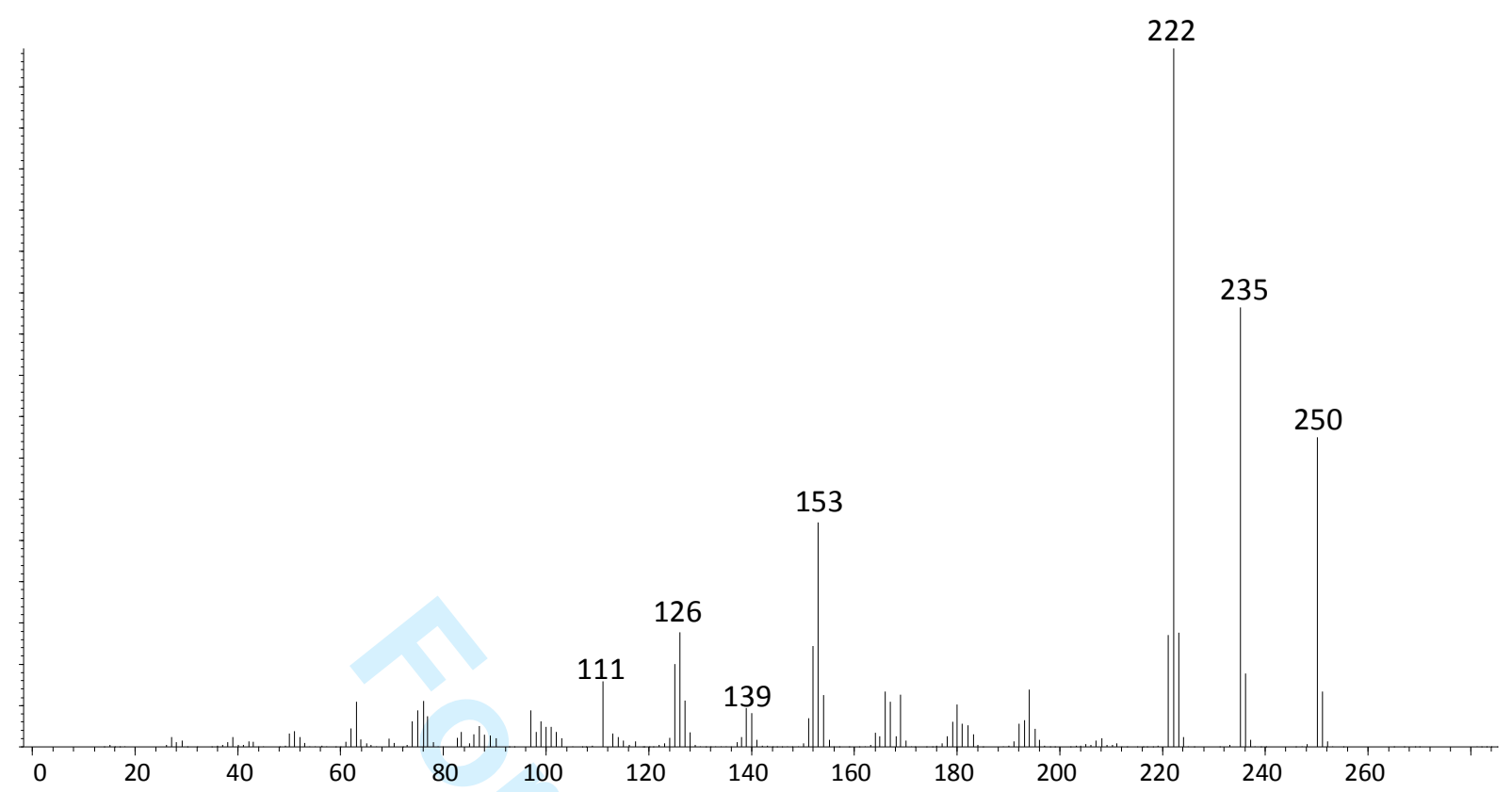

Figure S9 Unknown product $(222,235,250)$ at $15.7 \mathrm{~min}$ found in PV23.

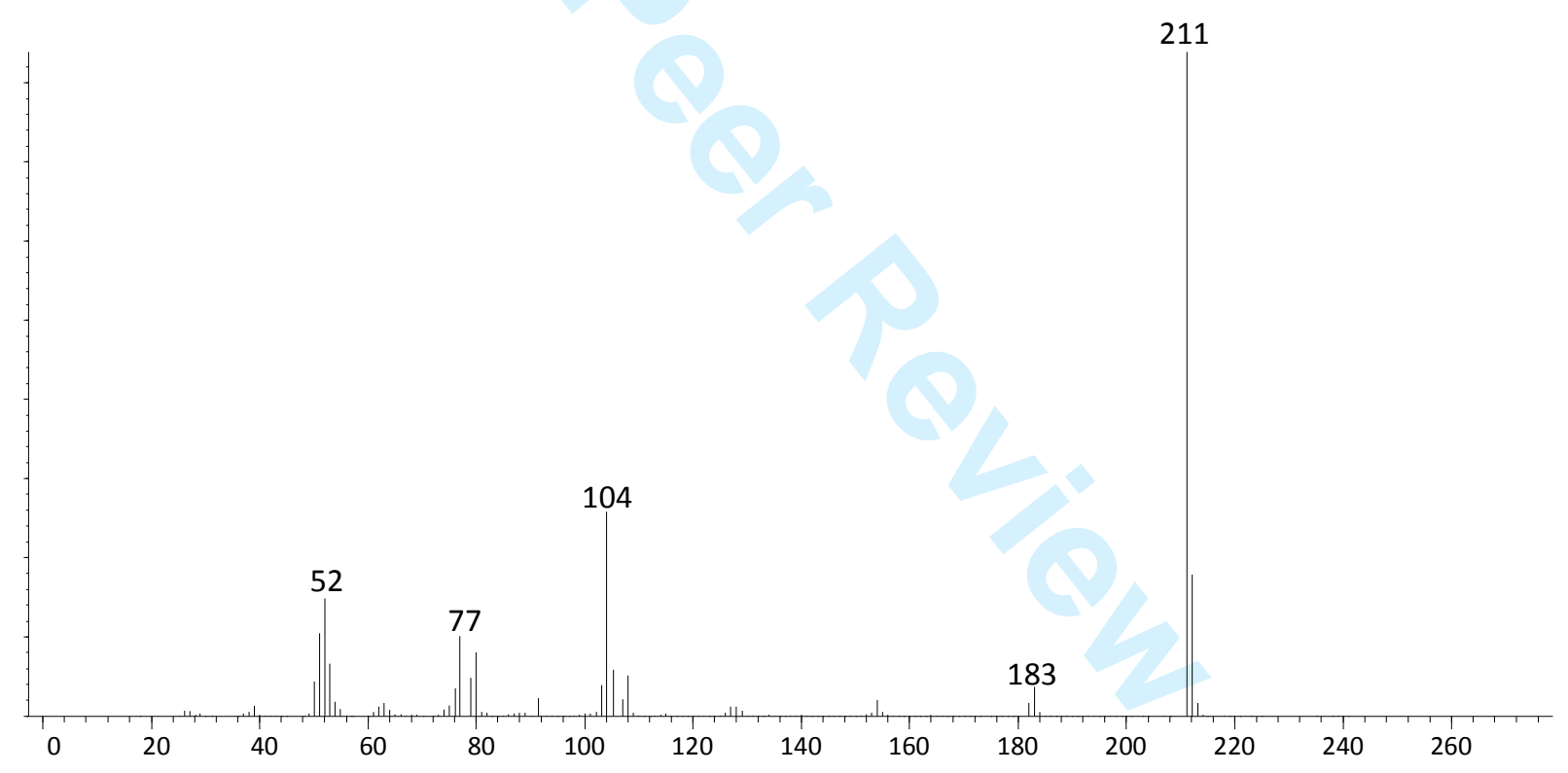

Figure S10 Unknown product $(211,104)$ at $14.7 \mathrm{~min}$ found in PV37. 


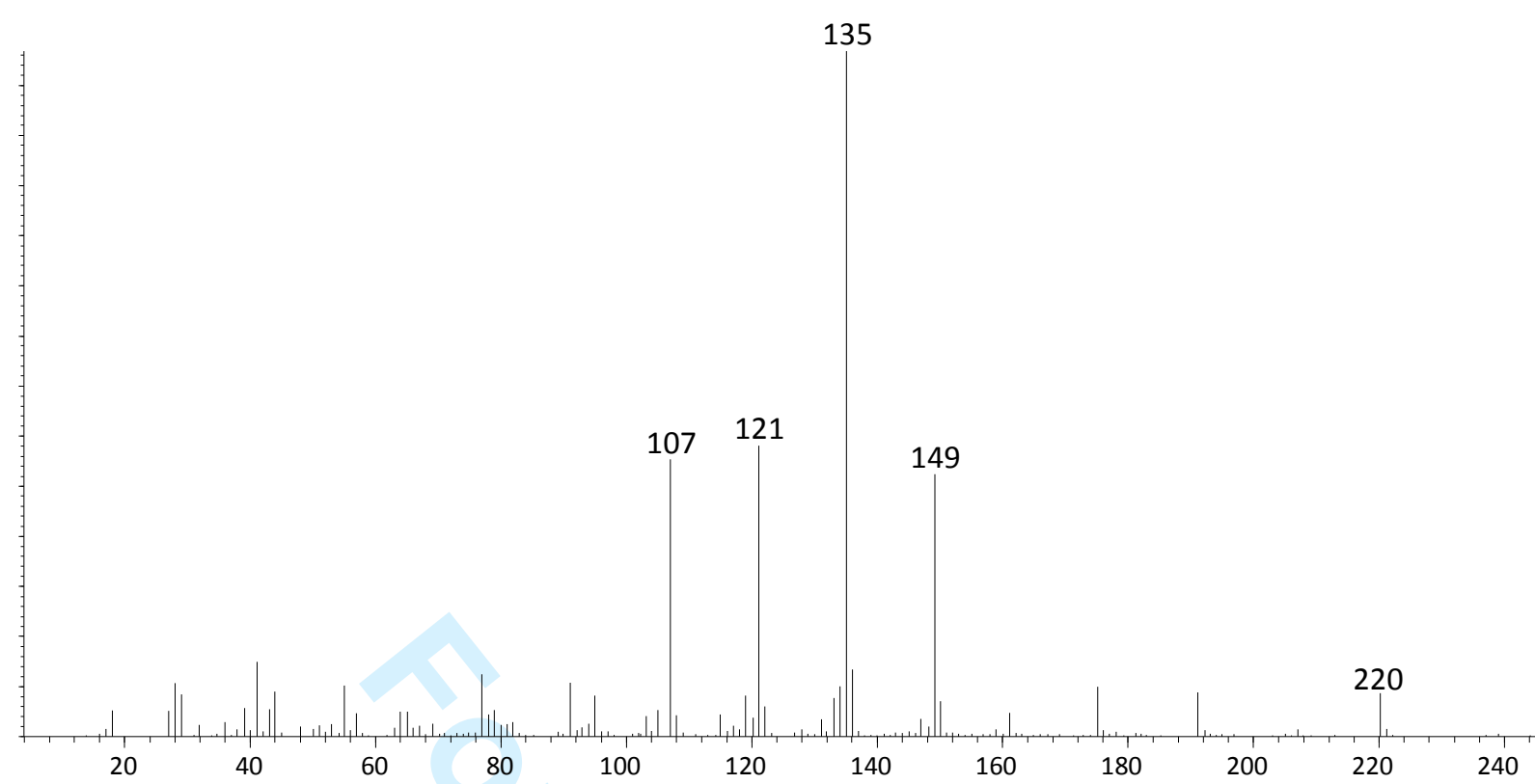

Figure S11 Unknown product $(135,121,107,149)$ at 12.5 min found in PR90:1.

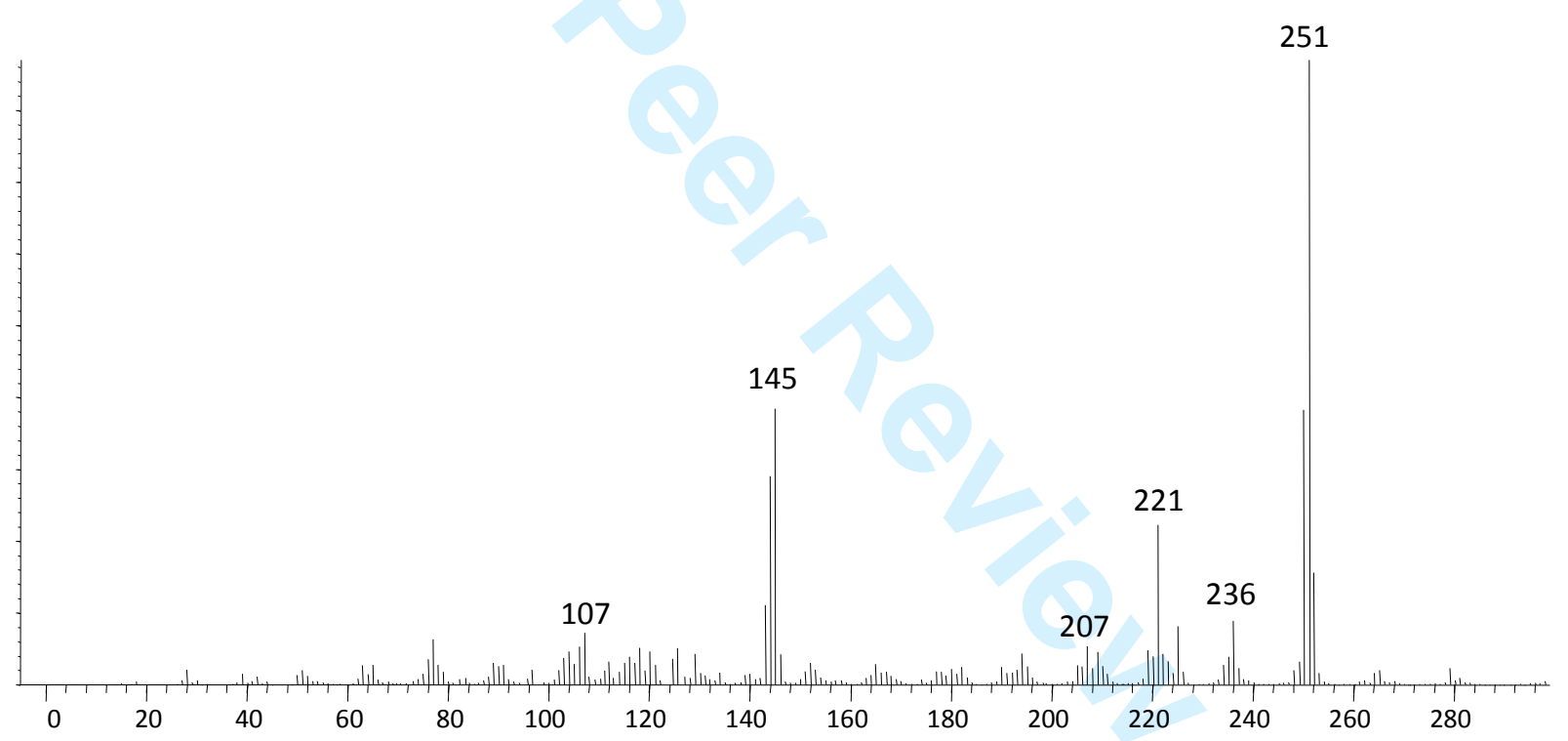

Figure S12 Unknown product $(251,145,221,236)$ at 16.99 min found in PV27. 


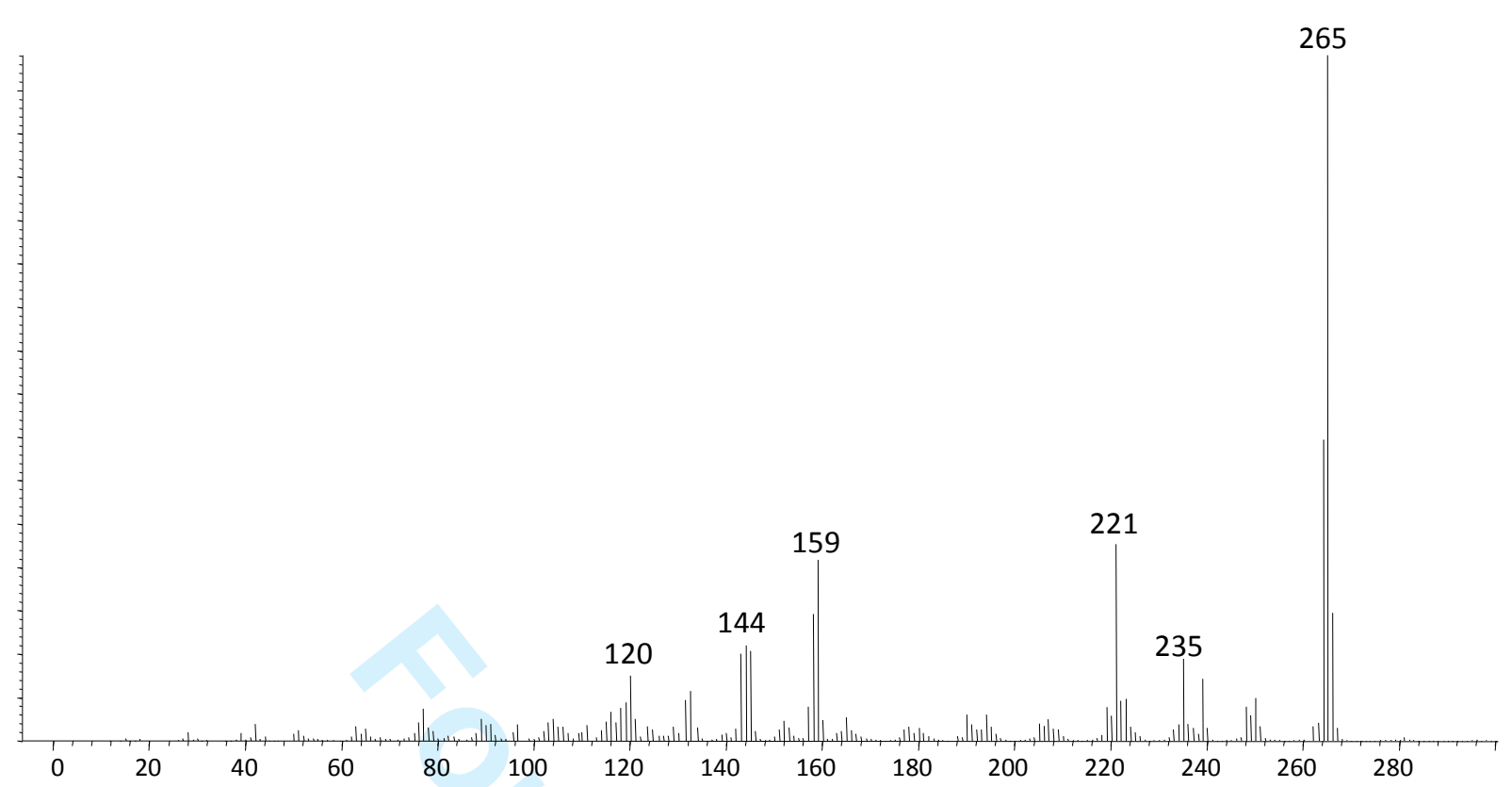

Figure S13 Unknown product $(265,221,159,144)$ at 17.05 min found in PV27.

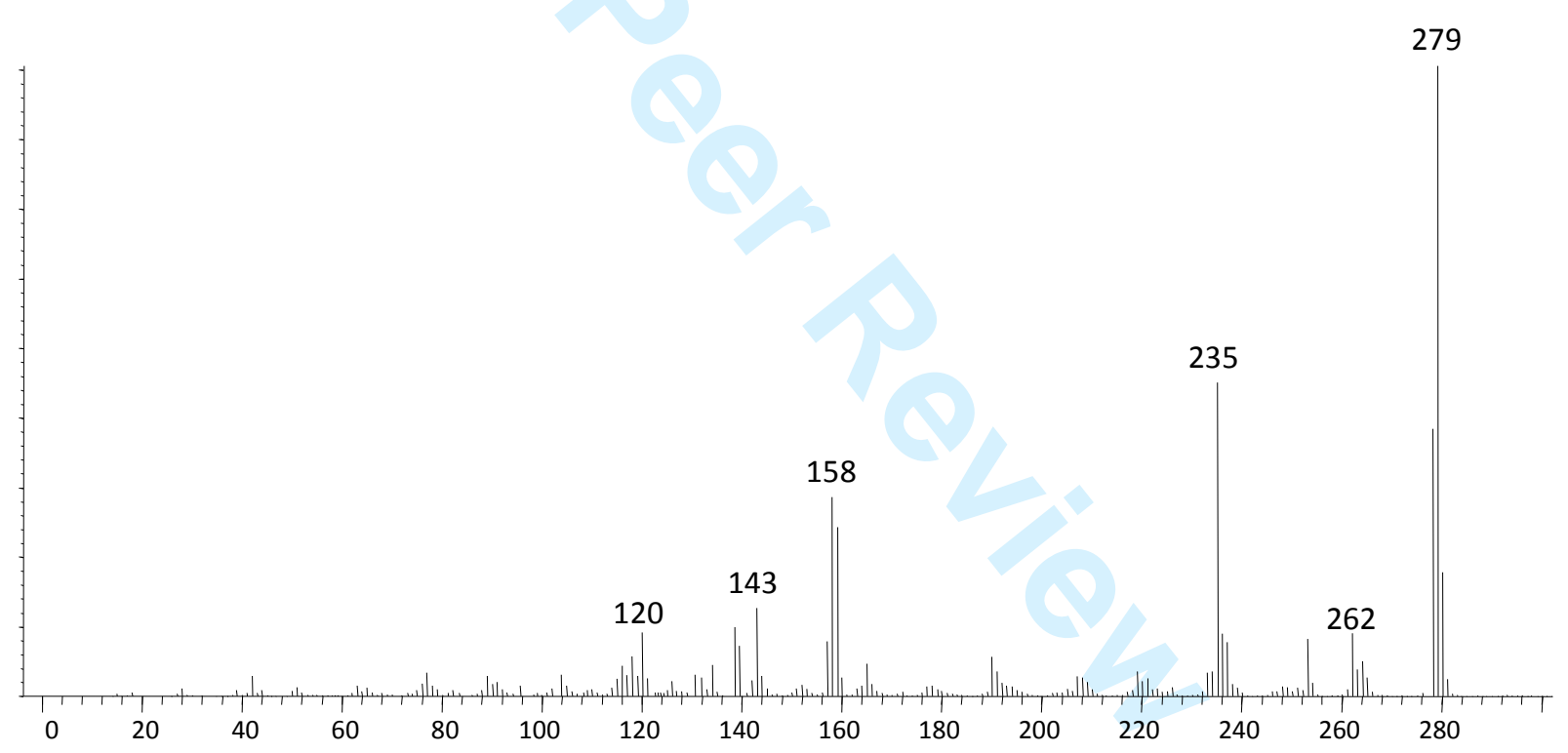

Figure S14 Unknown product $(279,235,158,143)$ at $17.11 \mathrm{~min}$ found in PV27. 


\section{Pyrograms of the paint samples analysed}

Jackson Pollock

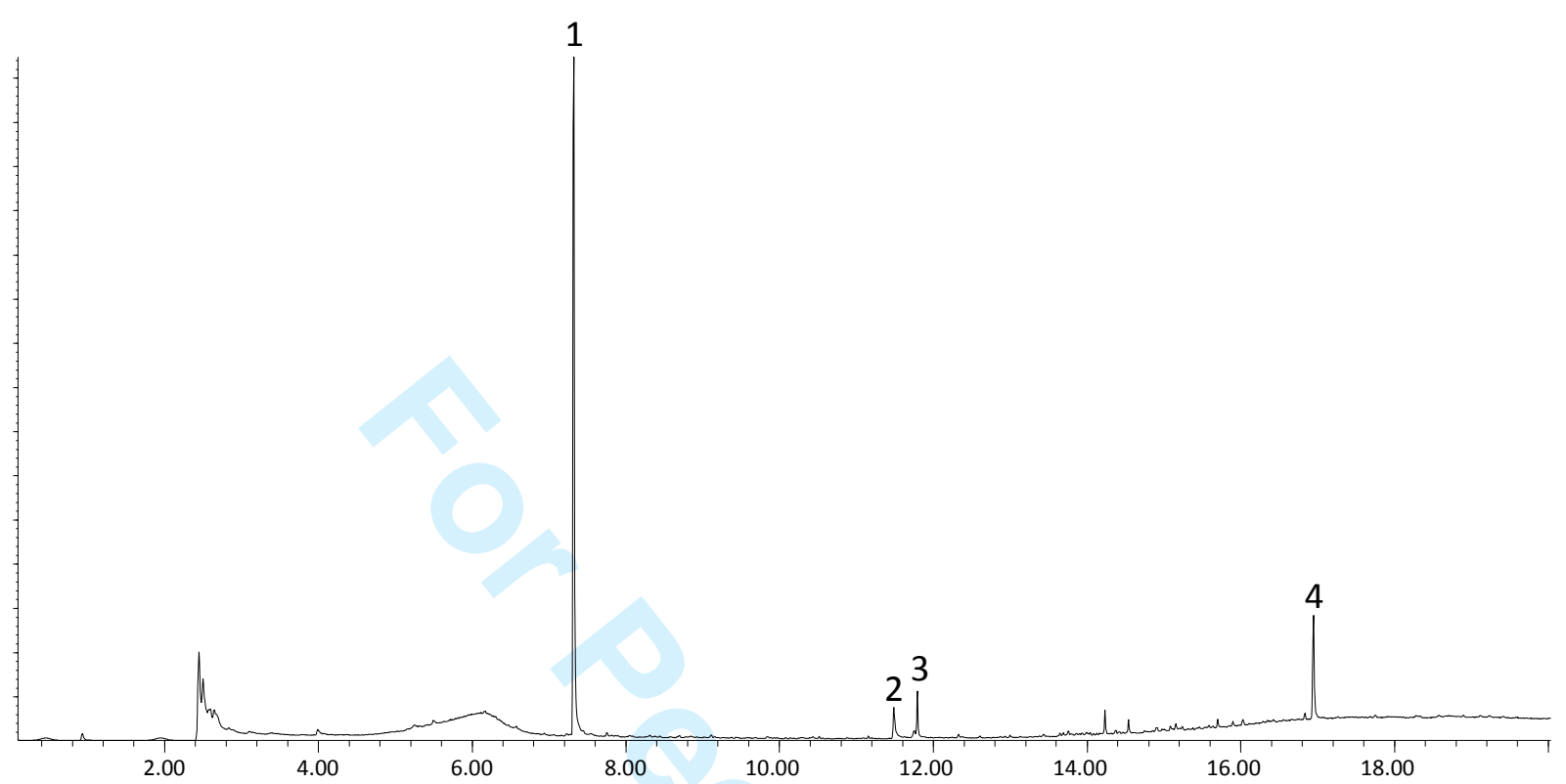

Figure S15 Pyrogram of Jackson Pollock paint sample \#8, from Mural (1943). 1. n-buthyl methacrylate; 2. 2-naphthol; 3. diethyl phthalate; 4 . unknown characteristic PR3 product (m/z 275, 246, 128). 
Clyfford Still
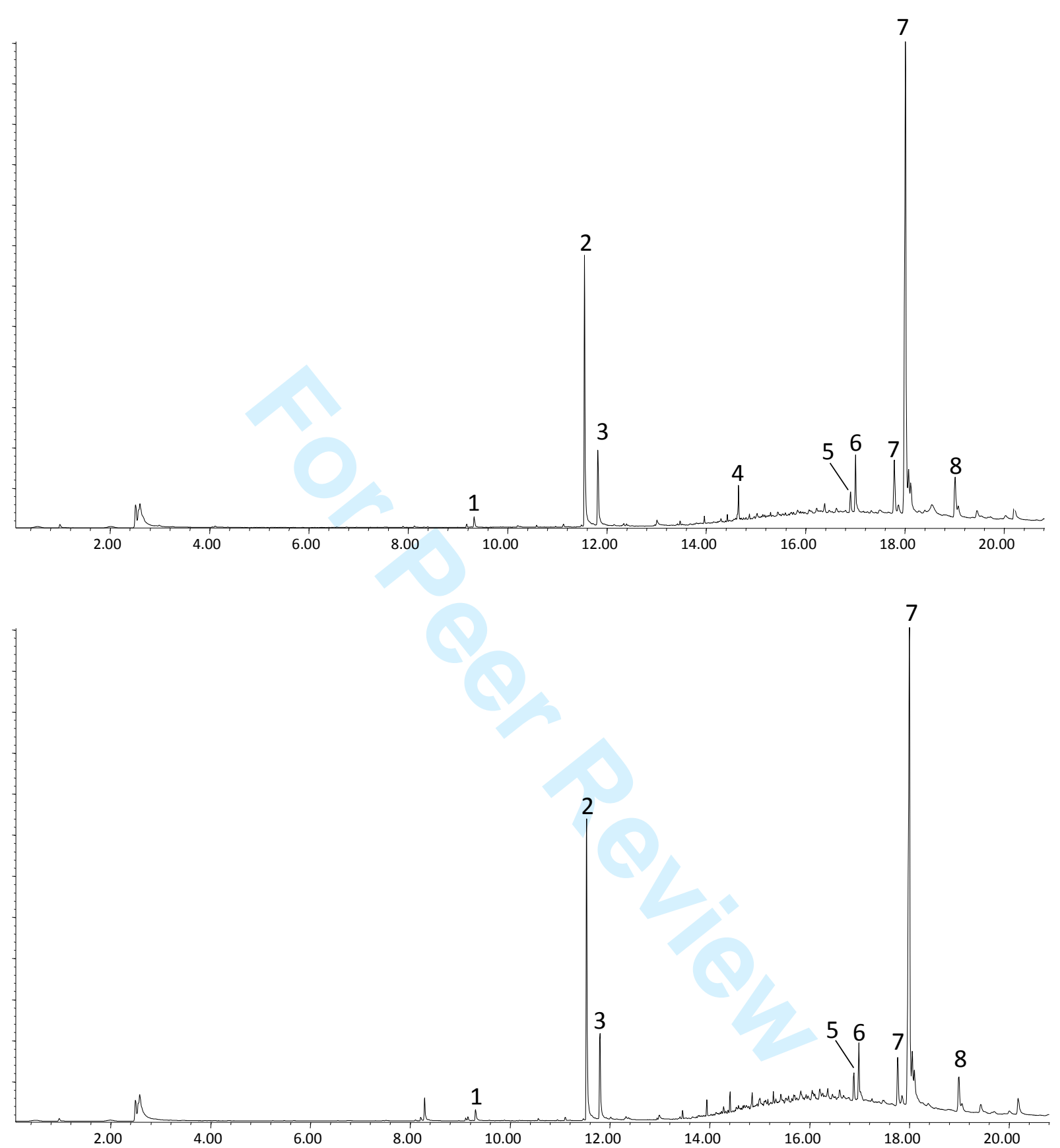

Figure S16 Pyrograms of samples \#18 (top) and \#21 (bottom), two pigments found in Still' studio. 1. naphthalene; 2. 2-naphthol; 3. 2-naphthalenamine; 4. 1-propene 1,2,3-tricarboxylic acid, tributyl ester; 5. 2,2'-dinaphthyl ether; 6. naphthalene, 1-(2naphthalenyloxy)-; 7. dinaphtho[2,1b:1,2-d]furan and dinaphtho[2,1b:1'2'-d]furan; 8. benzo[f]naphtho[2,1-c]cinnoline. 


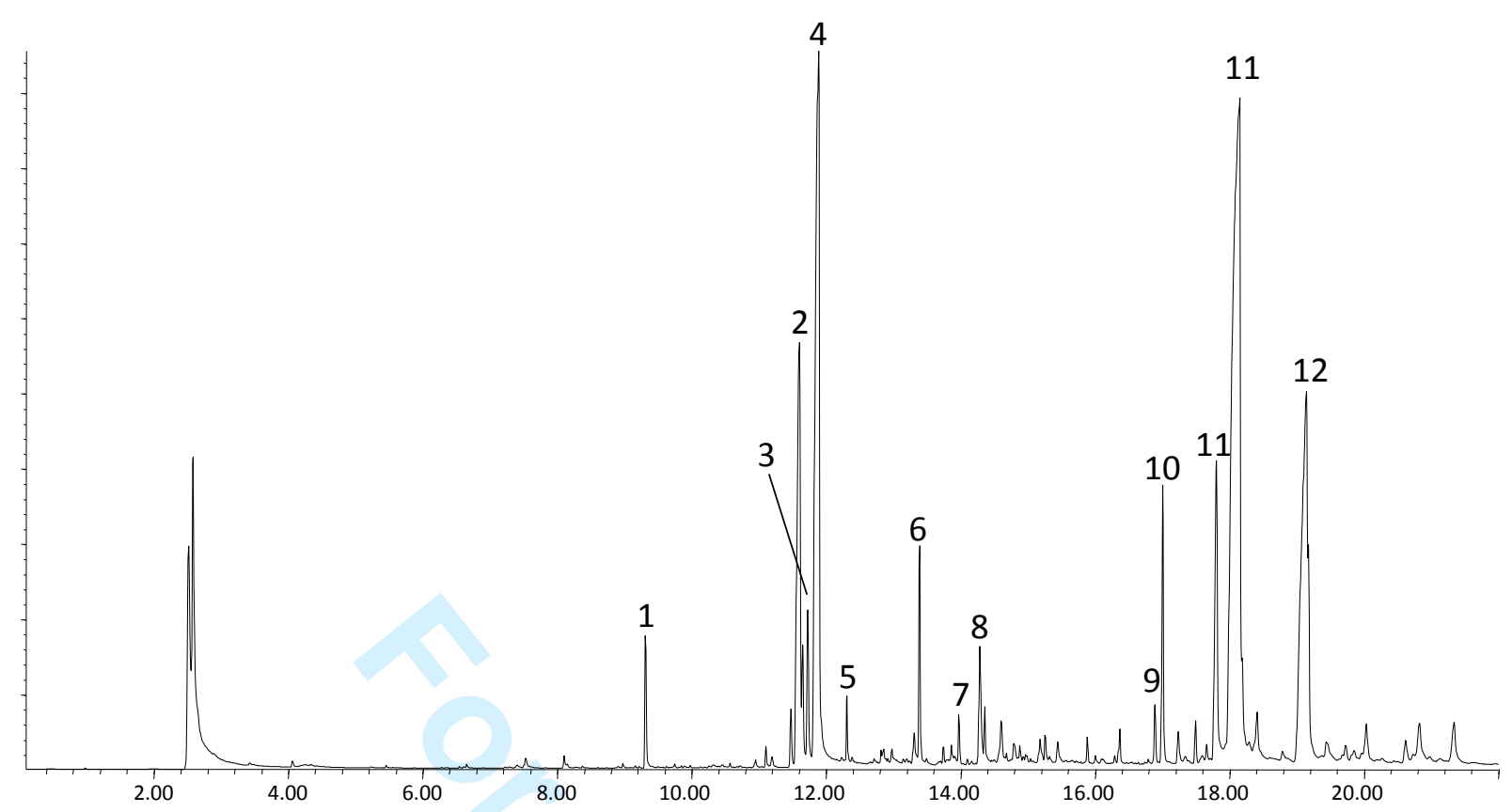

Figure S17 Pyrogram of sample \#38, a pigment found in Still' studio. 1. Naphthalene; 2. 2-naphthol; 3. 1-naphthalenamine; 4. 2naphthalenamine; 5. Cyclododecane; 6. 1-hexadecanol; 7. Cyclotetradecane; 8. 1,13-tetradecadiene; 9. 2,2'-dinaphthyl ether; 10. naphthalene, 1-(2-naphthalenyloxy)-; 11. dinaphtho[2,1b:1,2-d]furan and dinaphtho[2,1b:1'2'-d]furan; 12. benzo[f]naphtho[2,1c]cinnoline.

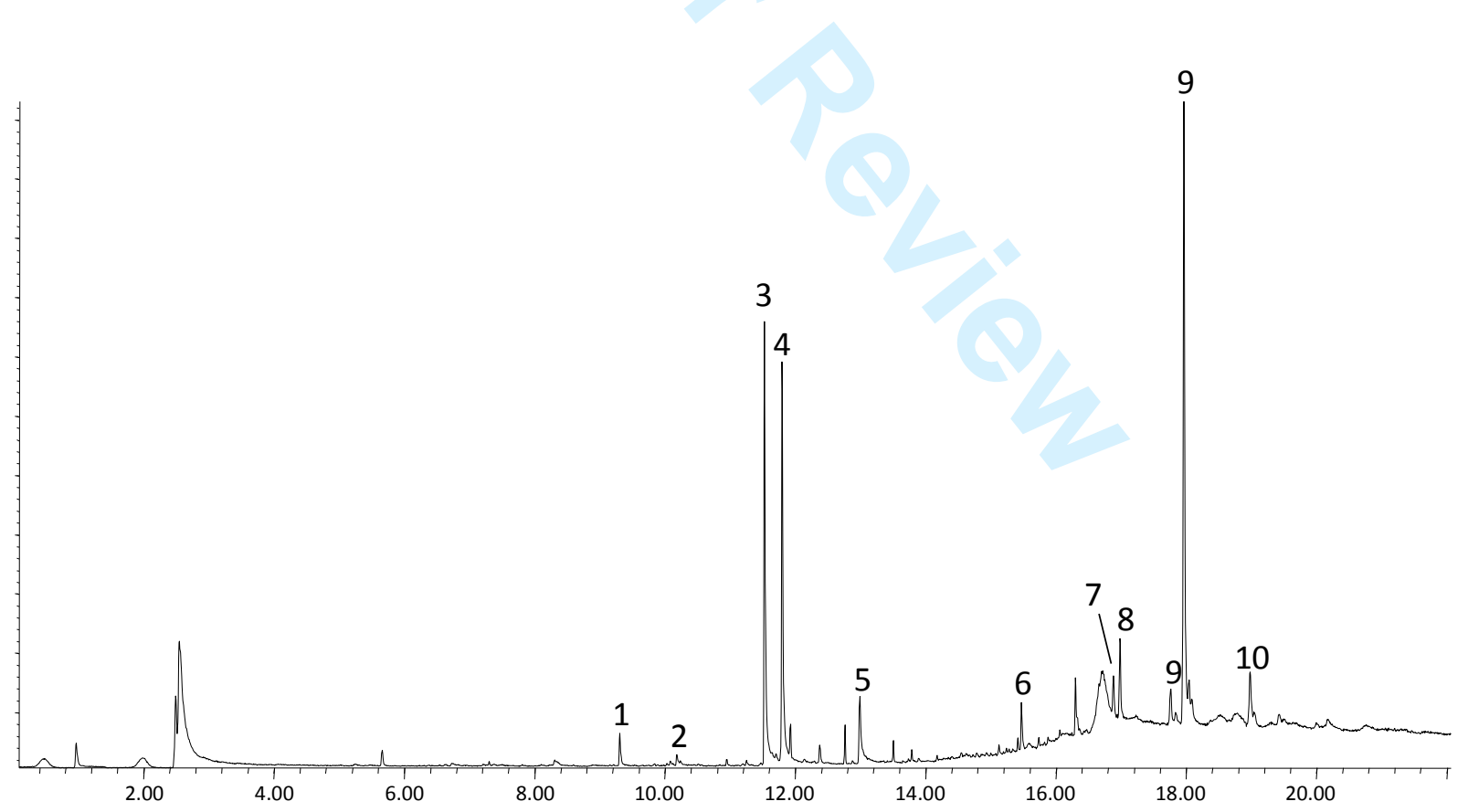

Figure S18 Pyrogram of sample \#40a, a pigment found in Still' studio. 1. Naphthalene; 2. phthalic anhydride; 3. 2-naphthol; 4. 2naphthalenamine; 5. 2-naphthol, 1-amino; 6. 2Hphenantro[9,10b]pyran; 7. 2,2'-dinaphthyl ether; 8. naphthalene, 1-(2naphthalenyloxy)-; 9. dinaphtho[2,1b:1,2-d]furan and dinaphtho[2,1b:1'2'-d]furan; 10. benzo[f]naphtho[2,1-c]cinnoline. 


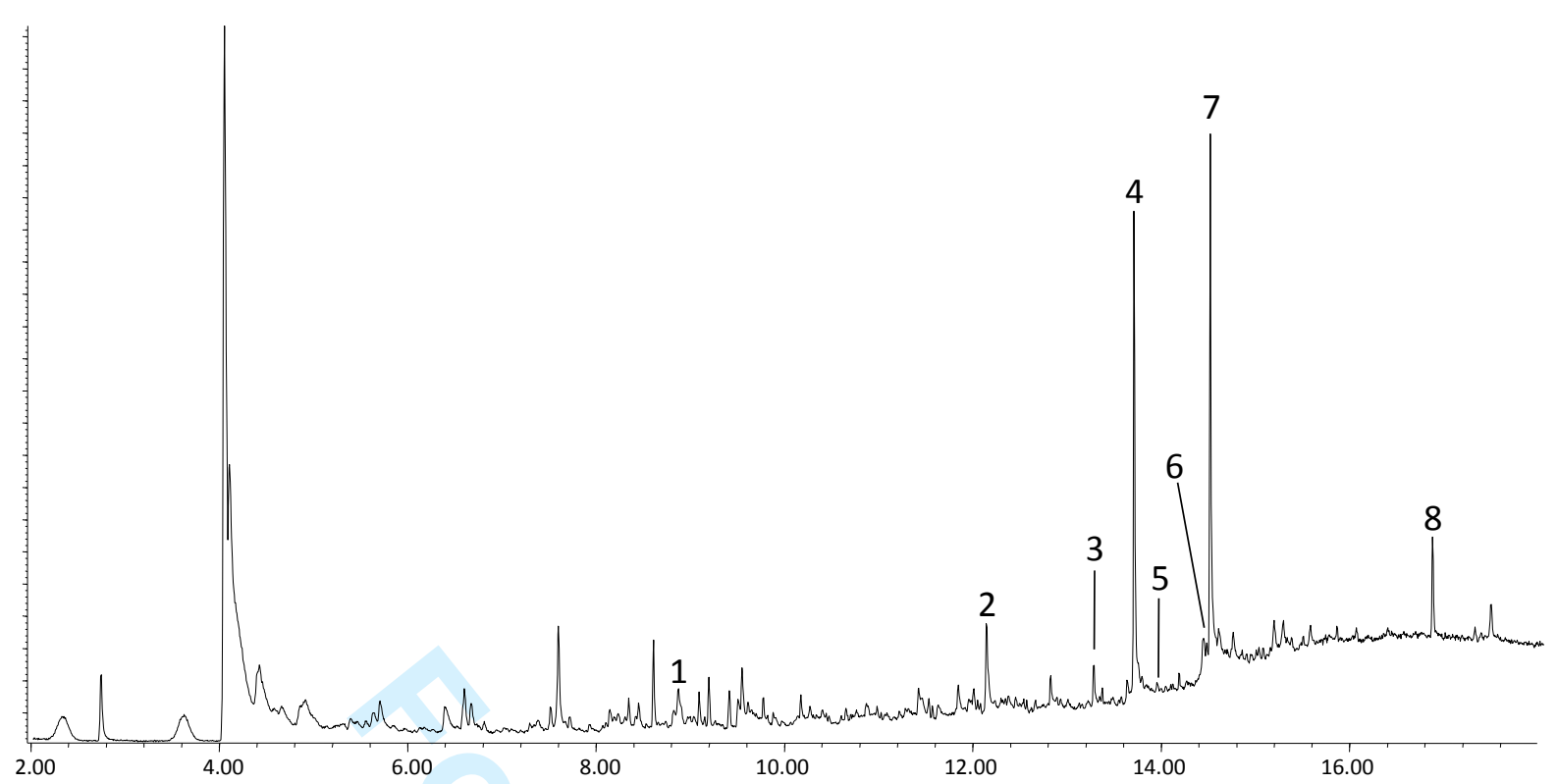

Figure S19 Pyrogram of Clyfford Still paint sample 339_11, from Untitled (1948 a). 1. caprylic acid; 2. azelaic acid; 3. phenanthrene; 4. palmitic acid; 5. anthrone; 6. 9,10-anthracenedione,2-hydroxy; 7. stearic acid, 8. squalene (anthropogenic contamination).

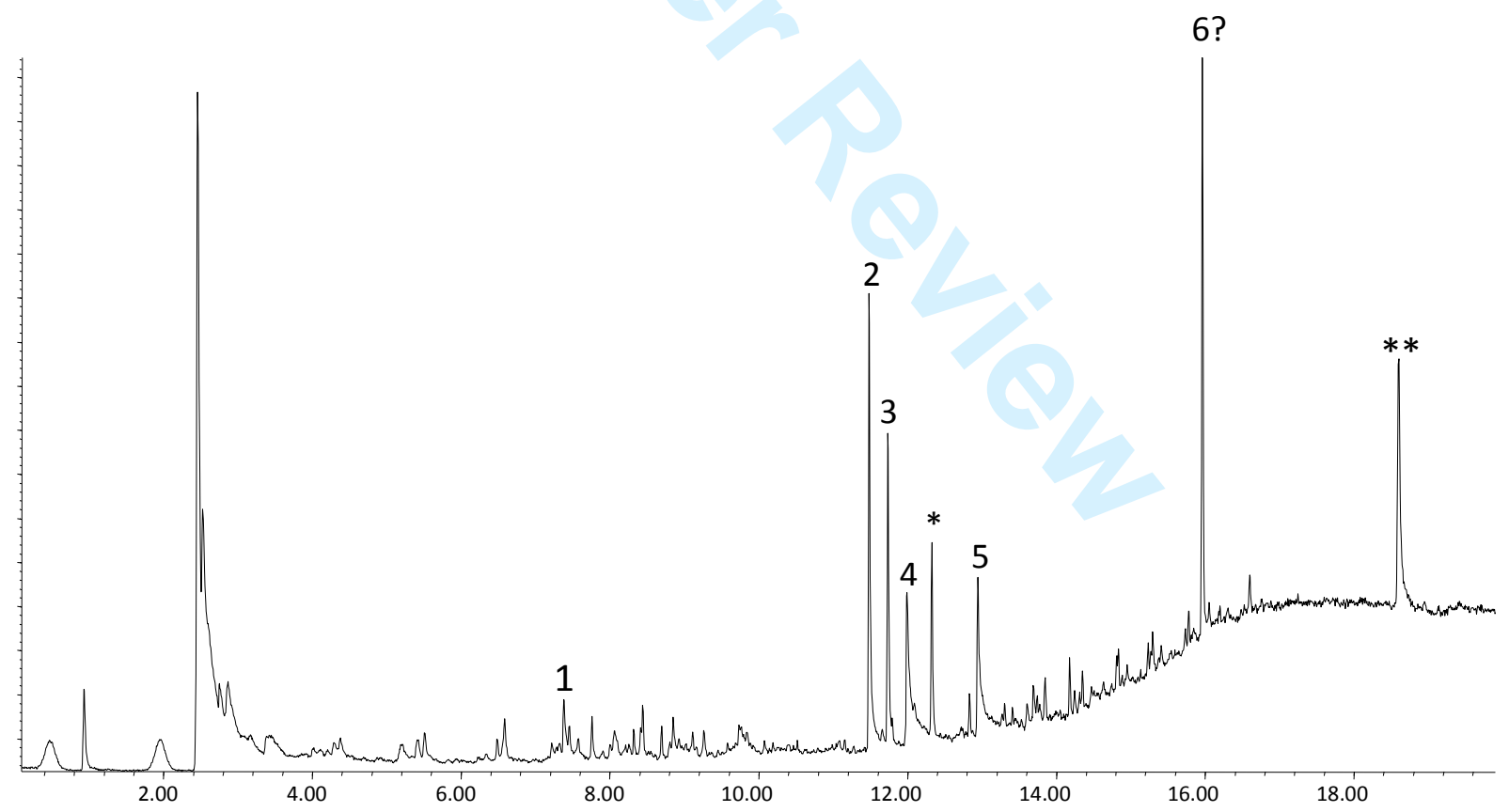

Figure S20 Pyrogram of Clyfford Still paint sample 322_11, from Untitled (1948 a). 1. aniline; 2. 2-naphthol; 3. naphthalene, 1isocyanato-; 4. p-nitroaniline; 5. 2-naphthol, 1-amino; $\overline{6}$. 4-hydroxy-3methyl-beta-phenylcinnamonitrile? (m/z 235); *unknown product characteristic of red pigments (m/z 183, 154, 114); **unknown product (m/z 263, 207, 92, 107, 281). 


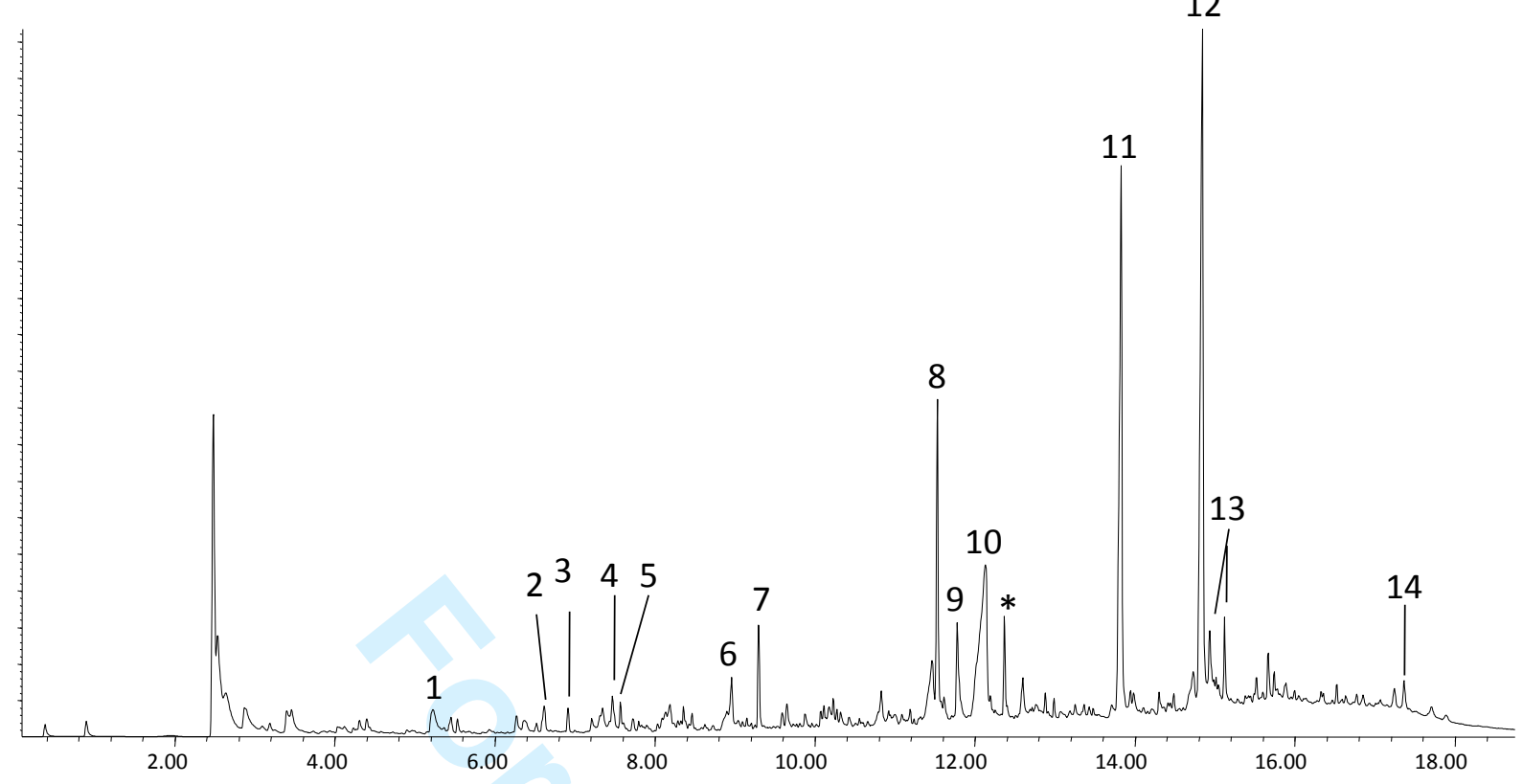

11

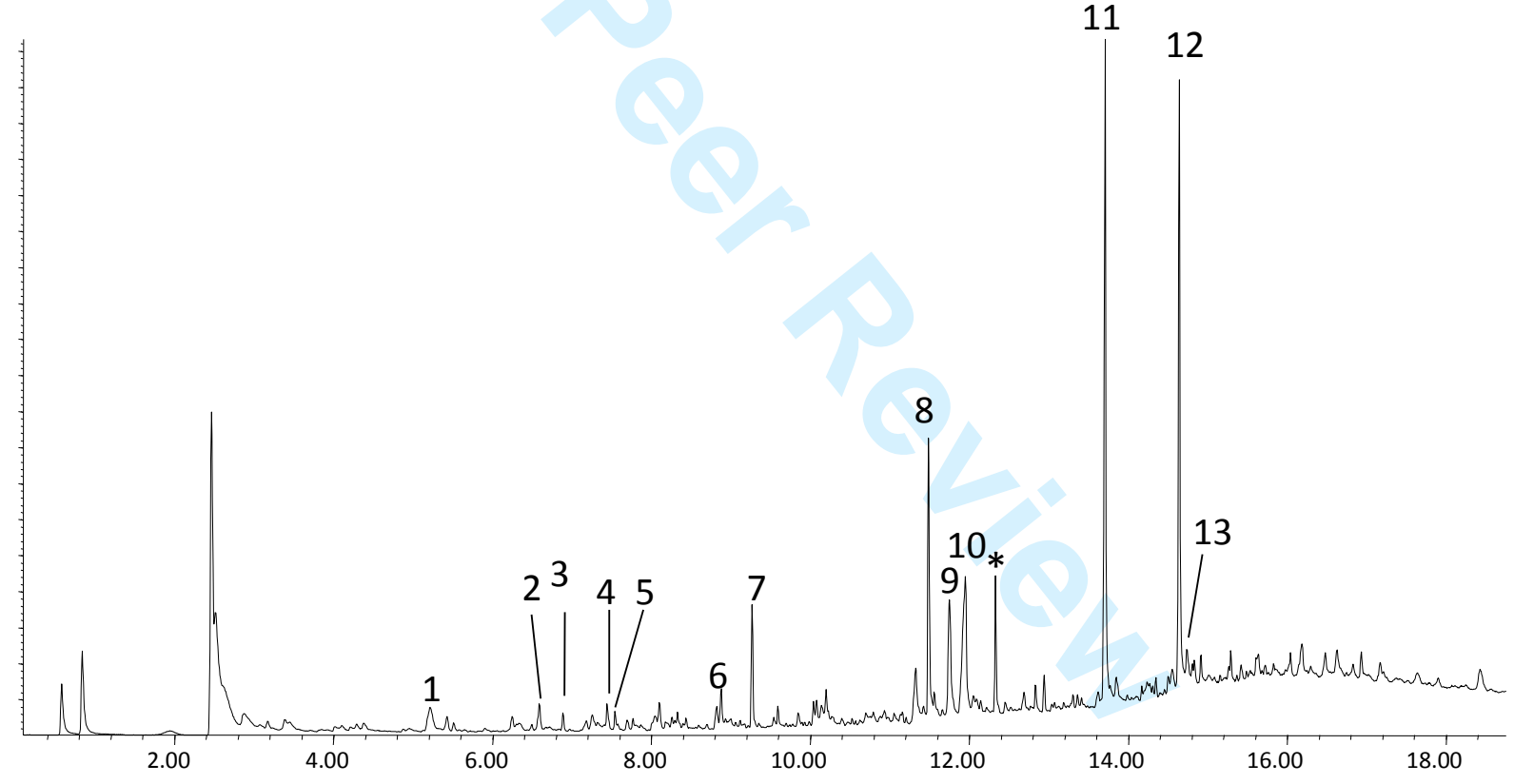

Figure S21 Pyrograms of Clyfford Still paint samples 968_1 (top) and 968_2 (bottom), both from Untitled (1951-1952). 1. toluene; 2. cyclohexanone; 3. benzene, 1-methylethyl; 4. alpha-methylstirene; 5. benzene, tert-butyl-; 6. octanoic acid; 7. naphthalene: 8. 2naphthol; 9. naphthalene, 1-isocyanato-; 10. azelaic acid; 11 . palmitic acid; 12 . stearic acid; 13 . linoleic acid; 14 . naphthalene, 1 -(2naphthalenyloxy)-; " unknown product characteristic of red pigments (m/z 183, 154, 114). 
Figure S22 Pyrogram of Clyfford Still paint sample 969_2, from Untitled (1954). 1. toluene; 2. ethylbenzene; 3. styrene; 4. benzene, 1-methylethyl; 5. alpha-methylstyrene; 6. benzene, tert-butyl; 7. benzene, 2-methyl-1-propenyl; 8. octanoic acid; 9. naphthalene; 10. naphthalene, 2-methyl-; 11. octanedioic acid; 12. 2-naphthol; 13. 2-naphthalenamine; 14. azelaic acid; 15. palmitic acid; 16. stearic acid; 17. linoleic acid; 18. naphthalene, 1-(2-naphthalenyloxy)-; *unknown product characteristic of red pigments (m/z 183, $154,114)$.

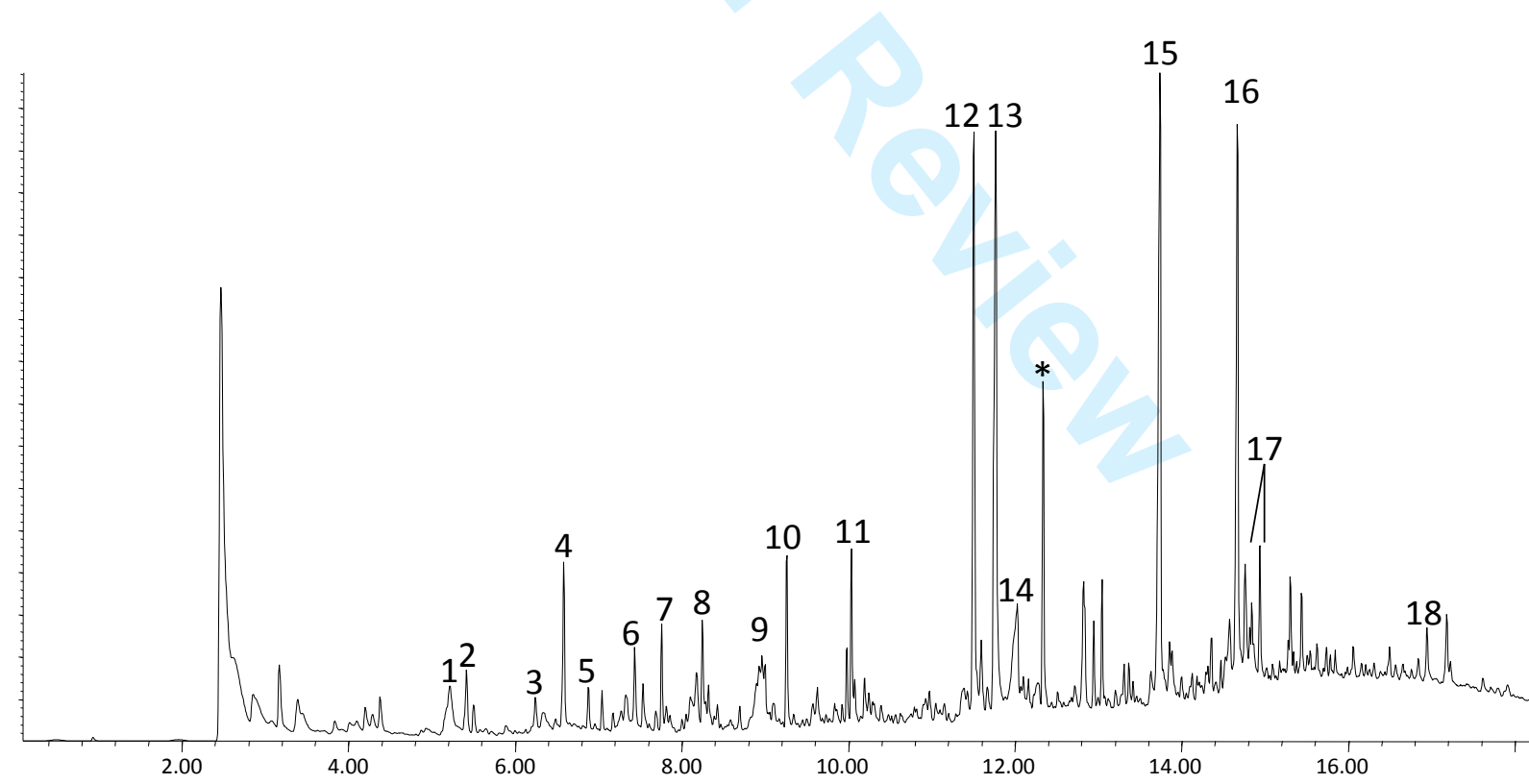

Figure S23 Pyrogram of Clyfford Still paint sample 693_4, from Untitled (1960). 1. toluene; 2. cyclopentanone; 3. ethylbenzene; 4. cyclohexanone; 5. benzene, 1-methylethyl-; 6. alpha-methylstyrene; 7. cycloheptanone; 8. p-aminotoluene; 9. octanoic acid; 10. naphthalene; 11. benzenamine, 3-chloro-4-methyl-; 12. 2-naphthol; 13. 2-naphthalenamine; 14. azelaic acid; 15. palmitic acid; 16. stearic acid; 17. linoleic acid; 18. naphthalene, 1-(2-naphthalenyloxy)-. 